\title{
Estudo Topológico de Órbitas Periódicas no Circuito Experimental de Chua
}

\author{
Dariel Mazzoni Maranhão
}

20 de Junho de 2006 


\section{Agradecimentos}

Agradeço...

Ao meu orientador Professor José Carlos Sartorelli pela paciência e dedicação.

Aos colegas do Laborátorio de Fenômenos Não-Lineares.

À minha esposa, Silvana e à minha filha e herdeira, Luísa.

Aos meus pais, Célia e Hênio.

Aos meus irmãos Viviane, Marcel e "Deninho".

Ao Dr. Murilo Baptista que incentivou com entusiasmo esse trabalho.

Ao CNPq e a FAPESP pelo apoio financeiro. 


\section{Resumo}

Estudamos o comportamento dinâmico de séries temporais experimentais obtidas de um circuito de Chua quando dois parâmetros de controle, $\Delta R_{1}$ e $\Delta R_{2}$, são variados. Investigamos os comportamentos caótico e periódico, analisando as séries temporais ao redor e no interior de duas janelas periódicas presentes no espaço de parâmetros $\left(\Delta R_{1}, \Delta R_{2}\right)$ do circuito.

$\mathrm{Na}$ vizinhança da janela de período três, analisamos como a dinâmica simbólica se altera quando construída em diferentes seções de Poincaré de um mesmo atrator, e investigamos a dimensão dos mapas de retorno, uni ou bidimensional, para diferentes atratores caóticos presentes nessa região do espaço de parâmetros. Ainda nessa vizinhança, empregamos técnicas de caracterização topológica para confirmar a existência de fibras caóticas, que são curvas de codimensão um no espaço de parâmetros onde as propriedades caóticas dos atratores são preservadas.

Ao redor da janela de período quatro, investigamos a transição entre os três comportamentos caóticos para os quais construímos os respectivos moldes topológicos. Propusemos também um molde topológico para o regime caótico após a crise por fusão ocorrer no circuito. Finalizando, investigamos as bifurcações e a estrutura topológica das órbitas periódicas que formam as janelas de período três e de período quatro, construindo um espaço de parâmetros topológico, baseado em um mapa bi-modal, para descrever as duas janela periódicas. 


\section{Abstract}

We have studied the dynamical behavior of experimental time series obtained from a Chua's circuit by variation of two parameter control, $\Delta R_{1}$ and $\Delta R_{2}$. We investigated the chaotic and periodic behaviors of the circuit, analyzing temporal series around and inside of two periodic windows in the two-parameter space $\left(\Delta R_{1}, \Delta R_{2}\right)$.

In the period-three window neighborhood, we analyzed how the symbolic dynamics changes when it is built by different Poincaré sections of an attractor, and we studied the dimension of return map, one- or two-dimensional, for many chaotic attractors in this region of the parameter space. In this neighborhood, we also applied topological techniques to confirm the existence of chaotic fibers: codimension one curves where the chaotic properties of the attractors remain unchanged in the two-parameter space.

Around the period-four window, we investigated, by template analysis, the transition between three chaotic attractors found in the Chua's circuit. We proposed a template for chaotic regime of the circuit after merge-crisis. Finally, we investigated the bifurcations and topological structure of periodic orbits in period-three and period-four windows and also proposed a topological parameter space, based in a bimodal map model, that describe these two periodic windows. 


\section{Conteúdo}

$\begin{array}{ll}\text { Introdução } & 1\end{array}$

1 Aspectos Teóricos $\quad 6$

1.1 Abordagem métrica dos sistemas dinâmicos caóticos . . . . . . . . . . 6

1.1.1 Reconstrução da dinâmica e dimensão de imersão . . . . . . . . . 6

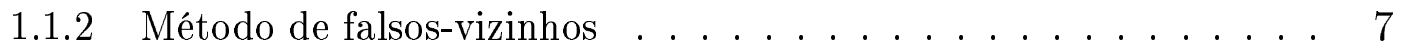

1.1.3 Expoentes e dimensão de Lyapunov . . . . . . . . . . . . . 8

1.2 Abordagem topológica dos sistemas dinâmicos caóticos . . . . . . . . 9

1.2.1 Dinâmica simbólica . . . . . . . . . . . . . . . . . 9

1.2.2 Localização das órbitas periódicas instáveis . . . . . . . . . . 13

1.2 .3 Planos simbólicos . . . . . . . . . . . . . . . . . 15

1.2.4 Entropia topológica . . . . . . . . . . . . . . . 17

1.2.5 Espaço de parâmetros topológicos . . . . . . . . . . . . 18

1.2 .6 Moldes topológicos . . . . . . . . . . . . . . . 23

1.3 Espaço de parâmetros e janelas periódicas . . . . . . . . . . . 31

1.3.1 O espaço de parâmetros . . . . . . . . . . . . . 31

1.3.2 O sistema de Rössler . . . . . . . . . . . . . . . . . 32

$1.3 .3 \quad$ O circuito de Chua . . . . . . . . . . . . . . . . 34

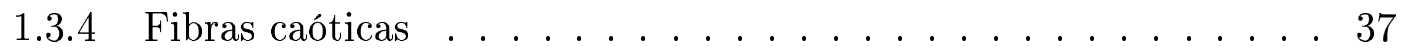

2 Resultados e Análises $\quad 38$

2.1 Descrição do Arranjo Experimental . . . . . . . . . . . . . . . 38

2.2 Atratores e diagramas de bifurcações . . . . . . . . . . . . . . 38

2.3 Caracterização métrica das séries temporais . . . . . . . . . . . 39

2.3.1 Dimensão de imersão . . . . . . . . . . . . . . . . . 40

2.4 Dinâmica simbólica na vizinhança da janela de período três . . . . . . . . 44

2.4.1 Dinâmica nas seções de Poincaré . . . . . . . . . . . . . 44 
2.4.2 Comportamento dinâmico: bi- ou unidimensional? . . . . . . . . . 47

2.5 Fibras caóticas e o espaço de parâmetros . . . . . . . . . . 54

2.5.1 Caracterização métrica das séries ............ 55

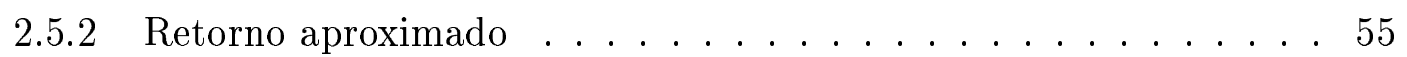

2.5.3 Espectro de órbitas e números de ligações . . . . . . . . . 57

2.5.4 Planos simbólicos . . . . . . . . . . . . . 62

2.5.5 Entropia topológica .................... 64

2.6 Caracterização topológica dos atratores no circuito de Chua . . . . . . 66

2.6.1 Atratores e mapas de retorno ............. 66

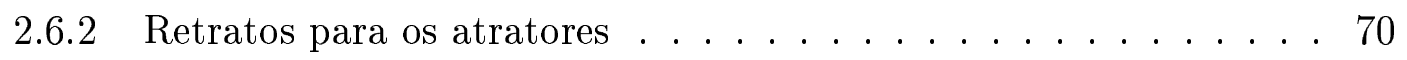

2.6.3 Moldes topológicos ......................... 70

2.6.4 Verificação dos moldes topológicos . . . . . . . . . 73

2.6.5 O molde topológico e a crise por fusão . . . . . . . . . . 85

2.7 Topologia das janelas periódicas no espaço de parâmetros . . . . . . . 90

2.7.1 Dinâmica simbólica das órbitas no interior das janelas . . . . . . . 90

2.7.2 Bifurcações e as janelas periódicas . . . . . . . . . . . 93

2.7.3 Mapa bimodal e o espaço de parâmetros topológico . . . . . . . 97

$\begin{array}{ll}\text { Conclusão } & 101\end{array}$

$\begin{array}{ll}\text { Referências Bibligráficas } & 104\end{array}$

$\begin{array}{ll}\text { Apêndice A } & 111\end{array}$

$\begin{array}{lr}\text { Apêndice B } & 112\end{array}$

$\begin{array}{ll}\text { Apêndice C } & 113\end{array}$ 


\section{Introdução}

O sucesso atual da Ciência está na capacidade de relacionar causa com efeito. Por exemplo, devido à descoberta das leis da gravitação, eclipses podem ser previstos com muitos anos de antecedência. Entretanto, existem fenômenos naturais que, apesar de deterministas, não podem ser previstos como o movimento da atmosfera e as variações climáticas [1], reações químicas [2, 3], torneiras pingando [4, 5, 6], dinâmica de crescimento de populações biológicas [7] e muitos outros, pois apresentam comportamento imprevisível. Mesmo o comportamento de um sistema simples como um pêndulo forçado é essencialmente irregular. Não importam o conhecimento das leis que regem seu movimento e a determinação precisa de suas condições iniciais: esse tipo de irregularidade é intrínseca e sistemas que apresentam tal comportamento são chamados de caóticos [8]. Essa característica dos sistemas caóticos foi observada primeiro por Poincaré [9] ao estudar o problema de três corpos da mecânica clássica. Poincaré percebeu que pequenas diferenças no estado inicial desse sistema provocam grandes diferenças no estado final, ou seja, sistemas caóticos apresentam dependência sensivel às condições iniciais.

A dinâmica simbólica surgiu como uma tentativa de determinar os possíveis movimentos de um sistema dinâmico quando não se pode encontrar explicitamente suas equações do movimento. Sua origem se deve a Hadamard [10] ao descrever, qualitativamente, os diversos estados dinâmicos existentes sobre curvas geodésicas em uma variedade Riemanniana com curvatura negativa, um sistema dinâmico caótico conhecido como "bilhar de Hadamard". Hadamard mostrou que um conjunto finito de símbolos pode ser usado para descrever os estados sobre as geodésicas. Essa técnica de análise foi posteriormente desenvolvida por Morse e Hedlund [11] seguindo as idéias originais de Hadamard.

Após Hadamard, Morse e Hedlund, Smale [12] usou a dinâmica simbólica para analisar topologicamente os processos de estiramentos e dobras em sistemas dissipativos não-lineares. O modelo concebido por Smale, o mapa da ferradura, forneceu uma de- 
monstração visual da sensibilidade às condições iniciais [13]. Depois de Smale, Metropolis, Stein e Stein [14] empregaram a dinâmica simbólica para estudar o comportamento dos ciclos periódicos que ocorrem em um mapa quadrático.

A introdução do molde topológico por Birman e Williams [15] permitiu que a topologia e a dinâmica simbólica descrevessem o comportamento global de alguns sistemas caóticos de baixa dimensão. A abordagem topológica de tais sistemas, ao contrário da abordagem métrica, permite a obtenção de quantidades que são invariantes às mudanças dos parâmetros. Na abordagem topológica os processos de estiramentos e dobras agem de modo a organizar as órbitas periódicas instáveis imersas em sistemas dinâmicos caóticos. O molde topológico, então, captura a organização das órbitas periódicas instáveis existentes no atrator caótico.

Recentemente, a abordagem por moldes topológico para atratores com baixa dimensão de imersão foi aplicada à uma variedade de sistema físicos $[2,3,16,17,18,19,20,27]$. A identificação dos invariantes topológicos associados à dinâmica de um dado sistema, permitiu o desenvolvimento de uma metodologia para a caracterização por meio de moldes topológicos. Esses invariantes topológicos são associados às órbitas periódicas instáveis que existem em abundância imersas em atratores caóticos.

Nesse trabalho nós estudamos topologicamente os estados dinâmicos de um sistema experimental conhecido como circuito de Chua [21]. Nós coletamos e analisamos séries temporais que foram obtidas através da variação de dois parâmetros, ou seja, estudamos os estados dinâmicos do circuito em um espaço de parâmetros. O espaço de parâmetros, os conjuntos de séries temporais analisados e os respectivos diagramas de bifurcações podem ser vistos nas figuras 1 e 2 .

Em um espaço de parâmetros, o comportamento dinâmico de um sistema pode ser compreendido de modo global. Estudando este espaço pode-se observar como se organiza a coleção de diferentes estados dinâmicos do sistema. Com freqüência o comportamento dinâmico caótico coexiste com comportamento periódico, como exemplificado por Gaspard e colaboradores [22] que mostraram, à partir de um estudo analítico, como as janelas periódicas se organizam no espaço de dois parâmetros de um sistema homoclínico cujos auto-valores obedecem à condição de Sil'nikov. Gallas [23], estudando o mapa de Hénon, mostrou que as janelas periódicas no espaço de parâmetros se organizam em uma estrutura principal de período $n$ e uma sucessão infinita, ao redor da estrutura principal, de janelas de período $n .2^{m}$, onde $m=1,2, \ldots$ é o número de duplicações de período da órbita no interior da estrutura principal. 

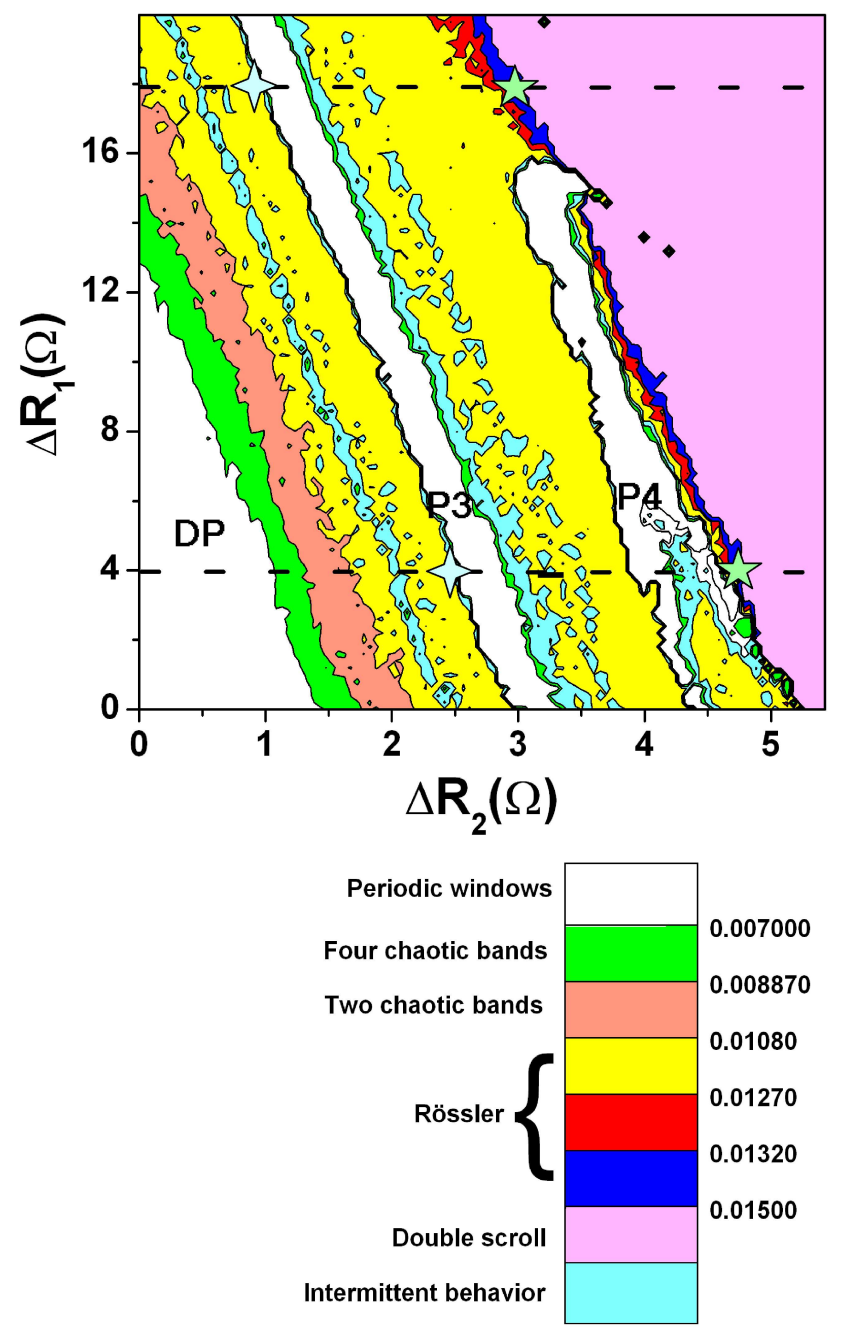

Figura 1: Espaço de parâmetros para o circuito experimental de Chua, determinado a partir da estimativa do maior expoente de Lyapunov $\lambda_{\max }$ das séries temporais obtidas variando-se os parâmetros $\Delta R_{1}$ e $\Delta R_{2}$ do circuito. Regiões de mesma tonalidade representam atratores com comportamento dinâmico similar: a cor branca indica comportamento periódico; as cores indicam comportamento caótico.

Analisamos o comportamento dinâmico do circuito de Chua ao longo de seu espaço de parâmetros, dividindo esse trabalho em três partes. Na primeira parte, aplicamos algumas técnicas topológicas nos atratores caóticos situados na vizinhança da janela de período três. Investigamos a natureza dos mapas de retorno gerados pelos atratores, que poderiam ser unidimensionais ou bidimensionais. Para tal, comparamos o comportamento dinâmico das séries temporais geradas pelo circuito de Chua com o comportamento de dois mapas conhecidos: o mapa logístico, um mapa unidimensional 


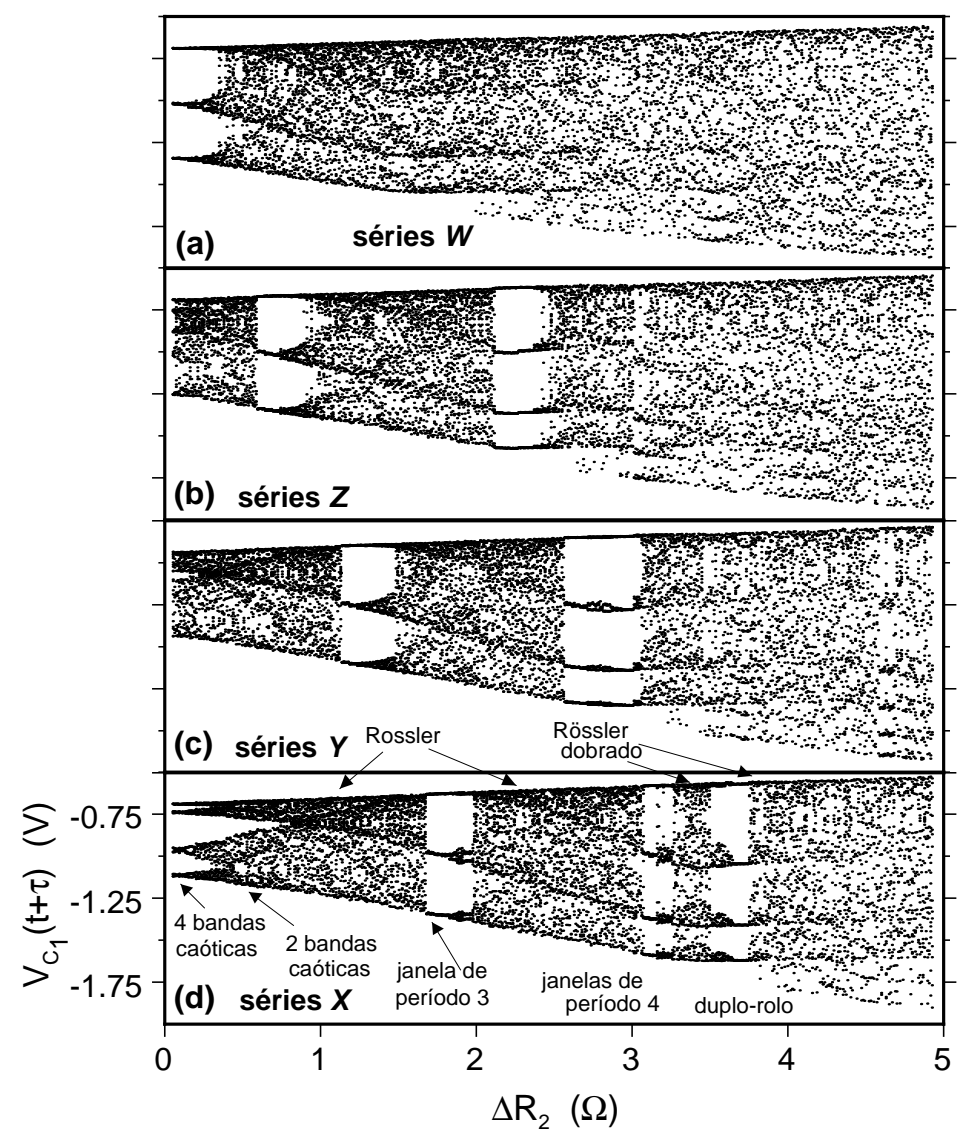

Figura 2: Diagramas de bifurcações para os conjuntos de séries temporais (a) $W$; (b) $Z$; (c) $Y$ e (d) $X$ obtidas do circuito experimental de Chua, onde pode-se ver a presença de diversas janelas periódicas entre comportamento caótico. Indicados na figura estão alguns dos atratores caóticos que podem ser observados no circuito de Chua.

e o mapa de Hénon, bidimensional.

Investigamos também a existência das fibras caóticas [24] na vizinhança da janela de período três. As fibras caóticas são regiões no espaço de parâmetros ao longo das quais algumas propriedades métricas (expoentes e dimensão de Lyapunov) e topológicas (conjunto de órbitas periódicas instáveis, entropia topológica) dos atratores nelas situados são preservadas, mesmo quando tratamos de sistemas não robustos, ou seja frágeis, com diversas janelas periódicas surgindo ao variarmos seus parâmetros. Para mostrar a existência das fibras caóticas aplicamos, nos atratores estudados, dois métodos distintos. O primeiro é baseado na identificação de invariantes topológicos relacionados às órbitas periódicas instáveis (OPI), através do qual extraímos conjuntos de órbitas periódicas e calculamos os números de ligações associados às órbitas. O segundo é ba- 
seado numa análise simbólica por grão grosso, pelo qual aplicamos procedimentos como a construção de planos simbólicos e a estimativa da entropia topológica.

Na segunda parte desse trabalho, analisamos o comportamento dinâmico do circuito de Chua próximo da janela de período quatro. Empregamos moldes topológicos para mostrar como ocorre a transição entre os três tipos de atratores presentes nessa região: o atrator tipo Rössler, o Rössler-dobrado, e o duplo-rolo. Essa análise é importante porque as bifurcações que originam a janela de período quatro no espaço de parâmetros estão relacionadas com a transição entre os atratores Rössler e Rössler-dobrado.

Finalmente, na terceira parte, mostramos como ocorrem as bifurcações que originam as janelas de períodos três e quatro através da identificação das suas estruturas topológicas. Esse estudo permitiu propor um modelo topológico, baseado em um mapa bimodal (um mapa unidimensional com um ponto de máximo e um ponto de mínimo), usado para representar as janelas periódicas do circuito em um espaço de parâmetros topológico. Essa é a primeira vez que o espaço de parâmetros topológico, proposto originalmente por Hansen [25, 26], é empregado para caracterizar um sistema dinâmico experimental. 


\section{CAPÍTULO 1}

\section{Aspectos Teóricos}

\subsection{Abordagem métrica dos sistemas dinâmicos caó- ticos}

Introduzimos aqui algumas técnicas de análise métrica para séries temporais obtidas de um sistema dinâmico não-linear. São revistos a reconstrução do espaço de fases [28, 29], o método de falsos vizinhos para obter a dimensão de imersão e as estimativas dos expoentes e dimensão de Lyapunov.

\subsubsection{Reconstrução da dinâmica e dimensão de imersão}

Reconstruir o espaço de fases de um sistema dinâmico a partir das medidas de uma única variável escalar é conhecido como reconstrução da dinâmica. Seja $V_{C_{1}}(n)=$ $V_{C_{1}}\left(t_{0}+n \Delta t\right)$ a variável medida para algum sistema dinâmico. O espaço de fases pode ser reconstruído através do método proposto por Takens [28]. Seja o vetor $d$-dimensional $\vec{y}(n)$

$$
\vec{y}(n)=\left\{V_{C_{1}}(n), V_{C_{1}}(n+\tau), V_{C_{1}}(n+2 \tau), \ldots, V_{C_{1}}[n+(d-1) \tau]\right\},
$$

onde $d$ é a dimensão do espaço reconstruído e $\tau$, um inteiro, é o passo de reconstrução (ou tempo de atraso). Cada elemento do vetor representa uma variável dinâmica do sistema reconstruído em dimensão $d$. Assim reconstruído, o espaço de fases é topologicamente equivalente ao espaço de fases real do sistema dinâmico. Entretanto a dimensão $d$ não é necessariamente igual a dimensão de imersão $d_{E}$ do espaço de fases das variáveis físicas do sistema. Qualquer $d \geq d_{E}$ mantém a equivalência topológica entre o sistema reconstruído e o sistema real. 
Em geral a dimensão de imersão $d_{E}$ deve ser suficientemente grande para se assegurar a equivalência entre os atratores no sistema reconstruído e no sistema físico real. De acordo com Takens [28, 29] tomar $d_{E}=2 D_{0}+1$, onde $D_{0}$ é a dimensão fractal, é suficiente para assegurar a equivalência. Entretanto, dependendo das características do atrator, a reconstrução em uma dimensão menor que $2 D_{0}+1$ é suficiente para desdobrar o atrator. Um dos método para se determinar a dimensão de imersão de um atrator é conhecido como método dos falsos vizinhos.

\subsubsection{Método de falsos-vizinhos}

O método de falsos vizinhos [30] consiste em estimar, na série temporal de um sistema dinâmico, o número de falsos auto-cruzamentos das trajetórias, originados da reconstrução do atrator em uma dimensão baixa para representá-lo adequadamente. Quando o atrator é reconstruído em uma dimensão alta o suficiente, o número de falsos vizinhos (falsos auto-cruzamentos) cai a zero. O método consiste, então, em pesquisar qual a menor dimensão em que o atrator estará suficientemente desdobrado, tal que o número de falsos vizinhos seja zero.

O método é implementado do seguinte modo. Seja $R_{d}^{2}(n)$ o quadrado da distância entre um determinado ponto $\vec{y}(n)$ e seu vizinho mais próximo $\vec{y}^{v}(n)$ (para a distância euclidiana, por exemplo) em um atrator reconstruído em dimensão $d$. Se $\vec{y}^{v}(n)$ for um falso vizinho, $R_{d}^{2}(n)$ aumentará muito quando passamos de uma dimensão $d$ para $d+1$. Assim, $\vec{y}^{v}(n)$ será falso se

$$
\left[\frac{R_{d+1}^{2}(n)-R_{d}^{2}(n)}{R_{d}^{2}(n)}\right]^{1 / 2}>R_{c}
$$

onde $R_{c}$ é uma razão crítica entre distâncias. A condição eq. (1.2) é necessária, mas não suficiente, para se declarar o vizinho como falso. Como na prática sempre temos um número finito de pontos para as séries, eventualmente o vizinho mais próximo $\vec{y}(k)$ estará a uma distância da ordem do tamanho do atrator $R_{A}$, ou seja, $R_{d}(k) \approx R_{A}$ e $R_{d+1}(k) \approx 2 R_{A}$. Logo, um segundo critério para estabelecer se um dado vizinho é falso é então

$$
\frac{R_{d+1}(n)}{R_{A}} \geq 2 .
$$




\subsubsection{Expoentes e dimensão de Lyapunov}

\section{A. Espectro de expoentes de Lyapunov}

Os expoentes de Lyapunov medem a taxa de divergência entre trajetórias vizinhas em um sistema dinâmico. Para um sistema dinâmico dissipativo essa taxa é um invariante da dinâmica, logo, não depende da posição do espaço de fases em que é determinada, isto é, os expoentes de Lyapunov são invariante sobre a evolução temporal do sistema [31].

O espectro de Lyapunov para uma série temporal experimental pode ser determinado pelo método de Eckmann-Ruelle [31, 32]. Seja o mapa $\vec{F}(\vec{y})$ descrevendo os pontos de um atrator reconstruído. A linearização de $\vec{F}$ em torno de um ponto $\vec{x}$ é dada pela expressão

$$
\vec{F}(\vec{y}) \approx J_{\vec{y}} \vec{y}+\vec{a}
$$

onde $J_{\vec{y}}$ é a matriz Jacobiana de $\vec{F}$ no ponto $\vec{x}$ e $\vec{a}$ é um vetor.

A Jacobiana $J_{\vec{y}}$ e o vetor $\vec{a}$ podem ser determinados se considerarmos a evolução dinâmica da trajetória de referência $\vec{y}\left(t_{i}\right)$ e de seus pontos vizinhos $y_{j}^{v}, j=1,2, \ldots$, de modo que

$$
\left|y\left(t_{i}\right)-y_{j}^{v}\left(t_{i}\right)\right|<\varepsilon, \quad j=1,2, \ldots,
$$

onde $\varepsilon$ é suficientemente pequeno para possibilitar a aproximação linear.

Tomemos um ponto $y\left(t_{i}\right)$ na trajetória de referência e $y_{j}^{v}\left(t_{i}\right)$ seus $j$ pontos vizinhos no instante $t_{i}$ satisfazendo a eq. (1.5). Após um intervalo de tempo $\Delta t$ a Jacobiana $J_{\vec{y}}$ e o vetor $\vec{a}$ podem ser obtidos através do ajuste de mínimos quadrados sobre os pontos $y_{j}^{v}$, obtendo a aproximação

$$
J_{\vec{y}\left(t_{i}\right)}\left[y\left(t_{i}\right)-y_{j}^{v}\left(t_{i}\right)\right] \approx y\left(t_{i}+\Delta t\right)-y_{j}^{v}\left(t_{i}+\Delta t\right)
$$

Procede-se da mesma forma para os instantes $t_{i}+2 \Delta t, t_{i}+3 \Delta t_{i}, \ldots$ até percorrer toda a trajetória de referência.

O espectro de expoentes de Lyapunov é definido por

$$
\lambda_{k}=\lim _{n \rightarrow \infty} \frac{1}{n \Delta t} \sum_{j=1}^{n} \ln \left|\Lambda_{j}^{k}\right|,
$$

onde $\Lambda_{j}^{k}$ são os auto-valores da matriz

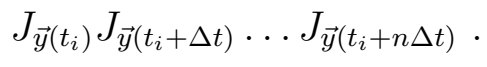


Para se obter os auto-valores $\Lambda_{j}^{k}$, pode-se aplicar o método de ortogonalização de Gram-Schmidt [33, 34] ou o método de triangularização de Householder [31] ao produto de matrizes definido na eq. (1.8).

\section{B. Conjetura de Kaplan-Yorke}

A conjetura de Kaplan-Yorke [35] estabelece uma relação entre os expoentes de Lyapunov e a dimensão fractal (ou de Hausdorff) para um dado atrator. Conhecida como dimensão de Lyapunov ou dimensão de Kaplan-Yorke tal dimensão é dada por

$$
D_{K Y}=j+\frac{\sum_{i=1}^{j} \lambda_{i}}{\left|\lambda_{j+1}\right|},
$$

onde $j$ é o maior inteiro tal que a soma $\sum_{i=1}^{j} \lambda_{i}$ mantém-se positiva. De acordo com a conjetura de Kaplan-Yorke $D_{K Y}=D_{0}$ tal que $D_{0}$ é a dimensão fractal.

Para o caso de um sistema caótico e dissipativo em duas dimensões temos $\lambda_{1}>0$, $\lambda_{2}<0$ e $\lambda_{1}+\lambda_{2}<0$ e a aplicação da conjetura resulta em

$$
D_{K Y}=1+\frac{\lambda_{1}}{\left|\lambda_{2}\right|}
$$

Para um sistema caótico e dissipativo em três dimensões temos $\lambda_{1}>0, \lambda_{2}=0$, $\lambda_{3}<0$ e $\sum_{i=1}^{3} \lambda_{i}<0$ o que resulta em

$$
D_{K Y}=2+\frac{\lambda_{1}}{\left|\lambda_{3}\right|} .
$$

\subsection{Abordagem topológica dos sistemas dinâmicos caóticos}

\subsubsection{Dinâmica simbólica}

Chama-se dinâmica simbólica o processo de descrever a evolução dinâmica de um sistema através de símbolos $[14,18,36,37,20,27]$. Ao invés de quantificar as variáveis de um sistema dinâmico em seu espaço de fases, a dinâmica simbólica associa a algum complicado movimento uma seqüência de poucos símbolos, de modo a preservar suas características qualitativas. Além disso, a dinâmica simbólica apresenta todos os possíveis movimentos de forma organizada. Ilustraremos o processo aplicando a dinâmica simbólica ao mapa logístico. 


\section{A. O mapa logístico}

O mapa logístico é definido como

$$
x_{n+1}=f\left(x_{n}\right)=\mu x_{n}\left(1-x_{n}\right),
$$

onde $\mu \in \mathbb{R}$ é o parâmetro de controle e $n=1,2, \ldots$ descreve a evolução da variável $x$. Um mapa $f$ tal que $f: I \rightarrow I, I \in[0,1]$ é chamado unimodal [38, 39] se:

- $f(0)=f(1)=0$.

- $f$ tem um único ponto crítico $c$ onde $0<c<1$.

A evolução dinâmica do mapa logístico pode ser compreendida se estudarmos qualitativamente os estiramentos e dobras de suas trajetórias.

\section{B. Estiramentos e dobras}

Para $\mu=4$ o mapa logístico é caótico [38]. Para $\mu=4$ a eq. (1.12) toma a forma $f(x)=4 x(1-x)$, e o mapa logístico apresenta como ponto máximo $x_{c}=\frac{1}{2}$. Tomemos um ponto inicial $x_{0} \in I, I \in[0,1]$. A primeira iteração é dada por $x_{1}=f\left(x_{0}\right)$, a qual chamaremos simplesmente de $f$. A segunda iteração é $x_{2}=f\left(x_{1}\right)=f\left(f\left(x_{0}\right)\right)=f^{2}\left(x_{0}\right)$, ou seja $f^{2}$. Assim, a $n$-ésima iteração $x_{n}=\underbrace{f \ldots f}_{n \text { vezes }}\left(x_{0}\right)=f^{n}\left(x_{0}\right)$ será $f^{n}$.

Consideremos o ponto crítico como uma partição para cada iterada do mapa $f$. Se o ponto iterado está à direita do ponto de máximo (no intervalo ]c, 1]) atribuímos o símbolo $\mathbf{R}$ ("Right"). Caso contrário (intervalo $[0, c[$ ) atribuímos L ("Left"). O resultado do processo para sucessivas iterações de $f$ pode ser visto na figura 1.1. Na primeira iteração $f^{1}(I)$, o intervalo $I$ é esticado e dobrado uma vez resultando em duas possibilidades: R ou L. Na segunda iteração $f^{2}$ o intervalo $I$ é esticado e dobrado duas vezes, resultando em quatro possibilidades: LL, RL, RR e LR. A terceira iteração $f^{3}(I)$ resulta em 8 possibilidades: LLL, RLL, RRL, LRL, LRR, RRR, RLR, LLR. Na n-ésima iteração $f^{n}(I)$ teremos $2^{n}$ possibilidades de caminhos diferentes.

Assim, com a dinâmica simbólica, uma dada trajetória não é mais descrita por sua posição exata mas sim qualitativamente, através de uma seqüência de símbolos, de acordo com o caminho percorrido por um dado ponto inicial.

\section{Espaço das seqüências $\Sigma_{2}$}

Como os símbolos "L" e "R" definem os estados do mapa logístico (um ponto $x$ qualquer é dado por uma seqüência infinita de símbolos) vamos definir o espaço $\Sigma_{2}$ 


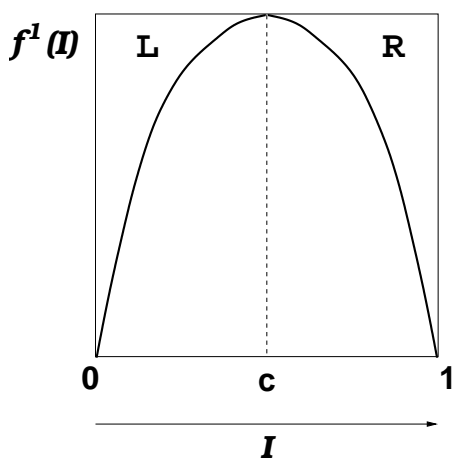

(a)

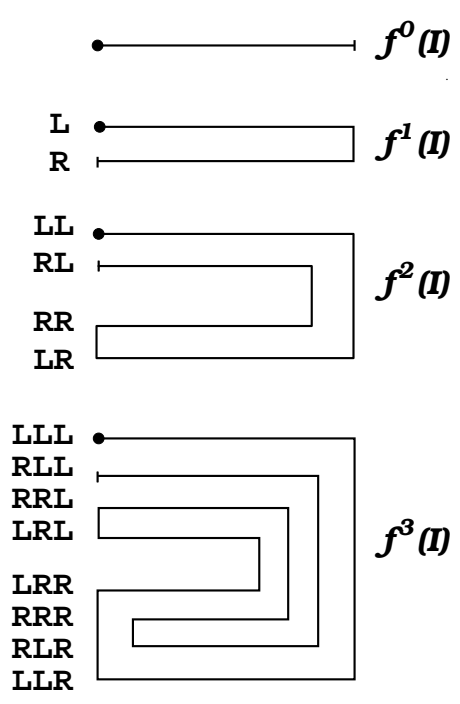

(b)

Figura 1.1: (a) Mapa unimodal definido pela função $f$ sobre o intervalo unitário $I$ particionado pelo ponto de máximo. (b) Sucessivas aplicações do mapa unimodal $f$ sobre $I$ e a classificação simbólica de cada aplicação.

para as seqüências de símbolos. Substituindo L por 0 e R por 1, vem

$$
\Sigma_{2}=\left\{\mathbf{s}=\left(s_{0} s_{1} s_{2} \ldots\right) \mid s_{j}=0 \text { ou } 1\right\}
$$

de modo que $\Sigma_{2}$ é chamado de espaço de seqüências de símbolos "0" e "1". Pontos nesse

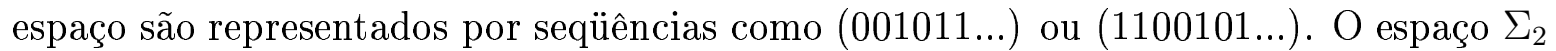
é o equivalente simbólico ao espaço real $\mathbb{R}$ para o mapa logístico, uma vez que em ambos os espaços os pontos são representados sem ambiguidades e são dotados de métricas.

\section{Mapa de deslocamentos $\sigma$}

O mapa do deslocamentos $\sigma$ fornece a dinâmica em $\Sigma_{2}$ do mesmo modo que mapa logístico [eq. (1.12)] fornece a dinâmica em $\mathbb{R}$. O mapa $\sigma$ é definido por

$$
\sigma\left(s_{0} s_{1} s_{2} \ldots\right)=\left(s_{1} s_{2} s_{3} \ldots\right)
$$

ou seja, a ação de $\sigma$ em um ponto de $\Sigma_{2}$ é suprimir o primeiro símbolo e deslocar todos os outros uma posição para a esquerda.

Para $\sigma$ existem $2^{n}$ seqüências periódicas de comprimento $n$ da forma

$$
\mathbf{s}=\left(s_{0} s_{1} \ldots s_{n-1}, s_{0} s_{1} \ldots s_{n-1}, \ldots\right),
$$




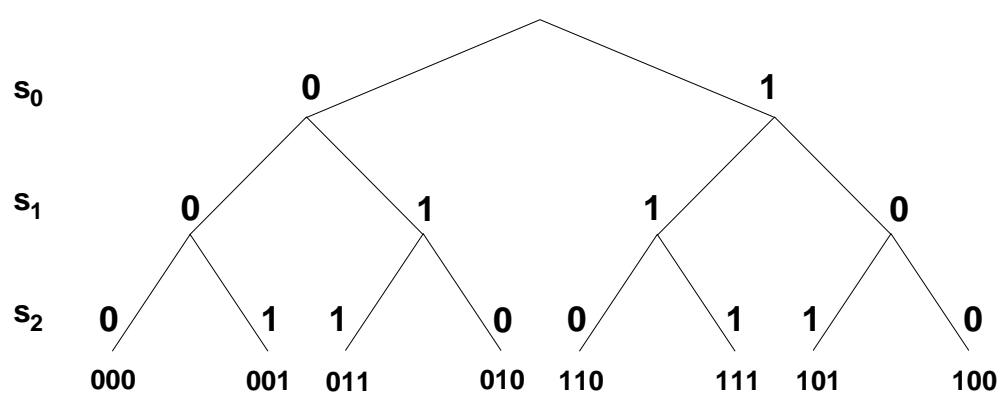

Figura 1.2: Árvore alternante binária mostrando as possíveis trajetórias até o terceiro nível $\left(s_{0} s_{1} s_{2}\right)$.

tal que a cadeia de $n$ símbolos " $s_{0} s_{1} \ldots s_{n-1}$ " repete-se infinitamente. Assim, órbitas de período 1 são dadas por

$$
(000 \ldots) \text { ou }(1111 \ldots)
$$

onde o símbolo "0" na primeira cadeia e "1" na segunda são repetidos infinitamente. Órbitas de período 2 são

$$
(101010 \ldots) \text { ou }(010101 \ldots)
$$

onde " $10 "$ e " 01 " são repetidos na primeira e segunda cadeias, respectivamente. Órbitas de período 3 são

$$
(100100100 \ldots),(101101101 \ldots)
$$

tal que "100" e "101" na primeira e segunda cadeias repetem-se infinitamente.

O mapa $\sigma$ também representa órbitas não-periódicas da forma

$$
\mathbf{s}=\left(s_{0} s_{1} s_{2} \ldots s_{n} \ldots\right)
$$

O número de órbitas não-periódicas é maior que o de periódicas. Os dois conjuntos de órbitas, periódicas e não-periódicas, são densos para $\sigma$ em $\Sigma_{2}$. A equivalência entre os mapas $\sigma$ e logístico, para o parâmetro $\mu>2+\sqrt{5}$, é demonstrada pela conjugação topológica [38].

\section{E. Árvore alternante binária}

A árvore alternante binária representa a dinâmica de $\sigma$ em $\Sigma_{2}$ em forma de um diagrama. Na árvore todos os possíveis itinerários para um dado ponto inicial $x_{0}$ estão representados. A árvore binária pode ser vista na figura 1.2. 
Um ponto $x \in \mathbb{R}$ qualquer, definindo o estado de um sistema dinâmico, é representado de modo qualitativo na árvore binária. Cada nível $i$ da árvore binária representa duas possibilidades de estados para o ponto iterado $f^{i}(x)$ : " 0 " se $f^{i}(x)$ estiver à esquerda ou " 1 " se $f^{i}(x)$ estiver à direita do ponto de máximo de $f$. Assim, o itinerário de $x$ dado por $f^{0}(x) f^{1}(x) f^{2}(x) \ldots f^{i-1}(x) \ldots$ é representado pela seqüência de símbolos $s_{0} s_{1} s_{2} \ldots s_{i-1} \ldots$, com $s_{j}=0$ ou 1 .

$\mathrm{Na}$ árvore binária todas as seqüências simbólicas aparecem ordenadas. Essa ordem ocorre em qualquer nível $i$ da árvore e é conhecida como ordem de precedência ou ordenação natural [36].

Como exemplo de um itinerário, seja a órbita de período 3 de seqüência (101...). Vamos representar essa órbita como $\overline{101}$, a barra indicando a seqüência periódica. Essa órbita tem três pontos periódicos: 101, 011 e 110. Cada ponto é obtido pela aplicação do mapa de deslocamentos $\sigma$ :

$$
\sigma(101)=011, \sigma(011)=110 \text { e } \sigma(110)=101
$$

E de acordo com a ordenação natural a ordem dos pontos é dada por:

$$
011 \rightarrow 110 \rightarrow 101
$$

\subsubsection{Localização das órbitas periódicas instáveis}

Uma típica trajetória caótica se aproxima, em sua evolução, das vizinhanças de muitas órbitas periódicas instáveis (OPI) de um atrator estranho. Em dado instante, a trajetória se aproxima de uma órbita instável ao longo de sua variedade estável, permanecendo em sua vizinhança por um certo intervalo de tempo, até que se afasta devido a ação da variedade instável. Nesse intervalo de tempo, um segmento da trajetória sombreia a órbita instável imersa no atrator caótico. Esse segmento da trajetória "imita" a órbita sombreada e pode ser tomado como uma aproximação para a órbita periódica instável.

Baseada nas observações acima a técnica do retorno aproximado [18, 41] pode ser usada para a identificação de OPI a partir de uma trajetória no atrator estranho [2, 18, 41]. Logo, essa técnica pode ser aplicada à séries temporais experimentais. Seja então a série temporal $\left(x_{1}, x_{2}, \ldots, x_{i}, \ldots, x_{N}\right)$ onde $i$ é a posição de um elemento qualquer e $N$ o comprimento da série. Procura-se por segmentos na série que satisfaçam a condição

$$
\left|x_{i}-x_{i+p(T / \Delta t)}\right|<\varepsilon
$$


para $i=1,2, \ldots N-p(T / \Delta t)$ onde $p T$ é o período da órbita instável, $\mathrm{T}$ o tempo característico do sistema e $\Delta t$ um intervalo de tempo arbitrário. Define-se $\Delta t$ de modo que $T / \Delta t$ seja uma constante característica. Os segmentos que satisfazem a eq. (1.18) sombreiam uma órbita instável de período $p T$ e são usados como uma aproximação para a órbita. Tipicamente, o limiar $\varepsilon$ é escolhido entre $1 \%$ a $5 \%$ da máxima amplitude da série temporal.

\section{A. Histogramas de retorno aproximado}

Na técnica de retorno aproximado procura-se por segmentos na série temporal que sombreiam uma OPI de período $p T$, onde $T$ é o tempo característico de 1 ciclo para a série e $p=1,2, \ldots$ um inteiro. Um histograma de retorno aproximado pode ser empregado para determinar o tempo característico $T$ diretamente da série temporal escalar.

Histogramas de retorno aproximado são construídos contando-se os retornos entre dois elementos $x_{i}$ e $x_{i+j}$ (uma recorrência) na séries temporal em função do tempo de recorrência, ou seja, calcula-se

$$
\text { número de retornos }(i, j)=\sum_{i} \Theta\left(\varepsilon-\left|x_{i}-x_{i+j}\right|\right)
$$

em função de $t_{j}=j \Delta t$ para um limiar $\varepsilon$. $\Theta$ é a função de Heaviside e $\Delta t$ um intervalo de tempo arbitrário.

Como exemplo, aplicamos a eq. (1.19) para um atrator do sistema de Rössler [42] definido pelo sistema de equações

$$
\left\{\begin{array}{l}
\dot{x}=-y-z, \\
\dot{y}=x+a y \\
\dot{z}=b-c z+x z
\end{array}\right.
$$

cujo histograma de retorno pode ser visto na figura 1.3. Em um histograma de retorno o tempo característico $T$ (ou tempo de recorrência) é dado pela distância entre os picos de número de retornos. Os picos na figura 1.3 são igualmente espaçados indicando que os retornos ocorrem em intervalos de tempo regulares: a cada $58 \Delta t$ intervalos ocorre um pico. Esse tempo é, aproximadamente, o tempo característico $T$ de 1 ciclo para as trajetórias no espaço de fases.

Assim, uma órbita de período $p$ é identificada, na série temporal, tomando $j=$ $(T / \Delta t) p=58 p$ e $T=58 \Delta t$ tal que $t_{\text {orbital }}^{p}=t_{j=58 p}=p T$, e procurando por segmentos 


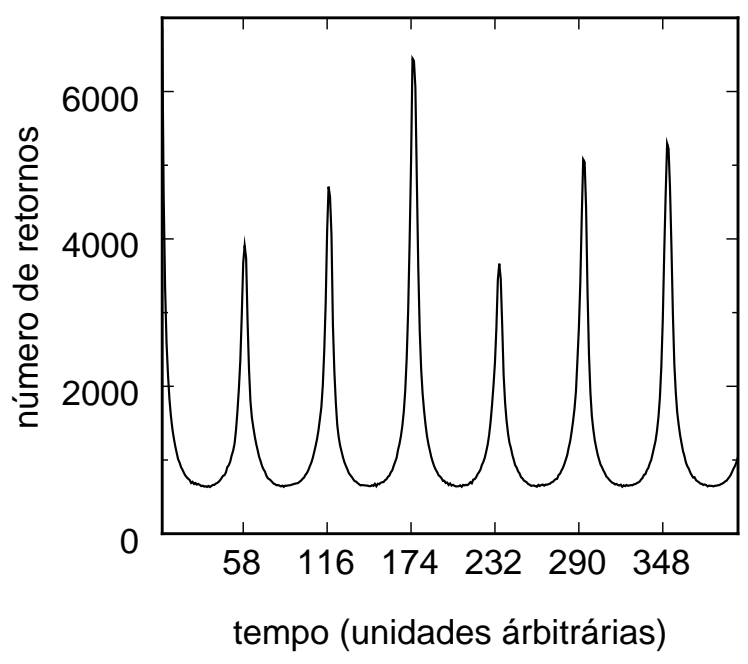

Figura 1.3: Histograma de retorno aproximado para a série temporal escalar formada pela variável $x$ no sistema de Rössler (eq. 1.20) integrado numericamente. Os parâmetros são: $a=0,2, b=0,2$ e $c=5,7$.

da trajetória que satisfaça à condição expressa na eq. (1.18). Com esse procedimento, órbitas de período 1 são identificadas fazendo $t^{p=1}=1 T=58 \Delta t$; órbitas de período 2 são identificadas por $t^{p=2}=2 T=116 \Delta t$; órbitas de período 3 por $t^{p=3}=3 T=174 \Delta t$ e assim por diante.

\subsubsection{Planos simbólicos}

O plano simbólico é uma maneira de representar graficamente a evolução dinâmica de sistema através de pontos em um diagrama bidimensional. Cada ponto $(\alpha, \beta)$ do plano simbólico é associado a uma seqüência simbólica, obtida a partir da trajetória do sistema dinâmico. No plano simbólico uma região preenchida (vazia) de pontos é uma região permitida (proibida) para uma seqüência simbólica encontrada (ou não) no sistema. Esta forma de representar a dinâmica tem sido utilizada na comparação e identificação de sistemas dinâmicos com características topológicas semelhantes (veja exemplos em $[44,45,46])$.

Para uma dada trajetória as coordenadas $(\alpha, \beta)$ são construídas de modo único a partir da seqüência simbólica

$$
\ldots s_{-m} \ldots s_{-2} s_{-1} . s_{0} s_{1} s_{2} \ldots s_{m} \ldots, s_{i} \in 0,1
$$

que representa a trajetória. O símbolo $s_{0}$ representa a posição atual ("presente simbó- 

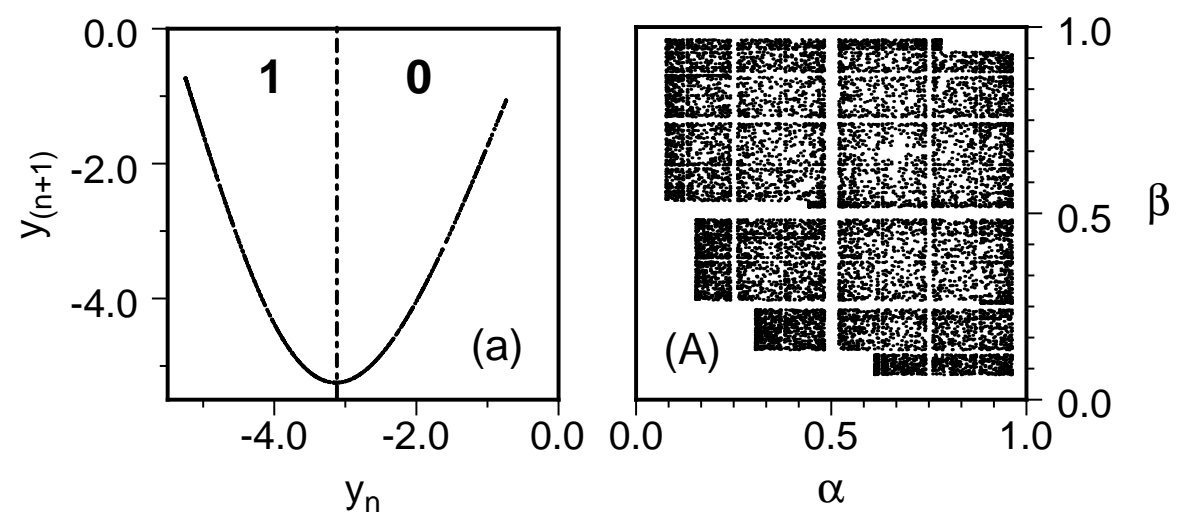

Figura 1.4: (a) Mapa de primeiro retorno para o sistema de Rössler [eq. (1.20) com parâmetros $a=0,429, b=2,0$ e $c=4,0]$ mostrando a partição pelo ponto de mínimo. (A) Plano simbólico para uma trajetória do mesmo atrator, representado por 12967 pontos, obtido usando a partição pelo ponto de mínimo dada por (a).

lico") e divide a seqüência em duas:.$s_{0} s_{1} s_{2} \ldots s_{m} \ldots$ chamada de "futuro simbólico" e $\ldots s_{-m} \ldots s_{-2} s_{-1}$. chamada de "passado simbólico". Para uma dinâmica simbólica com dois símbolos as coordenadas $(\alpha, \beta)$ do plano simbólico são dadas por

$$
\alpha=\sum_{i=1}^{m} \frac{a_{i}}{2^{i}}, \quad a_{i}=\sum_{j=0}^{i-1} s_{j} \quad(\bmod 2)
$$

e

$$
\beta=\sum_{i=1}^{m} \frac{b_{i}}{2^{i}}, \quad b_{i}=\sum_{j=1}^{i} s_{-j} \quad(\bmod 2),
$$

onde $\alpha$ e $\beta$ são números reais decimais. Como exemplo, a figura 1.4 mostra o plano simbólico para o atrator de Rössler [eq. (1.20)] com parâmetros $a=0,429, b=2,0$ e $c=4,0$. A figura 1.4(a) mostra o mapa de primeiro retorno para o atrator de Rössler construído com a seção de Poincaré

$$
P_{x}=\left\{(x, y, z) \in \mathbb{R}^{3} \mid x=x_{+}, y<y_{+}\right\}
$$

onde $x_{ \pm}=c \pm\left(c^{2}-4 a b\right)^{1 / 2} / 2$ e $y_{ \pm}=-c \pm\left(c^{2}-4 a b\right)^{1 / 2} / 2 a$ são as coordenadas dos pontos fixos da eq. (1.20). O mapa é particionado pelo ponto crítico em dois ramos: o ramo crescente $\mathbf{0}$ e o decrescente 1. A figura (A) mostra o plano simbólico para a série simbólica obtida a partir de uma trajetória no sistema de Rössler com a partição mostrada na figura (a). As regiões preenchidas (vazias) por pontos são determinadas por valores de $(\alpha, \beta)$ cujas as correspondentes sub-seqüências [eq. (1.21)] são permitidas (proibidas) no sistema dinâmico. 


\subsubsection{Entropia topológica}

A entropia topológica $h_{T}$ fornece a taxa com que o número $N$ de seqüências simbólicas permitidas, de comprimento $p$, são criadas em um dado sistema dinâmico, ou seja,

$$
N \propto e^{p \cdot h_{T}}
$$

Uma vez que o conjunto de órbitas periódicas instáveis nem sempre é conhecido, uma maneira prática de se obter $h_{T}$ é estima-lo através da seqüência simbólica para uma trajetória no sistema dinâmico.

Assim, a entropia topológica obtida a partir da seqüência simbólica $S=s_{0} s_{1} s_{2} \ldots s_{p-1}$ de comprimento $p$ é estimada por:

$$
h_{T}=\lim _{p \rightarrow \infty} \frac{\ln N_{p}(S)}{p},
$$

onde $N_{p}(S)$ é o número de diferentes seqüências $S$ de comprimento $p$ presentes no sistema dinâmico.

A entropia topológica apresenta uma relação estreita com a dinâmica simbólica de uma dado sistema. A entropia topológica (e métrica) é máxima quando a partição do espaço de fases é adotada na chamada partição geratriz [44, 66, 67].

Um método para se estimar a partição geratriz através do máximo de entropia foi proposto por Gonçalves e colaboradores [70, 71], e consiste em estimar a entropia topológica variando-se a posição em que é feita a partição no atrator. No caso de mapas unimodais a partição é efetuada em um único ponto, o ponto de máximo, gerando uma dinâmica simbólica binária através de dois símbolos. Mapas bidimensionais, ao contrário, são particionados em vários pontos, os pontos onde ocorrem as tangências homoclínicas, tal que a partição geratriz é uma linha descontínua. Portanto, no caso de mapas bidimensionais, esse método deve ser aplicado com alguma restrição uma vez que a partição é variada em uma única direção, enquanto que a partição em mapas bidimensionais é, em geral, bidimensional. Outro problema é quanto ao número de regiões usadas, pois o método faz uso de uma partição binária enquanto que alguns atratores requerem partições ternárias (dinâmica simbólica com um alfabeto de três símbolos) ou de maior ordem. 


\subsubsection{Espaço de parâmetros topológicos}

\section{A. O mapa $n$-modal}

Nossas motivações para estudar o mapa n-modal unidimensional são duas. Primeiro, esses mapas podem ser usados como modelos em alguns sistemas dinâmicos, em particular nos mapas de retorno obtidos para o circuito de Chua experimental. A segunda motivação é o surgimento de janelas periódicas em estruturas de bifurcações conhecidas como "swallow-tails" ou "camarões" em mapas n-modais. Como veremos mais tarde, estudaremos a existência de uma dessas estruturas nas séries experimentais para o circuito usando as propriedades topológicas dos mapas $n$-modais nesse estudo.

Um mapa unidimensional $x_{k+1}=f\left(x_{k}\right)$ contínuo e com $n$ pontos críticos (entre pontos de máximos e mínimos) é chamado de mapa n-modal. Esse mapa é uma generalização natural do mapa unimodal e apresenta bifurcações e seqüências simbólicas extremas análogas ao mapa unimodal, mas com um alfabeto simbólico maior e bifurcações mais complexas.

Da mesma forma que o mapa unimodal, um mapa $n$-modal, para determinados valores dos parâmetros, apresenta um conjunto de Cantor com $(n+1)^{l}$ intervalos remanescentes em cada nível $l$ de modo que um alfabeto com $(n+1)$ símbolos identifica unicamente os pontos no conjunto de Cantor.

Um exemplo de mapa $n$-modal é o mapa bimodal (veja a figura 1.5) dado pela função

$$
f(x)=x^{3}-a x+b .
$$

Esse mapa tem um ponto de máximo em $x_{c_{1}}=-\sqrt{a / 3}$ e um ponto de mínimo em $x_{c_{2}}=\sqrt{a / 3}$ para $a=3,5$ e $b=0$. O alfabeto simbólico $s \in\{0,1,2\}$ gera todas as seqüências permitidas para a dinâmica do mapa.

Um dado mapa $n$-modal apresenta $n$ pontos críticos identificados por $x_{c_{1}}, x_{c_{2}}, \ldots, x_{c_{n}}$. Um ponto $x_{k}$ no mapa poder ser representado por um símbolo $s_{k}$ do alfabeto

$$
s_{k}= \begin{cases}0 & \text { se } x_{k}<x_{c_{1}} \\ i & \text { se } x_{c_{i}}<x_{k}<x_{c_{i+1}} \\ n & \text { se } x_{k}>x_{c_{n}} \\ C_{i} & \text { se } x_{k}=x_{c_{i}}\end{cases}
$$

O itinerário de um ponto $x$ no mapa é dado pela seqüência $S(x)=s_{0} s_{1} s_{2} \ldots$ e a dinâmica agindo em $S(x)$ é dada pelo mapa de deslocamentos $\sigma$

$$
S\left(f^{m}(x)\right)=\sigma^{m} S(x)=s_{m} s_{1+m} s_{2+m} \ldots, m=0,1,2, \ldots
$$




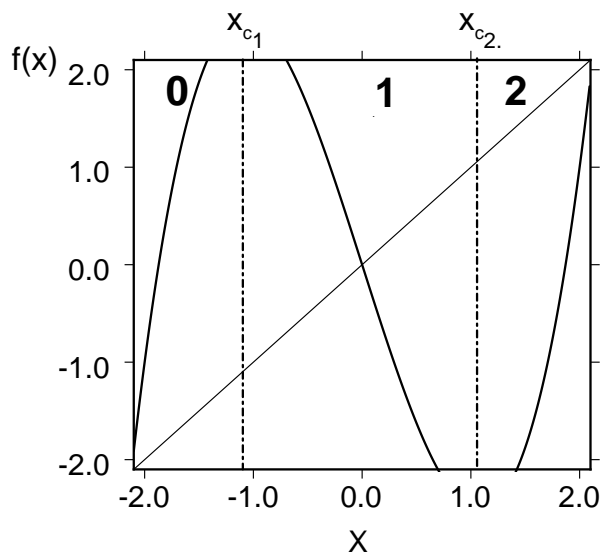

Figura 1.5: Mapa bimodal [eq. (1.27)] com $a=3,5$ e $b=0$. Os pontos críticos $x_{c_{1}}$ e $x_{c_{2}}$ particionam o mapa em três regiões identificadas pelos símbolos $\mathbf{0}, \mathbf{1}$ e $\mathbf{2}$. Nos intervalos ausentes as trajetórias escapam para $\pm \infty$.

Podemos associar a um itinerário um número $\gamma(S) \in[0 ; 1]$ da seguinte forma

$$
\gamma(S)=0, u_{0} u_{1} u_{2} \ldots=\sum_{i=0}^{\infty} \frac{u_{i}}{(n+1)^{i+1}}
$$

onde $u_{i}$ é dado pelas relações recursivas

$$
\begin{aligned}
& u_{0}=s_{0}, \\
& p_{0}=\left\{\begin{array}{lll}
1 & \text { se } & s_{0} \text { par } \\
-1 & \text { se } & s_{0} \text { impar }
\end{array}\right. \\
& u_{i}=\left\{\begin{array}{lll}
s_{i} & \text { se } & p_{i-1}=1, \\
n-s_{i} & \text { se } & p_{i-1}=-1
\end{array}\right. \\
& p_{i}=\left\{\begin{array}{lll}
p_{i-1} & \text { se } s_{i} \text { par } \\
-p_{i-1} & \text { se } & s_{i} \text { ímpar. }
\end{array}\right.
\end{aligned}
$$

A ordem entre dois pontos $x$ e $x^{\prime}$ é preservada por $\gamma(S)$, ou seja, se $x<x^{\prime}$ então $\gamma(x)<\gamma\left(x^{\prime}\right)$. A quantidade $\gamma(S)$ é conhecida como coordenada topológica ou coordenada simbólica $[25,26]$.

Entretanto, nem todas as órbitas são admissíveis em um dado mapa n-modal. No mapa bimodal na eq. (1.27), para determinados valores de $a$, o maior (menor) valor $x_{k}$ na órbita $x_{0} \rightarrow x_{1} \rightarrow \ldots \rightarrow x_{k} \rightarrow \ldots$ é menor (maior) ou igual a $f\left(x_{c_{1}}\right)\left[f\left(x_{c_{2}}\right)\right]$. 
As imagens dos pontos críticos são valores extremos para os valores $x_{k}$ das órbitas do mapa eq. (1.27) e são chamadas de valores críticos. O itinerário de um ponto crítico $K_{i}=S\left(x_{c_{i}}\right)$ é chamado de seqüência simbólica extrema.

Para o caso de um mapa bimodal, existem duas seqüências simbólicas extremas: a seqüência simbólica máxima $K_{1}=S\left(x_{c_{1}}\right)$ (para o ponto de máximo $x_{c_{1}}$ ) e a seqüência simbólica mínima $K_{2}=S\left(x_{c_{2}}\right)$ (para o ponto de mínimo). As coordenadas topológicas correspondente aos pontos críticos são dadas por

$$
\kappa_{i}=\gamma\left(K_{i}\right)=\gamma\left[S\left(x_{c_{i}}\right)\right], i=1,2
$$

e são chamadas de valores simbólicos extremos.

Podemos agora formular um critério para a admissibilidade de um ponto $x$ no mapa bimodal. Podemos observar que o ponto $x$ com itinerário $S(x)$ tal que $\gamma[S(x)]>\gamma\left(K_{1}\right)$ ou $\gamma[S(x)]<\gamma\left(K_{2}\right)$ não é uma órbita admissível porque assim teríamos $x>f\left(x_{c_{1}}\right)$ ou $x<f\left(x_{c_{2}}\right)$. Seja

$$
\gamma^{\max }(S)=\sup _{m} \gamma\left[\sigma^{m}(S)\right]
$$

o valor máximo e

$$
\gamma^{\min }(S)=\inf _{m} \gamma\left[\sigma^{m}(S)\right]
$$

o valor mínimo para uma órbita $x_{0} \rightarrow x_{1} \rightarrow x_{2} \rightarrow \ldots$

Critério de admissibilidade 1 (para mapas bimodais) Seja $\kappa_{1}\left(\kappa_{2}\right)$ o valor simbólico máximo (mínimo) do ponto crítico de máximo (mínimo), e seja $\gamma^{\max }(S)\left[\gamma^{\min }(S)\right]$ o valor máximo (mínimo) de uma órbita de seqüência $S$. Então a órbita $S$ é admissivel se e somente se $\gamma^{\max }(S) \leqslant \kappa_{1}$ e $\gamma^{\min }(S) \geqslant \kappa_{2}$.

Esse critério é uma extensão do critério de admissibilidade para mapas unimodais $[14,38,39]$. Assim, como nos mapas unimodais, os valores simbólicos $\kappa_{i}, i=1,2$, determinam completamente a dinâmica do mapa bimodal associado. Mas como a dinâmica do mapa é determinada por seus parâmetros (como os parâmetros $a$ e $b$ no mapa bimodal 1.27), os valores simbólicos $\kappa_{i}, i=1,2$, podem ser usados para parametrizar algum mapa bimodal. Os valores $\kappa_{i}$ são chamados de parâmetros topológicos. E, analogamente ao espaço de parâmetros $(a, b)$ do mapa, o espaço formado por $\left(\kappa_{1}, \kappa_{2}\right)$ é conhecido como espaço de parâmetros topológico ou espaço de parâmetros simbólico [25, 26].

As bifurcações encontradas no espaço de parâmetros "físico" ( $a, b)$ do mapa bimodal também podem ser encontradas no correspondente espaço de parâmetros topológico $\left(\kappa_{1}, \kappa_{2}\right)$. As relações

$$
\gamma^{\max }(S) \leqslant \kappa_{1} \text { e } \gamma^{\min }(S) \geqslant \kappa_{2}
$$




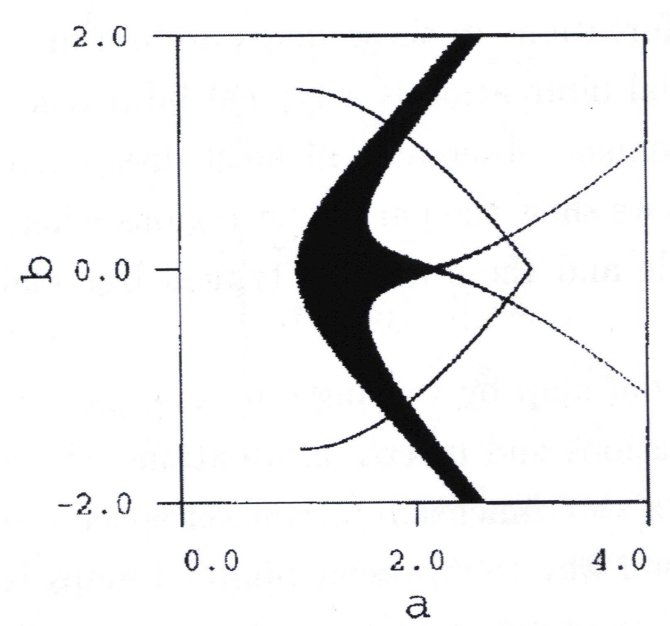

(a)

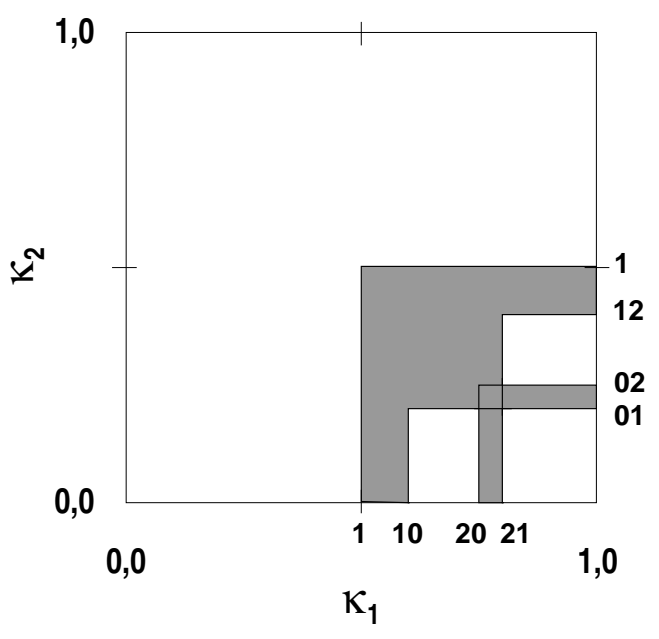

(b)

Figura 1.6: (a) Espaço de parâmetros $(a, b)$ mostrando a região onde as órbitas de período 2 são estáveis para o mapa bimodal (1.27) (adaptado de [25]). (b) Espaço de parâmetros topológico $\left(\kappa_{1}, \kappa_{2}\right)$ mostrando a região onde as órbitas de período 2 existem. Adaptado de Hansen [25]

descrevem uma área no plano de parâmetros $\left(\kappa_{1}, \kappa_{2}\right)$ para qual uma dada órbita $S$ existe.

Usando as relações (1.35) podemos determinar as condições de existência para as órbitas periódicas: $\overline{1}, \overline{21}, \overline{20}$ e $\overline{10}$, tal que a linha sobre os símbolos $\overline{s_{0} s_{1} \ldots s_{n-1}}$ indica sua infinita repetição. Para tal, calcularemos $\gamma(S)$ [dado pelas equação (1.30)] para cada órbita periódica e aplicaremos as relações (1.35). Assim,

$$
\begin{array}{lllll}
\overline{1} & \text { existe se } & \kappa_{1} \geqslant 0, \overline{1}=1 / 2 & \text { e } & \kappa_{2} \leqslant 0, \overline{1}=1 / 2, \\
\overline{21} & \text { existe se } & \kappa_{1} \geqslant 0, \overline{2101}=4 / 5 & \text { e } & \kappa_{2} \leqslant 0, \overline{1012}=2 / 5 \\
\overline{20} & \text { existe se } & \kappa_{1} \geqslant 0, \overline{20}=3 / 4 & \text { e } & \kappa_{2} \leqslant 0, \overline{02}=1 / 4 \text { e } \\
\overline{10} & \text { existe se } & \kappa_{1} \geqslant 0, \overline{1210}=3 / 5 & \text { e } & \kappa_{2} \leqslant 0, \overline{0121}=1 / 5
\end{array}
$$

No espaço de parâmetros $\left(\kappa_{1}, \kappa_{2}\right)$ as relações (1.36) resultam na região sombreada da figura 1.6(b). O intervalo $\left[\kappa\left(\mathcal{S}_{1}\right), \kappa\left(\mathcal{S}_{2}\right)\right]$ entre duas seqüências $\mathcal{S}_{1}$ e $\mathcal{S}_{2}$ representando a mesma órbita (região sombreada) é considerado um intervalo inadmissível, pois não há outras seqüências com $\kappa$ nesse intervalo, e está relacionado com os valores dos parâmetros $a$ e $b$ do mapa bimodal em que as órbitas são estáveis. A figura 1.6(a) mostra 


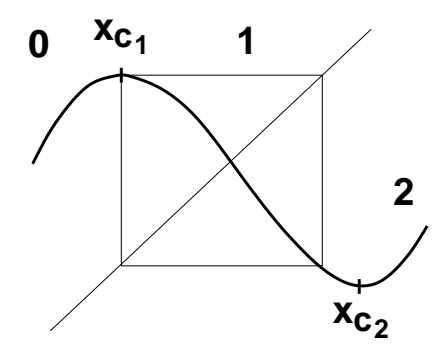

(a)

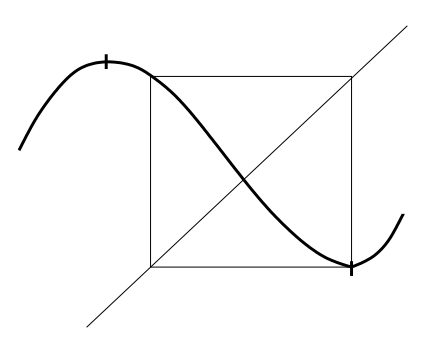

(b)

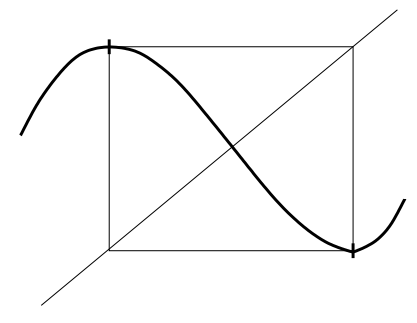

(c)

Figura 1.7: Mapas de primeiro retorno mostrando as três possíveis bifurcações da órbita periódica $\overline{1}$ para órbitas de período 2: (a) $\overline{10}$, (b) $\overline{21}$ e (c) $\overline{20}$.

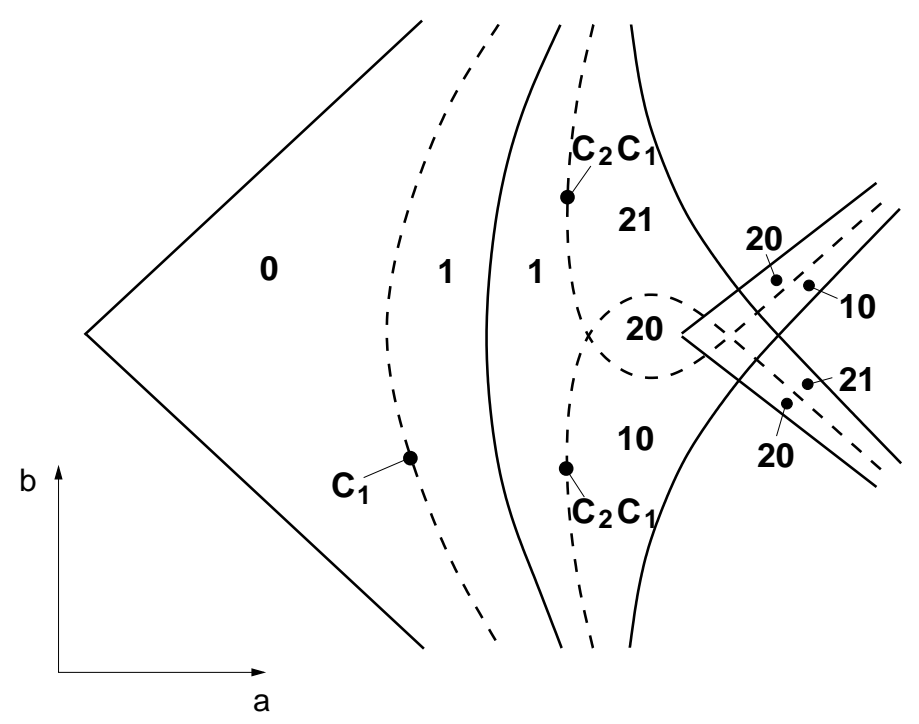

Figura 1.8: Espaço de parâmetros $(a, b)$ com as bifurcações (linha sólida) e as órbitas super-estáveis (linha tracejada) de período 1 e 2 no mapa bimodal. As diferentes regiões são identificadas por uma das possíveis bifurcações de período 2 da seqüência $\overline{1}$. Adaptado de Hansen [25].

a área no espaço de parâmetros real $(a, b)$ onde as órbitas de período dois do mapa bimodal (1.27) existem e são estáveis.

Podemos interpretar a figura 1.6(b) acompanhando as mudanças que as seqüências $\overline{1}, \overline{21}, \overline{20}$ e $\overline{10}$ sofrem no espaço de parâmetros $(a, b)$. A órbita $\overline{1}$ existe inicialmente como um ponto fixo $x_{p}$ entre os pontos $x_{c_{1}}$ e $x_{c_{2}}$. Deslocando-se no espaço $(a, b)$ essa órbita eventualmente sofre bifurcação e torna-se uma órbita de período dois. Essa órbita apresenta dois pontos fixos, $x_{p}^{1}$ e $x_{p}^{2}$ tal que $x_{c_{1}}<x_{p}^{1}<x_{p}^{2}<x_{c_{2}}$, antes de atingir a região de super-estabilidade. Tal órbita de período dois pode tornar-se uma órbita super-estável de três modos: (1) o ponto fixo $x_{p}^{1}$ desloca-se em direção à $x_{c_{1}}$ até 
atingir esse ponto crítico, mudando os símbolos da órbita para $\overline{10}$ [figura 1.7(a)], ou então (2) o ponto fixo à direita $x_{p}^{2}$ desloca-se em direção à $x_{c_{2}}$ mudando a órbita para $\overline{21}$ [figura 1.7(b)], ou então (3) $x_{p}^{1}$ e $x_{p}^{2}$ alcançam os dois pontos críticos simultaneamente e mudam a órbita para $\overline{20}$ [figura $1.7(\mathrm{c})$ ].

A figura 1.8 mostra as bifurcações das órbitas acima no espaço de parâmetros $(a, b)$ onde as linhas sólidas representam as bifurcações e as linhas pontilhadas representam a órbita super-estável. A comparação com com a figura 1.6(b) é imediata.

\subsubsection{Moldes topológicos}

O molde topológico, ou portador de nós, tem sido usado para descrever o conjunto de órbitas periódicas instáveis imersas em um atrator caótico assim como sua organização topológica. O molde foi usado pela primeira vez por Birman e Williams [15] para descrever a organização topológica das órbitas periódicas instáveis existentes no atrator de Lorenz [1]. O molde topológico, definido para fluxos tridimensionais, sumariza os processos de contração, dobras e distensão que o fluxo sujeita um dado atrator caótico. Esses processos organizam todas as órbitas periódicas instáveis do atrator de maneira única. A organização das órbitas permite a obtenção de invariantes topológicos, tal como o número de ligações, que podem ser usados para identificar topologicamente as características dinâmicas presentes em um atrator caótico.

\section{A. O Teorema de Birman e Williams em $\mathbb{R}^{3}$}

Os mecanismos de distender e dobrar que geram um determinado atrator podem ser resumidos em um "retrato" que imita o atrator em seu espaço de fases. O retrato é um modelo geométrico para um atrator construído em duas dimensões a partir das características topológicas geradas pelo fluxo em $\mathbb{R}^{3}$. A existência do retrato é garantida pelo teorema de Birman-Williams [15].

O teorema de Birman-Williams assume que um fluxo dissipativo em $\mathbb{R}^{3}$ gera um atrator caótico hiperbólico que apresenta três expoentes de Lyapunov $\lambda_{i}, i=1,2$ e 3 , tal que $\lambda_{1}>\lambda_{2}>\lambda_{3}$. Esses expoentes satisfazem às seguintes condições:

$$
\begin{array}{lll}
\lambda_{1}>0 & & \text { (sensitividade às condições iniciais) }, \\
\lambda_{2}=0 & \text { (direção do fluxo) }, \\
\lambda_{3}<\quad-\left|\lambda_{1}\right| & \text { (dissipativo). }
\end{array}
$$

A seguir, o teorema identifica dois pontos no espaço de fases, $\vec{x}_{1}$ e $\vec{x}_{2}$, sob a ação do 


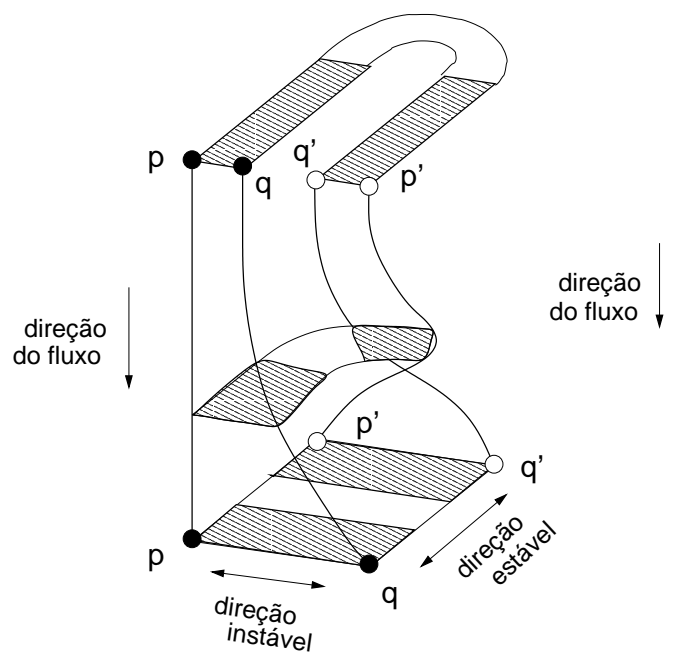

(a)
Projeção

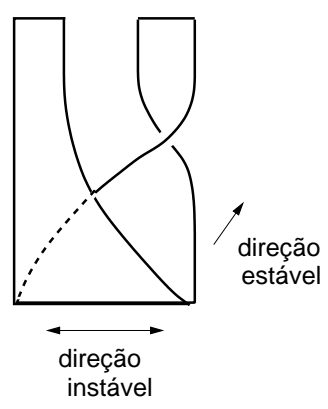

(b)

Figura 1.9: (a) Mapa de suspensão mostrando como os mecanismos de distensão e dobra atuam em um retângulo na base do mapa e (b) a projeção do fluxo sobre a direção instável, ao longo da direção estável, resultando em duas peças em uma variedade bidimensional.

fluxo $\vec{f}$ e com parâmetros $\vec{c}$ como tendo o mesmo futuro assintótico, ou seja,

$$
\vec{x}_{1} \sim \vec{x}_{2} \text { se } \lim _{t \rightarrow \infty}\left|\vec{f}\left(t, \vec{x}_{1}(t=0), \vec{c}\right)-\vec{f}\left(t, \vec{x}_{2}(t=0), \vec{c}\right)\right|=0
$$

Como conseqüência da identificação acima, a direção do fluxo (direção de $\lambda_{2}$ ) pode ser projetada sobre a direção instável $W^{u}$ (direção de $\lambda_{1}$ ) ao longo da direção estável $W^{s}$ (direção de $\lambda_{3}$ ). A figura 1.9 mostra como a projeção é feita.

A projeção é unívoca com os pontos periódicos do fluxo, de modo que cada ponto periódico corresponde a um único ponto projetado na direção instável do fluxo. Logo, todas as órbitas periódicas existentes no fluxo são únicas na projeção, tal que esta encerra a dinâmica subjacente às órbitas periódicas do fluxo no seu espaço de fases. Uma projeção construída dessa maneira é conhecida como molde topológico [2, 15, 18]. O molde topológico é considerado um semi-fluxo sobre uma variedade bidimensional ramificada, uma vez que órbitas inversas não são únicas sobre a variedade ramificada.

Um exemplo de uma projeção originando uma variedade bidimensional com dois ramos é dado na figura 1.10. O atrator de Rössler [figura 1.10(a)] é projetado no plano $x y$ ao longo da direção estável do fluxo (aproximadamente a direção de $z$ ). A ação do fluxo originando o atrator é dada pelo retrato na figura 1.10(b) onde os mecanismos de distensão e dobra originam duas peças. A figura 1.10(c) mostra o molde topológico em sua forma padrão formado por dois ramos (ramos "0" e " 1 "). Os dois ramos representam 


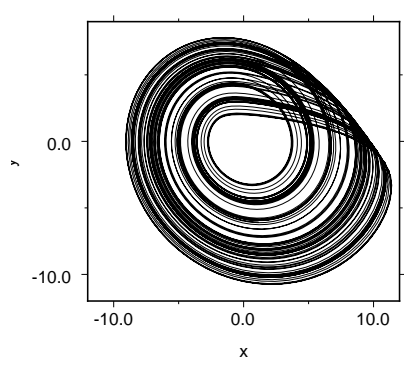

(a)

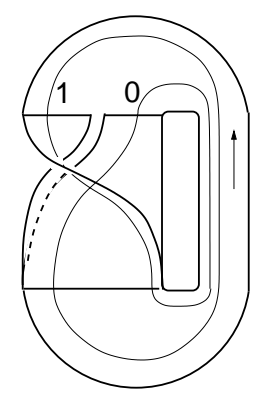

(c)

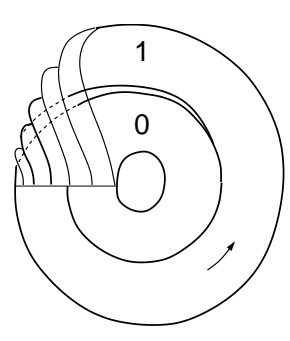

(b)

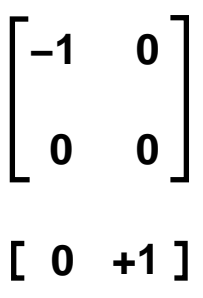

(d)

Figura 1.10: (a) Atrator de Rössler, integrado a partir das equações diferenciais (parâmetros usados na figura 1.3), projetado no plano $x y$. (b) Retrato do fluxo que gera o atrator em uma variedade bidimensional devido a projeção do fluxo sobre a direção instável. Esse retrato apresenta duas regiões topológicas distintas: a região assinalada por $\mathbf{0}$ na qual uma trajetória sofrem estiramentos, e a região assinalada por 1 na qual uma trajetória sofre uma dobra após estirar. (c) Molde topológico para o atrator com dois ramos " 0 " e "1" representando as duas regiões topológicas. (d) Representação algébrica do molde topológico através das matrizes de elos. Adaptado de Gilmore [27].

as duas peças observadas no retrato do fluxo. A figura 1.10(d) mostra a representação algébrica do molde em sua forma padrão. As descrições do molde assim como dessa matriz serão dadas adiante.

\section{B. Molde topológico algébrico}

O molde topológico é formado por ramos. Os ramos representam as diferentes regiões topológicas que podem ser encontradas em um atrator caótico. No molde os ramos mantém as mesmas características topológica que suas correspondentes regiões 


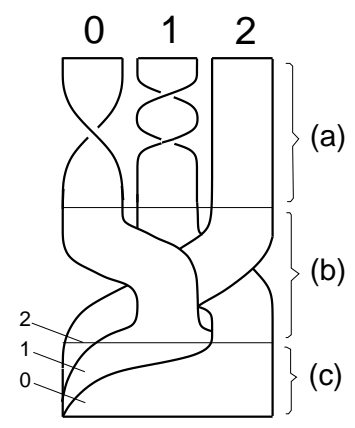

Convenção de cruzamentos

(a)
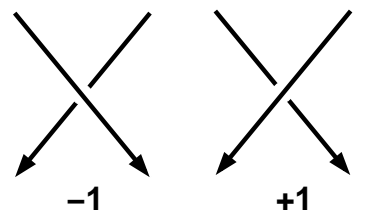

(c)

Figura 1.11: Molde topológico caracterizado por três regiões topológicas cada uma representando um tipo de informação referente aos ramos: (a) torções; (b) cruzamentos e (c) inserções no fluxo. A seqüência em que os ramos são inseridos está assinalado na base do molde. Todas as torções e cruzamentos seguem a convenção dada acima.

no interior do atrator. Tais características podem ser expressas de forma algébrica.

Um molde é composto por $n$ ramos enumerados por $0,1,2, \ldots, n-1$. Todas as informações topológicas contidas no molde estão na região dos ramos. Essa região é dividida em três partes conforme assinalado na figura 1.11: (1) na parte superior [identificada por (a)] tem-se a torção dos ramos descrevendo torções em $\pm \pi$ radianos; (2) na parte central [parte (b)] tem-se a estrutura de cruzamentos responsável por mostrar os cruzamentos entre os ramos e (3) o arranjo de inserção [parte (c)] que descreve como os ramos são inseridos de volta ao fluxo (por convenção, de trás para frente e da esquerda para a direita). As torções e cruzamentos são dados pela convenção da figura 1.11.

Todas essas informações podem ser expressas na forma de uma matriz quadrada de ordem $n$. Tal matriz é conhecida como matriz de elos $[2,27,18,48,49]$. Os elementos $T_{i j}$ da matriz de elos são definidos como: $T_{i i}$ é número de torções ( $\left.\pm \pi \mathrm{rad}\right)$ do $i$-ésimo ramo e $T_{i j}, i \neq j$, é o número de cruzamentos entre o $i$-ésimo e o $j$-ésimo ramos. A matriz $T$ é simétrica $\left(T_{i j}=T_{j i}\right.$, para $\left.i \neq j\right)$. A matriz de inserção, uma matriz linha de ordem $n$, é usada para descrever a ordem em que os ramos são re-inseridos de volta ao fluxo.

Como exemplo o molde da figura 1.11 tem a seguinte matriz de elos

$$
T=\left[\begin{array}{rrr}
-1 & 0 & -1 \\
0 & +2 & +1 \\
-1 & +1 & 0
\end{array}\right]
$$

Na matriz, o número de torções (em $\pm \pi$ radianos) para cada ramo são dados pelos elementos da diagonal principal: $T_{00}=-1$ (ramo "0"), $T_{11}=2$ (ramo "1") e $T_{22}=0$ 
(ramo "2"). O número de cruzamentos entre os ramos são dados pelos elementos $T_{i j}$, $i \neq j: T_{01}=0$ (para os ramos "0" e "1"), $T_{02}=-1(\operatorname{ramos}$ "0" e " $2 ")$ e $T_{21}=+1(\operatorname{ramos}$ "1" e "2"). A matriz de inserção é dada por

$$
\left[\begin{array}{lll}
1 & 0 & 2
\end{array}\right]
$$

onde o ramo "0" é o segundo a ser inserido (posição 1 da frente para atrás e da esquerda para a direita), o ramo "1" o primeiro (posição 0) e o ramo "2" o terceiro (posição 2).

Uma dada órbita periódica é representada no molde através de sua seqüência simbólica. Cada símbolo da seqüência mostra qual ramo do molde a órbita percorre. Assim, a órbita periódica $\overline{10}$ percorre os ramos "0" e "1" de um dado molde [veja figura 1.10(c)]. No molde, as órbitas suportadas apresentam a mesma organização que no interior do atrator. Para ordenar as órbitas no molde podemos podemos usar a seguinte regra de ordenação [38].

Regra de ordenação de seqüências simbólicas 1 Sejam dois itinerários, dados por $\mathbf{s}=\left\{s_{0} s_{1} \ldots s_{i} \ldots s_{n}\right\}$ e $\mathbf{t}=\left\{t_{0} t_{1} \ldots t_{i} \ldots t_{n}\right\}$. Seja também $\tau_{n}(\mathbf{s})$ o número de símbolos impares em $\mathbf{s}$. Seja ainda $s_{i}=t_{i}$ para $i \in[0, n[$. Dizemos que $\mathbf{s} \prec \mathbf{t}$ (s precede $\mathbf{t}$ ) se:

$$
\begin{aligned}
& \text { 1. } \tau_{n-1} \text { é par e } s_{n}<t_{n} \text { ou } \\
& \text { 2. } \tau_{n-1} \text { é ímpar e } s_{n}>t_{n} \text {. }
\end{aligned}
$$

Como exemplo, sejam as seqüências $\overline{012}$ e $\overline{011}$. Como as seqüências representam órbitas, cada uma apresenta três pontos periódicos, dados pela permutação cíclica de cada seqüência:

$$
012 \quad 201 \quad 120
$$

$\mathrm{e}$

$$
011101011 .
$$

Colocando as permutações em ordem ascendente temos

$$
011 \quad 012 \quad 101 \quad 110 \quad 120201 .
$$

Aplicando a regra de ordenação na seqüência acima obtemos

$$
012 \prec 011 \prec 120 \prec 110 \prec 101 \prec 210 \text {. }
$$

Essa é a ordem em que os pontos periódicos das órbitas $\overline{012}$ e $\overline{011}$ são inseridos no molde. 


\section{Número de ligações}

Um atrator caótico pode ser caracterizado através de suas quantidades invariantes. Essas quantidades são de três tipos: (1) invariantes métricos, (2) invariantes dinâmicos e (3) invariantes topológicos.

Invariantes métricos, (dimensões de várias ordens como dimensão fractal [51], funções de escala [52], etc.) e dinâmicos (como os expoentes de Lyapunov [53]) são independentes de transformações de coordenadas e das condições iniciais para um dado atrator. Entretanto, dependem de variações dos parâmetros de controle.

Invariantes topológicos associados às OPI são independentes de variações dos parâmetros de controle, ao menos enquanto as órbitas envolvidas existirem. Um invariante topológico simples associados às OPI é o número de ligações.

Os números de ligações podem ser obtidos diretamente dos dados experimentais de um sistema dinâmico e comparados com os números de ligações previsto pelo modelo topológico, ou seja, previstos pelo molde topológico para esse sistema $[2,3,18,19,27$, 48, 49]. Com esse procedimento, é possível estabelecer se um dado modelo topológico descreve, ou não, um determinado sistema dinâmico.

Sejam duas OPI $\alpha$ e $\beta$ no espaço de fases de um sistema dinâmico. O número de ligações $l g(\alpha, \beta)$ é, essencialmente, o número de vezes que $\alpha$ gira ao redor de $\beta$. Para uma única órbita $(\alpha=\beta), \lg (\alpha, \alpha)=\operatorname{alg}(\alpha)$ é chamado de número de auto-ligações.

O número de auto-ligações (respectivamente, número de ligações) são determinados pela soma (respectivamente, pela metade da soma) do número de cruzamentos de uma OPI com ela mesma (respectivamente, com outra OPI). Para demonstrar o cálculo do número de ligações, na figura 1.12(a) temos duas OPI: a órbita de período 1, $\overline{1}$ e a de período $3, \overline{100}$. O número de cruzamentos entre essas duas órbitas é +2 (seguindo a convenção na figura 1.11) e o número de ligações é metade desse valor $\lg (1,100)=$ $+2 / 2=+1$. O número de auto-ligações para as órbitas $\overline{1}$ e $\overline{100}$ também são calculados na figura 1.12(b) e (c), respectivamente. Para a órbita 1 não há auto-cruzamentos então $\lg (1,1)=\operatorname{alg}(1)=0$. Para a órbita $\overline{100}$ ocorrem dois auto-cruzamentos, resultando em $\operatorname{alg}(100)=+2$.

\section{Cálculo algébrico do número de ligações}

A matriz de elos para um dado molde topológico fornece um modo de calcular o número de ligações entre duas OPI imersas em um sistema dinâmico. Sejam as órbitas $\alpha=\overline{\alpha_{1} \alpha_{2} \ldots \alpha_{i} \ldots \alpha_{p_{1}}}$ e $\beta=\overline{\beta_{1} \beta_{2} \ldots \beta_{j} \ldots \beta_{p_{2}}}$ de períodos $p_{1}$ e $p_{2}$, respectivamente. Um 


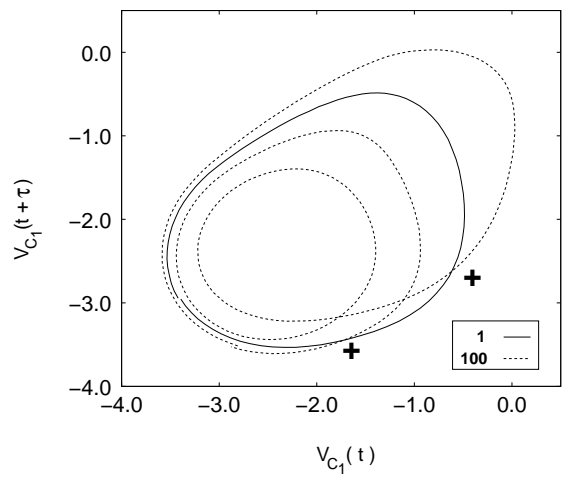

(a)

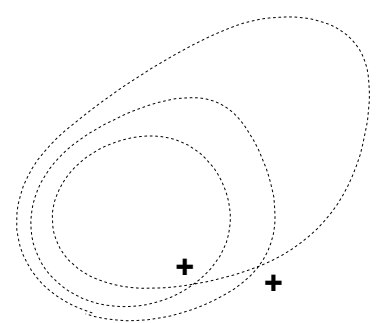

(c)

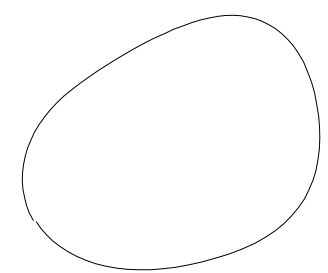

(b)

Figura 1.12: (a) Cálculo do número de ligações entre as OPI $\overline{1}$ e $\overline{100}$. Estas duas órbitas apresentam dois cruzamentos positivos (segundo a convenção na figura 1.11), resultando no número de ligações $l g(1,100)=+2 / 2=+1$. (b) O número de auto-ligações para a órbita $\overline{1}$ é $\operatorname{alg}(1)=0$ e (c) para a órbita $\overline{100}$ é $\operatorname{alg}(100)=+2$.

ponto periódico $i$ de $\alpha$ é expresso pela seqüência $\overline{\alpha_{i} \alpha_{i+1} \ldots \alpha_{p_{1}} \alpha_{1} \ldots \alpha_{i-1}}$ e, analogamente para um ponto $j$ da órbita $\beta$. Os cruzamentos em um molde podem ocorrer nas três regiões assinalados por (a), (b) e (c) na figura 1.11. Os cruzamentos originados em (a) e (b) podem ser computados diretamente da matriz de elos. Mas a matriz de elos não fornece diretamente os cruzamentos da região de inserção dos ramos em (c). Logo o número de ligações $l g(\alpha, \beta)$, obtido a partir da matriz de elos, é computado somando todos esses cruzamentos pela expressão

$$
\lg (\alpha, \beta)=\frac{1}{2}\left[\sum_{i=1}^{p_{1}} \sum_{j=1}^{p_{2}} T\left(\alpha_{i}, \beta_{j}\right)+\lg _{\text {inserção }}(\alpha, \beta)\right]
$$

onde $T\left(\alpha_{i}, \beta_{j}\right)$ são os elementos da matriz de elos $T$ e $l_{\text {inserção }}(\alpha, \beta)$ é o número de cruzamentos ocorridos na região de inserção. A notação $T\left(\alpha_{i}, \beta_{j}\right)$ indica que os elementos de $T$ são "indexados" pelos símbolos usados nos ramos do molde e o somatório aplicado sobre os elementos de $T$. Como exemplo, $T(0,1)$ corresponde ao elemento de $T$ posicionado na linha 0 e coluna 1 e se refere aos cruzamentos entre os ramos " 0 " e " 1 " do molde, ou seja, $T(0,1)$ é o elemento $t_{01}$ da matriz $T$.

Entretanto, os cruzamentos $l g_{\text {inserção }}$ podem ser obtidos se reproduzirmos a região 
de inserção dos ramos do molde. É necessário então reproduzir o arranjo dos pontos periódicos após sua passagem pelas regiões de torções e de cruzamentos. Aplicaremos duas regras [54] para ordenar os pontos periódicos de uma órbita na região de inserção do molde: (1) após a passagem por um ramo no molde com número ímpar de torções os pontos periódicos são posicionados em ordem inversa e (2) após a passagem por ramos que permutam de posição entre si, os pontos periódicos também permutam.

Como exemplo, vamos calcular o número de ligações entre as órbitas $\overline{10}$ e $\overline{101}$ a partir do molde que as suporta definido por

$$
T=\left[\begin{array}{rr}
0 & -1 \\
-1 & -1
\end{array}\right] \text {. }
$$

A ordem de precedência dos pontos periódicos dessas duas órbitas é dada pela regra de ordenação 1

$$
\overline{011} \prec \overline{01} \prec \overline{110} \prec \overline{10} \prec \overline{101} \text {. }
$$

As relações (1.43) acima estabelecem a ordem em que os pontos periódicos das órbitas $\overline{10}$ e $\overline{101}$ são dispostos na base do molde. Assim, o nível inferior da região dos ramos é dado pelas relações 1.43 , ou seja

$$
\underbrace{\overline{011} \overline{01}}_{\text {ramo } 0} \underbrace{\overline{110} \overline{10} \overline{101}}_{\text {ramo } 1} \text {. }
$$

O elemento $T_{11}=-1$ de $T$ indica que o ramo 1 do molde é torcido de $-\pi$ rad, um número ímpar de torções. Assim, aplicando a regra (1) sobre os pontos no ramo 1 temos

$$
\underbrace{\overline{011} \overline{01}}_{\text {ramo } 0} \underbrace{\overline{101} \overline{10} \overline{110}}_{\text {ramo } 1} \text {. }
$$

Os elementos $T_{01}=T_{10}=-1$ indicam que ramos 0 e 1 permutam de posição no molde uma vez. Então, aplicando a regra (2) temos

$$
\underbrace{\overline{101} \overline{10} \overline{110}}_{\text {ramo } 1} \underbrace{\overline{011} \overline{01}}_{\text {ramo } 0} \text {. }
$$

Essa é a configuração dos pontos periódicos após sua passagem pela região de cruzamentos dos ramos formando o nível superior da região de inserção.

Finalizando a reprodução, um ponto periódico do nível superior deve ser unido com sua respectiva permutação existente no nível inferior (unimos um ponto com sua imagem após a aplicação do mapa de deslocamentos $\sigma$ ), a partir da esquerda para a direita e de cima para baixo. O número de cruzamentos na região de inserção pode ser visto na figura 1.13 e vale $l g_{\text {inserção }}=+1$. 


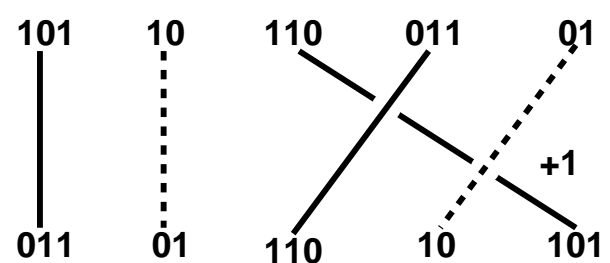

Figura 1.13: Reprodução da região de inserção dos ramos no molde topológico representado pela matriz (1.42). No nível superior tem-se a configuração final dos pontos periódicos após a passagem pelas regiões de torções locais e de cruzamentos entre os ramos. No nível inferior os pontos periódicos são organizados pela ordem de precedência. Cada ponto é unido a sua respectiva imagem, a partir da esquerda para a direita e de cima para baixo. Auto-intersecções são descartadas. Na figura $l g_{\text {inserção }}=+1$.

Podemos agora calcular o número de ligações $\lg (10,101)$ entre as duas órbitas, usando a equação 1.41. As somas na equação (1.41) ficam

$$
\begin{aligned}
\sum_{i=1}^{2} \sum_{j=1}^{3} T\left(\alpha_{i}, \beta_{j}\right) & =T(1,1)+T(1,0)+T(1,1)+T(1,0)+T(0,0)+T(0,1) \\
& =2 T(1,1)+3 T(1,0)+T(0,0) .
\end{aligned}
$$

Esse resultado, em adição ao número de cruzamentos de inserção $l g_{\text {inserção }}=+1$, resulta em

$$
\begin{aligned}
\lg (10,101) & =\frac{1}{2}\left[2 T(1,1)+3 T(1,0)+T(0,0)+\lg _{\text {inserção }}\right] \\
& =\frac{1}{2}[-2-3+0+1] \\
& =-2 .
\end{aligned}
$$

O número de ligações assim obtido está de acordo com aquele determinado a partir da contagem dos cruzamentos diretamente no molde [54].

\subsection{Espaço de parâmetros e janelas periódicas}

\subsubsection{O espaço de parâmetros}

Um sistema dinâmico determinístico é definido por dois componentes fundamentais: (i) uma "regra" ou dinâmica que determina como o sistema evoluirá no tempo e (ii) o estado inicial a partir do qual o sistema começa sua evolução. Tal regra pode ser definida pelas variáveis do sistema, pelas relações entre essas variáveis e pelo conjunto de 
parâmetros associado. Em geral, diferentes estados iniciais levam o sistemas à diferentes estados finais. Chamamos de bacia de atração ao conjunto de estados iniciais que levam ao mesmo estado final. Entretanto, não é só a mudança entre bacias de atração que leva o sistema a estados finais diferentes. A variação do conjunto de parâmetros também pode levar a estados finais diferentes.

Um diagrama de bifurcações é a coleção dos possíveis estados finais de um sistema dinâmico para a variação de apenas um elemento do conjunto de parâmetros. O espaço de parâmetros é uma generalização do diagrama de bifurcações o qual descreve os estados finais do sistema para variações de dois ou mais parâmetros.

O estudo do espaço de parâmetros permite a obtenção de regras para a descrição global do sistema dinâmico analisado. Por exemplo, o espaço de dois parâmetros tem sido empregado para investigar o surgimento do comportamento periódico em vários sistemas dinâmicos. Gallas [23] mostrou que o comportamento periódico do mapa de Hénon é organizado por uma estrutura principal, uma janela de periodicidade de período $n$ e com forma geométrica semelhante a um "camarão" ou "swalow-tail", e uma infinita sucessão, nas vizinhanças da estrutura principal, de janelas periódicas de período $n \times 2^{m}$, também com a forma de "camarão" e apresentando propriedades de escala.

\subsubsection{O sistema de Rössler}

Gaspard e colaboradores [22] mostraram que o sistema de equações diferenciais não-lineares, apresentando um conjunto de órbita homoclínica associadas a um ponto de sela cujo os auto-valores são da forma $(\rho \pm i \omega, \lambda)$, onde $|\rho / \lambda|<1$ (a condição de Sil'nikov [55]) também apresenta janelas de periodicidade no espaço de dois parâmetros. Ele observou que as janelas surgem continuamente conectadas no espaço de dois parâmetros, organizadas globalmente ao longo dos valores dos parâmetros onde ocorrem as órbitas homoclínicas.

Através de mapas obtidos por seções de Poincaré, Gaspard estudou analiticamente dois modelos para as bifurcações que o fluxo sofre nas vizinhanças do ponto de sela. No primeiro modelo, uma expansão linear e outra quadrática dos mapas bidimensionais em torno de dois parâmetros, resultam em um conjunto de órbitas homoclínicas $H$, de codimensão 1 , associado a um conjunto de janelas periódicas $P_{n}, n=1,2, \ldots$, conectadas entre si por uma estrutura governada por uma geometria espiral no espaço de dois parâmetros. O estudo da estabilidade das janelas periódicas resultam em três tipos de bifurcações: (i) uma família de bifurcações tangentes originando as órbitas periódicas 


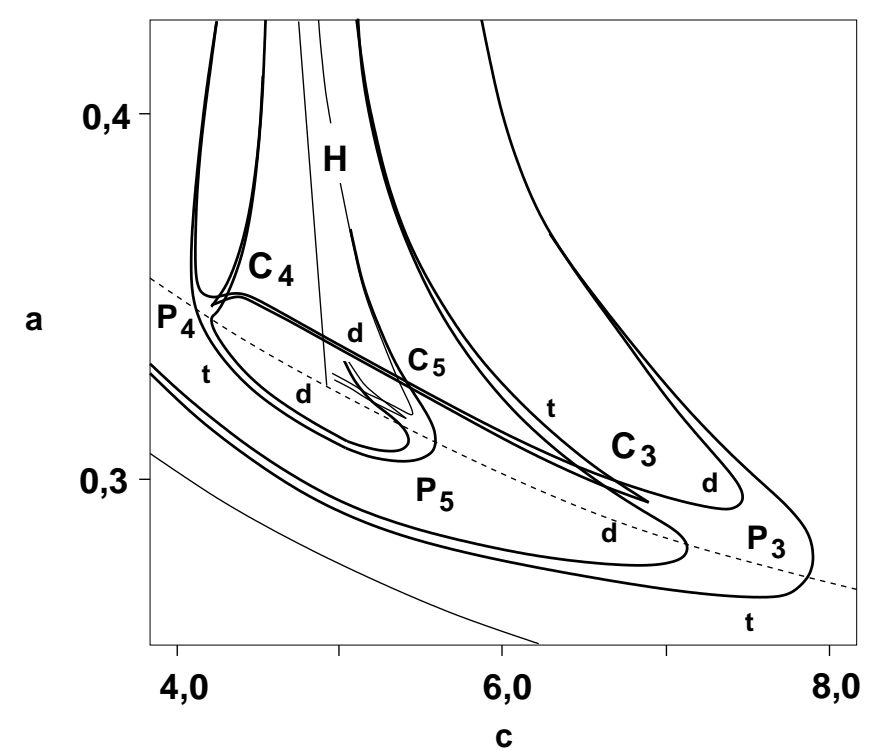

(a)

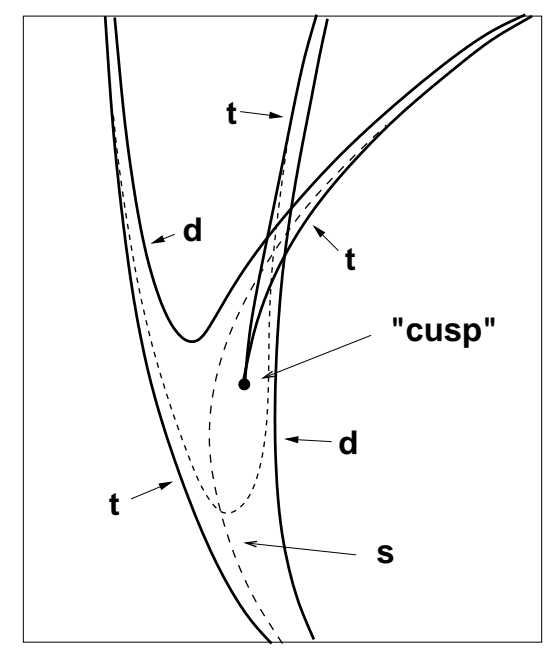

(b)

Figura 1.14: (a) Janelas periódicas $\mathrm{P}_{3}, \mathrm{P}_{4}$ e $\mathrm{P}_{5}$ de períodos 3,4 e 5, respectivamente, no espaço de dois parâmetros $(a, c)$ e $b=0,3$ no sistema de Rössler [eq. (1.44)] conectadas a uma estrutura espiral logarítmica. $H$ é o conjunto de sistema homoclínicos associados ao ponto de sela; $\mathbf{t}$ e $\mathbf{d}$ são as fronteiras das bifurcações tangente e duplicação de período das janelas periódicas; $C_{3}, C_{4}$ e $C_{5}$ as bifurcações "cusp". A linha pontilhada é a fronteira entre os comportamentos dominados pelos atratores dos tipos espiral e "parafuso" (também chamados de Rössler-dobrado). (b) Ampliação de uma das janelas periódicas onde estão aparentes as fronteiras t e d, o ponto de bifurcação "cusp" e as órbitas super-estáveis s. Adaptado de Gaspard et al. [22].

(janelas), acumulando-se nas vizinhanças dos sistemas homoclínicos $H$ no espaço de dois parâmetros; (ii) as órbitas periódicas sofrem uma seqüência de duplicações de período levando ao caos e (iii) bifurcações do tipo "cusp" surgem no interior das janelas periódicas com o sistema apresentando bi-estabilidade em duas novas soluções.

Um segundo modelo, um mapa bimodal aplicado às seções de Poincaré nas vizinhanças do ponto de sela, é usado para descrever as janelas periódicas no espaço de dois parâmetros. Desse modelo pode-se concluir que: (i) uma órbita de período $n$ surge, devido a uma bifurcação tangente, tornando-se de período $2 n$ na fronteira da duplicação de período; (ii) uma cascata de duplicação de período produz órbitas de período $n \times 2^{m}$, $m$ inteiro; (iii) existe uma hierarquia infinita de pontos de bi-estabilidades ("cusp") para cada órbita de período $n$. 
As figuras 1.14(a) e (b) mostram o resultado da análise de Gaspard do sistema de Rössler [43] definido como

$$
\left\{\begin{array}{l}
\dot{x}=-y-z, \\
\dot{y}=x+a y, \\
\dot{z}=b x-c z+x z,
\end{array}\right.
$$

no espaço de parâmetros $(a, c)$ e parâmetro $b=0,3$.

Na figura 1.14(a) podemos ver três janelas periódicas $\mathrm{P}_{3}, \mathrm{P}_{4}$ e $\mathrm{P}_{5}$ de período 3,4 e 5, respectivamente, conectadas por uma estrutura espiral no espaço de parâmetros $(a, c)$. $H$ é o conjunto de sistemas homoclínicos em $(a, c)$. As fronteiras de bifurcações tangente e duplicação de período são identificadas por $\mathbf{t}$ e $\mathbf{d}$, respectivamente. $\mathrm{C}_{3}, \mathrm{C}_{4}$ e $\mathrm{C}_{5}$ são os pontos de bifurcação "cusp" no interior das janelas periódicas. A figura 1.14(b) é a ampliação de uma janela periódica e mostra o ponto de bifurcação "cusp", as fronteiras de bifurcações tangente e duplicação de período e o conjunto de sistemas com órbitas periódicas super-estáveis $\mathbf{s}$ nas linhas pontilhadas.

Um sistema dinâmico caótico com dimensão de imersão $d_{E}=3$ apresenta três expoentes de Lyapunov. Assumindo que apenas um dos expoentes é positivo, o maior dos expoentes $\lambda_{\max }$, o comportamento dinâmico desse sistema pode ser determinado analisando $\lambda_{\max }$ : (i) se $\lambda_{\max } \leq 0$ o sistema dinâmico tem comportamento periódico ou quase-periódico e (ii) caso $\lambda_{\max }>0$ o sistema apresenta comportamento caótico. Esse fato permite uma forma alternativa, não analítica, de estimar o comportamento dinâmico do sistema em seu espaço de parâmetros, a partir das estimativas do maior expoente de Lyapunov $\lambda_{\max }$ das séries temporais, sejam as séries obtidas de sistemas experimentais ou do conjunto de eqüações diferenciais.

A figura 1.15 mostra a aplicação desse procedimento. A comparação com a análise de Gaspard é imediata: (i) ambos os métodos permitem visualizar as janelas periódicas conectadas a uma estrutura espiral e globalmente organizadas ao redor do conjunto de sistemas homoclínicos $H$; (ii) as fronteiras das janelas são formadas por regiões de comportamento caótico; (iii) ambos os métodos mostram regiões de bi-estabilidade no interior das janelas periódicas.

\subsubsection{O circuito de Chua}

O espaço de parâmetros para o circuito de Chua foi obtido experimentalmente por Baptista e colaboradores [24] através do mesmo aparato experimental usado no presente trabalho (veja seção 2.1 para mais detalhes). Baptista obteve o espaço de parâmetros 


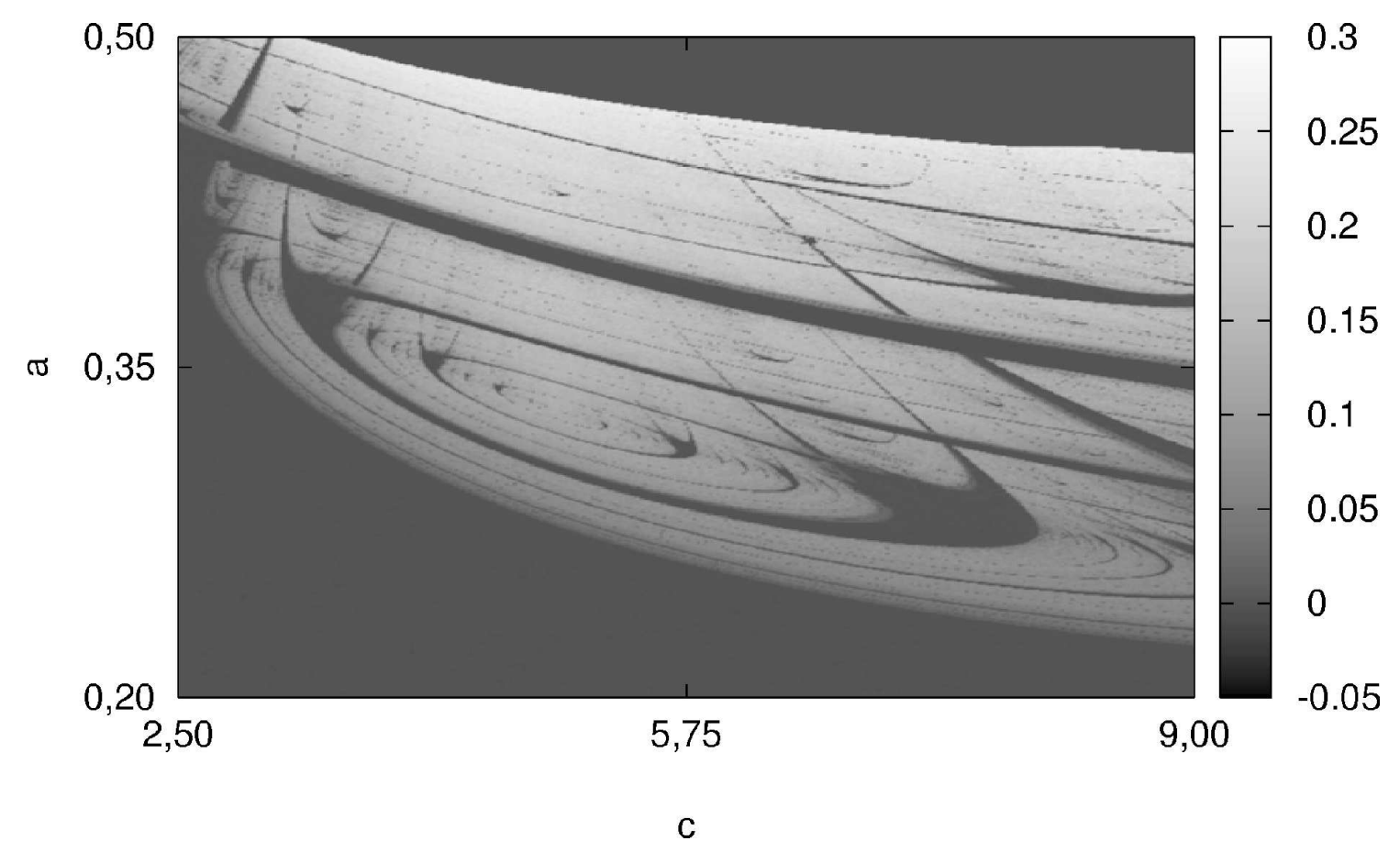

Figura 1.15: Espaço de dois parâmetros $(a, c)$ para o sistema de Rössler definido pelo sistema de equações (1.44), com $b=0,3$, obtido através da estimativa do maior expoente de Lyapunov $\lambda_{\max }$ em $(a, c)$. Regiões com a mesma tonalidade indicam atratores com valores do maior expoente de Lyapunov similares. As janelas periódicas estão representadas por cinza claro $\left(\lambda_{\max } \leq 0\right)$. $\mathrm{O}$ comportamento caótico é representado por cinza escuro $\left(\lambda_{\max }>0\right)$. Uma estrutura espiral conecta as janelas periódicas no espaço de parâmetros com acumulação nas vizinhanças do conjunto de sistemas homoclínicos (não mostrado na figura).

para variações de dois resistores lineares $\Delta R_{1}$ e $\Delta R_{2}$ do circuito. Procurando um método eficiente de comunicação usando um sistema dinâmico caótico, Baptista observou que algumas características métricas (o expoente de Lyapunov) assim como topológicas (a entropia topológica) dos atratores do circuito são preservadas quando os parâmetros são variados ao longo de direções especiais no espaço de parâmetros $\left(\Delta R_{1}, \Delta R_{2}\right)$. 

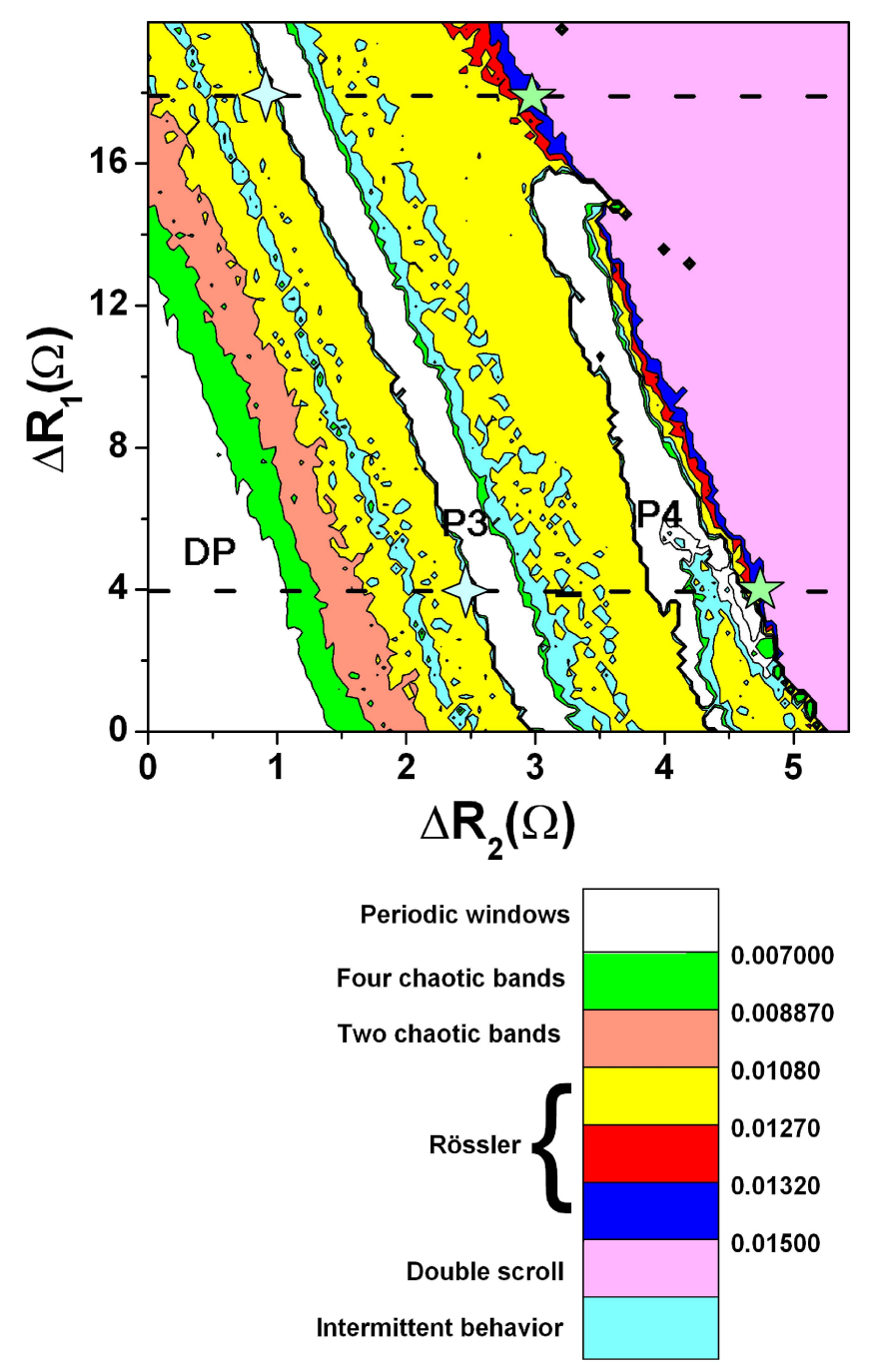

Figura 1.16: Espaço de parâmetros para o circuito experimental de Chua, obtido a partir da estimativa do maior expoente de Lyapunov $\lambda_{\max }$ para as séries temporais ao variarmos $\Delta R_{1}$ e $\Delta R_{2}$. Regiões de mesma tonalidade representam atratores com o mesmo intervalo para $\lambda_{\text {max }}$ indicando comportamento dinâmico similar: a cor branca indica comportamento periódico; as cores indicam comportamento caótico.

A figura 1.16, adaptada de Ref. [24], mostra o espaço de parâmetros para o circuito experimental, determinado através da estimativa do maior expoente de Lyapunov $\lambda_{\max }$ como descrito na seção 1.3.2. Na figura, uma dada tonalidade de cor representa atratores com o mesmo intervalo para o maior expoente de Lyapunov. Tons claros indicam comportamento periódico ou quase-periódico. Tons escuros indicam comportamento caótico. Nessa figura são visíveis três grandes janelas periódicas: a primeira, assinalada por DP, é delimitada pela linha de acumulação de duplicação de período; a segunda, 
P3 na figura, é uma janela de período três e a terceira, P4 na figura, é uma janela de período quatro.

O comportamento dinâmico das regiões caóticas pode ser observado em três tipos da atratores. (1) Os atratores do tipo Rössler (recebem esse nome devido a semelhança com o atrator obtido no sistema de Rössler) com quatro, duas e uma bandas caóticas. Esses atratores surgem logo após a primeira janela periódica, no final da cascata de duplicação de período, e logo após a janela de período três. (2) Atratores do tipo Rössler-dobrado (essencialmente um atrator de Rössler com duas dobras ao invés de uma), que surgem logo após a janela de período quatro. (3) Atratores conhecidos como "duplo-rolo", criados por uma crise por fusão [56] da bacia de atração de dois atratores Rössler-dobrado coexistentes.

\subsubsection{Fibras caóticas}

O espaço de dois parâmetros também foi empregado para mostrar a similaridade entre atratores caóticos de sistemas que apresentam ao menos um expoente de Lyapunov positivo. Em [60] mostrou-se numericamente que existem regiões abertas no espaço de dois parâmetros do sistema de Lorenz tais que os expoentes de Lyapunov positivo apresentam valores similares, indicando que os atratores em tais regiões apresentam comportamento dinâmico similar. Em [24], Baptista mostrou que certas características métricas e topológicas dos atratores caóticos mantém-se invariantes ao longo de estruturas no espaço dos parâmetros chamadas de fibras caóticas. Tais fibras caóticas agem de modo a sustentar o comportamento caótico dos atratores nelas situados, mesmo quando se trata de um sistema dinâmico frágil, onde o comportamento caótico pode dar lugar ao comportamento periódico para variações arbitrárias dos parâmetros de controle.

As fibras caóticas, conjetura-se, tem a mesma codimensão das janelas periódicas situadas em suas vizinhanças. Baseando-se nos trabalhos de Barreto [62] e Baptista [63], onde sugere-se que uma janela periódica no espaço de dois parâmetros tem sua forma e topologia relacionadas com a região de comportamento caótico situada em sua vizinhança, uma fibra caótica vizinha a essa janela apresenta a mesma codimensão $k$ da janela, onde $k$ é o número de expoentes de Lyapunov positivos da região caótica. Conseqüentemente, para preservar o caos, a despeito da fragilidade do sistema, basta alterarmos $k+1$ parâmetros simultaneamente de modo que a alteração percorra uma dada fibra caótica. 


\section{CAPÍTULO 2}

\section{Resultados e Análises}

\subsection{Descrição do Arranjo Experimental}

O arranjo experimental para o circuito de Chua é mostrado na figura 2.1. No circuito $R_{N L}$ é um resistor não-linear, $L$ é um indutor, $C_{1}$ e $C_{2}$ são dois capacitores. As variáveis dinâmicas do sistema são: $i_{L}$ a corrente elétrica que atravessa o indutor, $V_{C_{1}}$ e $V_{C_{2}}$ as voltagens pelos capacitores. Os parâmetros de controle para o circuito são duas resistência $R_{1}=R_{10}-\Delta R_{1}$ e $R_{2}=R_{20}-\Delta R_{2}$, onde $R_{10}$ e $R_{20}$ tem valores fixos e $\Delta R_{1}$ e $\Delta R_{2}$ são dois potenciômetros acionados por motores de passo. Nós coletamos 4 conjuntos de séries temporais, chamadas de $\mathrm{X}, \mathrm{Y}, \mathrm{Z}$ e W, para parâmetros $\Delta R_{1}$ e $\Delta R_{2}$ entre os intervalos $\Delta R_{1}=[0 ; 15] \Omega$ e $\Delta R_{2}=[0 ; 5] \Omega$. Cada conjunto de series temporais corresponde a um valor fixo de $\Delta R_{1}$ : aproximadamente $0,08 \Omega$ para o conjunto X; $4,57 \Omega$ para o conjunto $\mathrm{Y} ; 9,57 \Omega$ para $\mathrm{Z}$ e $14,6 \Omega$ para $\mathrm{W}$. As séries temporais foram obtidas gravando a voltagem $V_{C_{1}}$ sobre o capacitor $C_{1}$ no circuito através de um circuito analógico-digital (ADC) de 12 bits à razão de $400 \mathrm{k}$ amostras/s. Cada série temporal tem comprimento de 100000 dados.

\subsection{Atratores e diagramas de bifurcações}

O circuito de Chua apresenta uma grande variedade de atratores e bifurcações encontrados em vários sistemas dinâmicos [21]. Algumas dessas bifurcações podem ser vistas na figura 2.2. Ao variarmos o parâmetro $\Delta R_{2}$ do circuito, as séries temporais (por exemplo o conjunto $X$ ) exibem um ponto de equilíbrio que perde estabilidade por uma bifurcação de Hopf levando à criação de um ciclo limite. Uma série de bifurcações de período levam à atratores com 4 bandas caóticas seguido por atratores com duas 


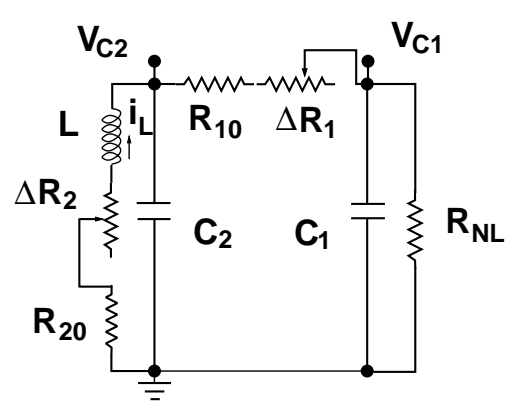

Figura 2.1: Circuito de Chua e seus componentes eletrônicos. Os parâmetros são: $R_{10} \approx 1,4 \mathrm{k} \Omega$, $R_{20} \approx 37 \Omega, C_{1} \approx 4,7 \mathrm{nF}, C_{2} \approx 56 \mathrm{nF}$ e $L \approx 9,2 \mathrm{mH}$.

bandas caóticas que se fundem para formar o chamado atrator do tipo Rössler. Após uma crise interna, os atratores tipo Rössler são destruídos e surge uma janela periódica de período 3. Esta janela é chamada, devido a forma e largura que assume no espaço de parâmetros, de janela periódica estendida (veja a figura 1.16). A janela de período 3 desaparece, através da duplicação de período, levando novamente ao atrator do tipo Rössler seguido pelo atrator Rössler-dobrado (basicamente um atrator do tipo Rössler com três regiões topológicas). As bacias de atração de dois atratores Rösslerdobrado coexistentes fundem-se, através de uma crise por fusão [56], formando o atrator conhecido como "duplo-rolo".

Nesse ponto surge uma diferença no comportamento dinâmico entre os quatro conjuntos de séries. Antes do surgimento do atrator Rössler-dobrado, os conjuntos $X, Y$ e $Z$ apresentam uma janela de período quatro, inexistente para o conjunto $W$. Entretanto a forma dessa janela não é a mesma em todos os conjuntos. Enquanto que em $Y$ e $Z$ a janela surge uma única vez, em $X$ ela surge duas vezes. Esse comportamento se relaciona com a forma geométrica que as janelas periódicas assumem no espaço de dois parâmetros para o circuito de Chua (veja seção 1.3.3). A projeção bidimensional dos três tipos de atratores, Rössler, Rössler-dobrado e duplo-rolo podem ser vistas na figura 2.3(a), (b) e (c) respectivamente.

\subsection{Caracterização métrica das séries temporais}

Nessa seção determinamos a dimensão de imersão $d_{E}$ que melhor representa os atratores reconstruídos a partir das séries temporais obtidas do circuito de Chua experimental. Aplicamos o método dos falsos vizinhos à três séries temporais que representam três tipos de atratores que podem ser encontrados no circuito: os atratores tipo Rössler, 


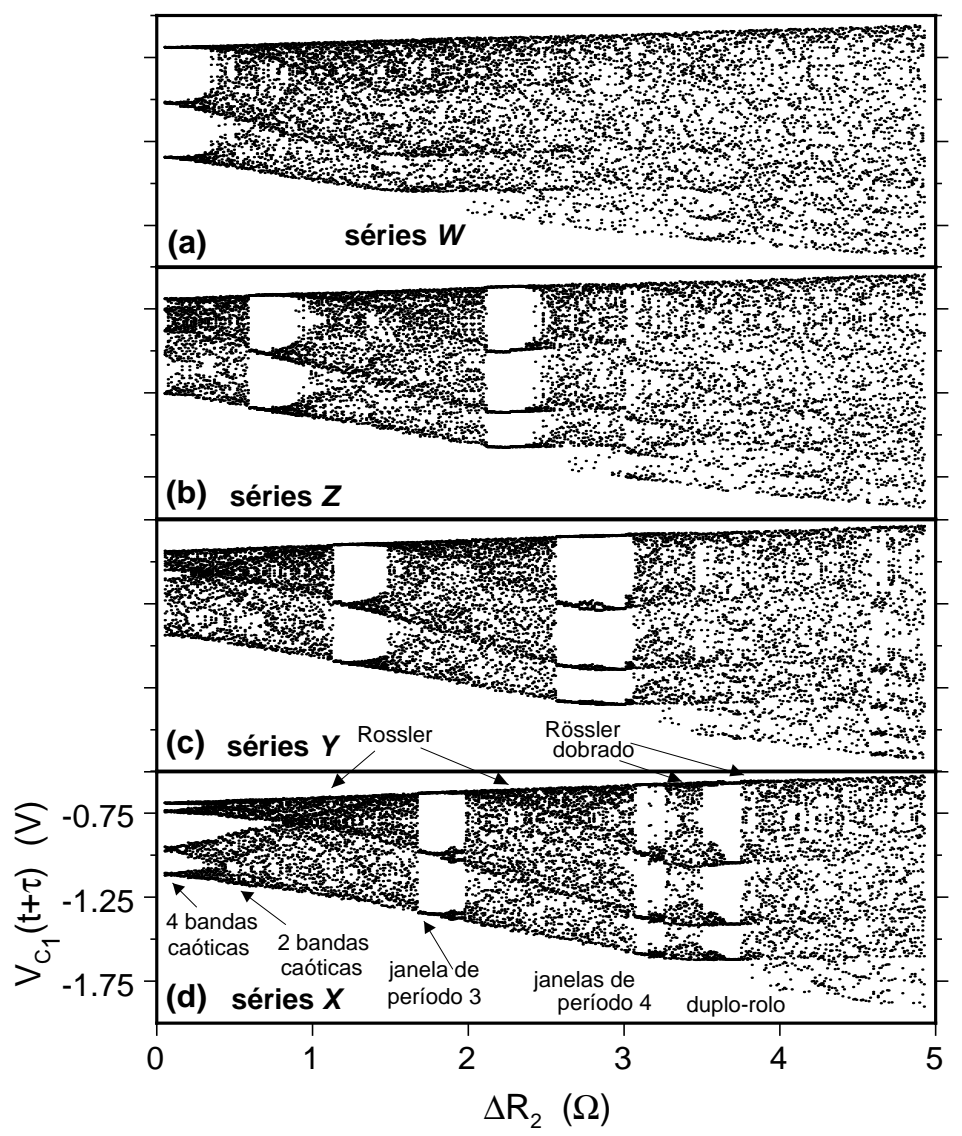

Figura 2.2: Diagramas de bifurcações para quatro os conjuntos de séries temporais medidas: (a) $W$; (b) $Z$; (c) $Y$ e (d) $X$. A janela de período 3 surge em todos os conjuntos enquanto a janela de período quatro surge apenas em $X, Y$ e $Z$.

Rössler-dobrado e duplo-rolo. Determinamos também os expoentes de Lyapunov e a dimensão de Lyapunov para esses três atratores para determinar a validade do teorema de Birman-Williams e prosseguir com o análise topológica.

\subsubsection{Dimensão de imersão}

Alguns dos métodos topológicos empregados nesse trabalho (moldes topológicos e números de ligações $[2,27])$ foram desenvolvidos, originalmente, para sistemas fortemente dissipativos imersos em um espaço de fases tridimensional [15]. Esses métodos podem ser empregados em qualquer sistema dinâmico de "baixa-dimensão" efetiva [27, 57], desde que em tais sistemas as variáveis dinâmicas do fluxo relaxem suficientemente rápido para confiná-lo a um espaço de imersão $d_{E}=3$. Nesses sistemas, a dimensão de Lyapunov é $D_{K Y}<3$. Mostraremos que as séries temporais experimentais obtidas do 


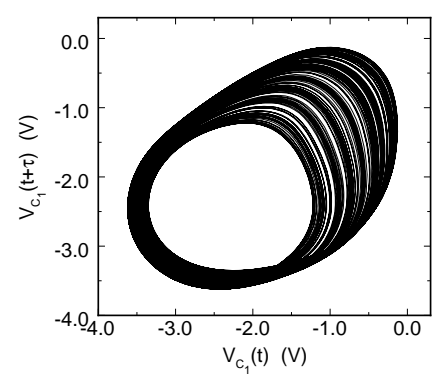

(a)

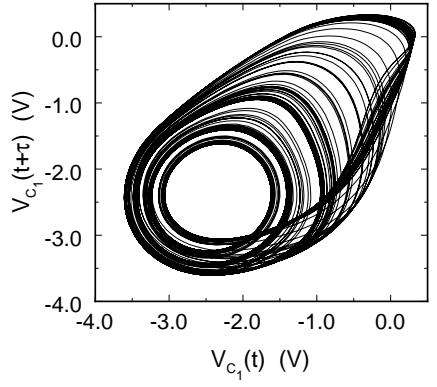

(b)

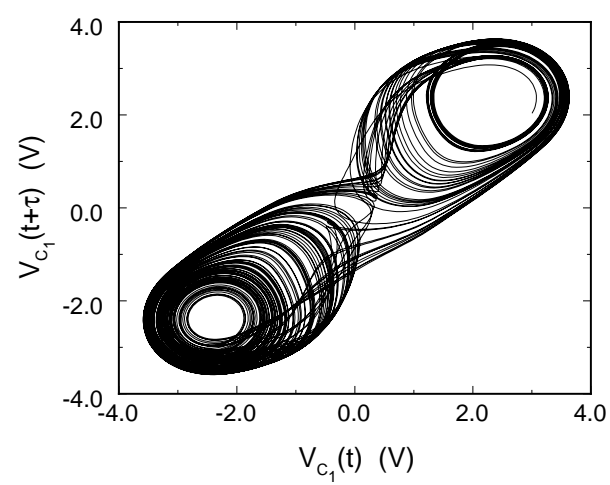

(c)

Figura 2.3: Projeção bidimensional dos atratores reconstruídos a partir do conjunto de séries $X$ $\left(\Delta R_{1}=0,08 \Omega\right)$ : (a) atrator tipo-Rössler $\left(\Delta R_{2}=1,06 \Omega\right)$; (b) Rössler-dobrado $\left(\Delta R_{2}=3,78 \Omega\right)$ e (c) duplo-rolo $\left(\Delta R_{2}=4,76 \Omega\right)$

circuito de Chua satisfazem a condição $D_{K Y}<3$.

A fim de demonstrar que os atratores do circuito de Chua são bem representados imersos em um espaço de fases tridimensional, e que, portanto, os invariantes topológicos são bem definidos (no fluxo em $\mathbb{R}^{3}$ ), estimamos a dimensão de imersão $d_{E}$ (utilizando o método de falsos vizinhos), a dimensão de Kaplan-Yorke (ou de Lyapunov) $D_{L}=D_{K Y}$ e os expoentes de Lyapunov para três séries temporais experimentais do circuito.

Empregamos o método dos falsos vizinhos, utilizando o pacote TISEAN [73], a três séries temporais do conjunto $X\left(\Delta R_{1}=0.08 \Omega\right)$, cada uma representando, quando reconstruída a dinâmica, um dos tipos de atratores: Rössler $\left(\Delta R_{2}=1,06 \Omega\right)$, Rösslerdobrado $\left(\Delta R_{2}=3,78 \Omega\right)$ e duplo-rolo $\left(\Delta R_{2}=4,76 \Omega\right)$. O passo da reconstrução (tempo de atraso) é $\tau=18 \Delta t=45 \mu \mathrm{s}$ (o tempo de 18 dados para $\Delta t=2,5 \mu \mathrm{s}$ ). As figuras $2.4(\mathrm{a})$, 


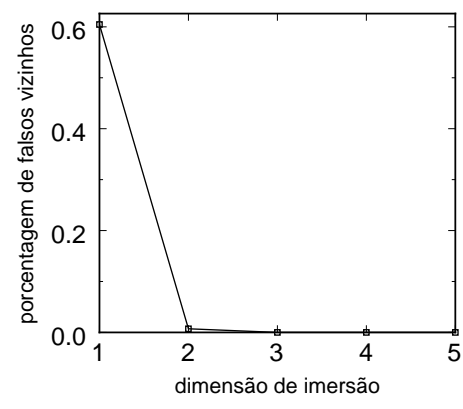

(a)

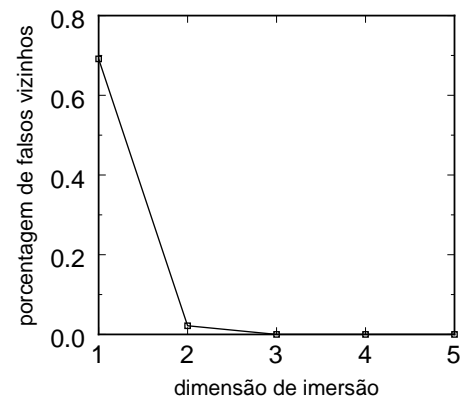

(b)

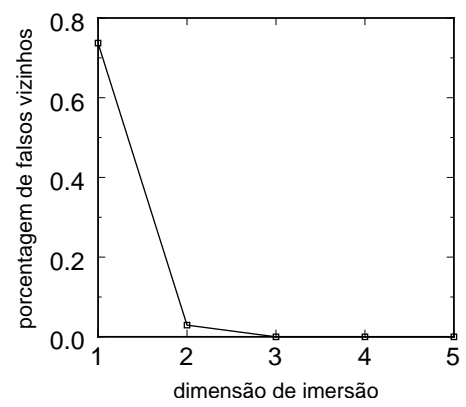

(c)

Figura 2.4: Método dos falsos vizinhos aplicado a três atratores reconstruídos a partir do conjunto de séries temporais $X\left(\Delta R_{1}=0,08 \Omega\right)$ : (a) tipo-Rössler $\left(\Delta R_{2}=1,06 \Omega\right)$; (b) Rössler-dobrado $\left(\Delta R_{2}=3,78 \Omega\right)$ e (c) duplo-rolo $\left(\Delta R_{2}=4,76 \Omega\right)$. Para os três atratores a dimensão de imersão para o qual o número de falsos vizinhos se aproxima de zero é $d_{E}=3$.

(b) e (c) mostram o resultado da aplicação do método dos falsos vizinhos. Em todas as três séries o número de falsos vizinhos cai a aproximadamente zero para a dimensão de imersão $d_{E}=3$. Logo, a reconstrução da dinâmica das séries em uma dimensão de imersão $d_{E}=3$ é suficiente para assegurar a equivalência entre os atratores reconstruídos e os atratores originais no espaço de fases real.

Sabendo que os atratores gerados pelo circuito de Chua são bem representados em uma dimensão da imersão $d_{E}=3$, a dimensão de Lyapunov para tais atratores tem que satisfazer $2<D_{K Y}<3$. Isso implica em atratores apresentando variedade tridimensional com apenas uma direção instável, com um coeficiente de Lyapunov positivo, como pode ser verificado na tabela 2.1, onde estimamos os expoentes $\lambda_{i}, i=1,2$ e 3 , e a dimensão de Lyapunov através da utilização do pacote TISEAN [73]. Podemos observar 
Tabela 2.1: Estimativas dos coeficientes de Lyapunov para os atratores do tipo Rössler, Rösslerdobrado e duplo-rolo, reconstruídos a partir das séries temporais do conjunto $X$. A dimensão de Lyapunov foi estimada como $D_{K Y}=2+\left|\lambda_{1} / \lambda_{3}\right|$ (conjetura de Kaplan-Yorke).

\begin{tabular}{|c|c|c|c|c|c|}
\hline \multirow[t]{2}{*}{ Atrator } & \multirow[t]{2}{*}{$\Delta R_{2}(\Omega)$} & \multicolumn{3}{|c|}{ Expoentes de Lyapunov } & \multirow[t]{2}{*}{$D_{K Y}$} \\
\hline & & $\lambda_{1} \times 10^{-2}$ & $\lambda_{2} \times 10^{-3}$ & $\lambda_{3} \times 10^{-2}$ & \\
\hline Rössler & 1,06 & $1,200(10)$ & $-5,702(72)$ & $-7,968(16)$ & $2,151(1)$ \\
\hline Rössler dobrado & 3,78 & $1,526(17)$ & $-5,414(13)$ & $-9,705(24)$ & $2,157(2)$ \\
\hline duplo-rolo & 4,76 & $1,612(27)$ & $-2,63(18)$ & $-7.052(33)$ & $2.228(4)$ \\
\hline
\end{tabular}

que todas as séries analisadas, quando reconstruída a dinâmica, geram atratores satisfazendo às condições do teorema de Birman-Williams [27]; todas as séries apresentam $\lambda_{1}>0, \lambda_{2}=0, \lambda_{3}<-\left|\lambda_{1}\right|$ e $2<D_{K Y}<3$. Esses resultados mostram que as séries temporais geradas pelo circuito de Chua apresentam as condições necessárias para a aplicação das técnicas de análise topológica, como o cálculo do número de ligações e construção dos moldes topológicos. 


\subsection{Dinâmica simbólica na vizinhança da janela de período três}

Nessa seção vamos investigar o comportamento da dinâmica simbólica para diferentes seções de Poincaré de um mesmo atrator. O objetivo desse estudo é verificar se a dinâmica simbólica, construída a partir de diferentes seções de um atrator, influencia na análise topológica dos atratores. Também vamos analisar se as séries temporais do circuito de Chua, em especial na vizinhança da janela de período 3, geram mapas de retorno com estruturas uni- ou bidimensional. É importante estabelecer essa diferença pois a evolução dinâmica em sistemas que geram mapas unidimensionais não é a mesma que para sistemas gerando mapas bidimensionais. Em geral, a aplicação da dinâmica simbólica é diferente nos dois sistemas [44, 64, 66, 67, 68, 69].

\subsubsection{Dinâmica nas seções de Poincaré}

Inicialmente, estudamos como se modificam a dinâmica simbólica e a topologia para um atrator, obtido a partir de uma série temporal na vizinhança da janela de período três, quando analisado em diferentes seções de Poincaré. Com efeito, selecionamos uma série temporal na vizinhança da janela de período 3 , a qual denominamos de $X_{1}$, com parâmetros $\Delta R_{1}=0,08 \Omega$ e $\Delta R_{2}=1,65 \Omega$. Reconstruímos a dinâmica de $X_{1}$ (método de Takens) com passo de reconstrução de $\tau=18 \Delta t=45 \mu$ s (o tempo de 18 dados para $\Delta t=2,5 \mu \mathrm{s})$. Construímos mapas de retorno em 6 seções de Poincaré posicionadas ao longo do espaço de fases do atrator e seguindo uma revolução completa de uma trajetória. A projeção bidimensional do atrator reconstruído $\left[\left(V_{C_{1}}(t), V_{C_{1}}(t+\tau)\right]\right.$, as seções de Poincaré no espaço de fases e os mapas de retorno $\left[V_{C_{1}}^{(n+1)}\right.$ vs $V_{C_{1}}^{(n)}$, onde $V_{C_{1}}^{(n)}=V_{C_{1}}(n T)$ para seções $\mathbf{a}, \mathbf{b}, \mathbf{c}$, e e f, e $V_{C_{1}}^{(n)}=V_{C_{1}}(n T+2 \tau)$ para a seção $\mathbf{d}, T$ o intervalo de tempo entre duas intersecções consecutivas na seção de Poincaré] podem ser vistos na figura 2.5. Todos os mapas de retorno, exceto os mapas para as seções $\mathbf{b}$ e c, exibem uma estrutura bidimensional.

É necessário, agora, verificar se as seções de Poincaré levam a diferentes comportamentos dinâmicos quando comparadas entre si e, especificamente, se os mapas b e c na figura 2.5(b) (similares aos mapas unidimensionais) geram uma dinâmica simbólica diferente dos mapas a, d, e e f (semelhantes aos mapas bidimensionais). Para isso determinamos como a entropia topológica, estimada através das seções de Poincaré $\mathbf{a}, \ldots, \mathbf{f}$, varia em função da posição da partição em cada um dos mapas de retorno. $\mathrm{O}$ 


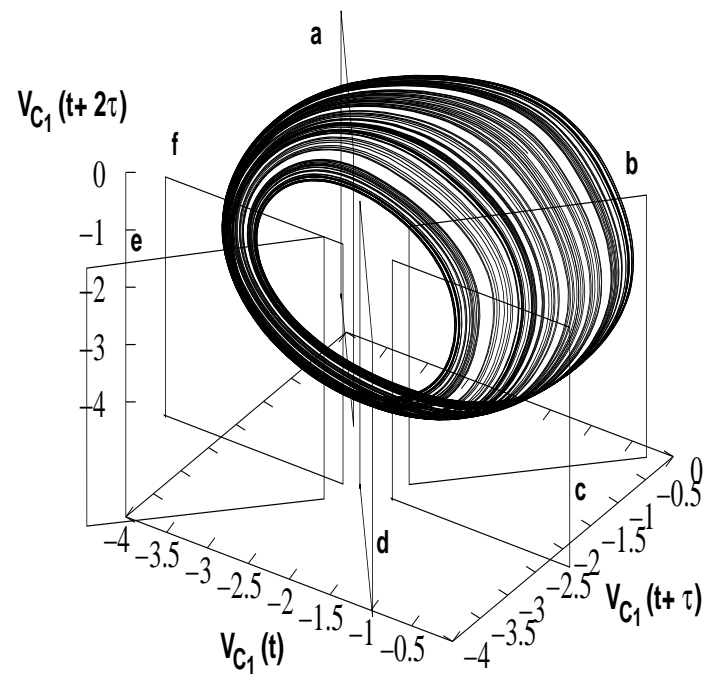

(a)
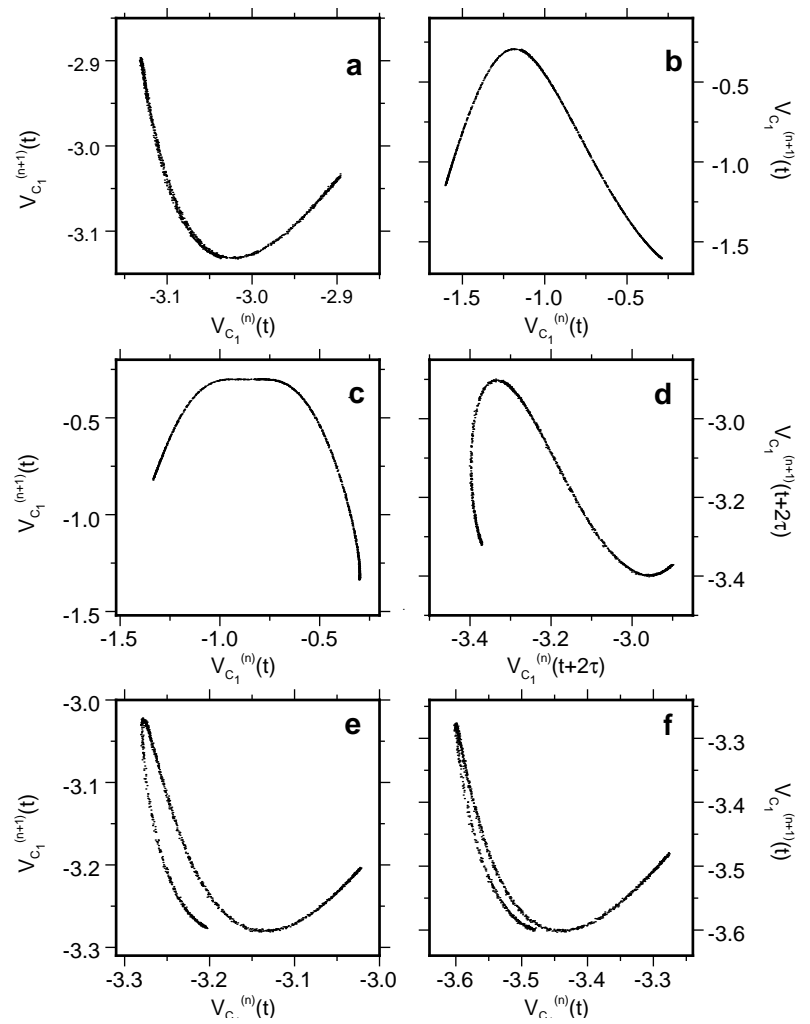

(b)

Figura 2.5: (a) Atrator reconstruído a partir da série temporal $X_{1}$ e as 6 seções de Poincaré denotadas por $a, b, \ldots, f$ percorrendo uma revolução completa no espaço de fases. (b) Mapas de primeiro retorno para as seções de Poincaré mostradas em (a).

resultado pode ser visto na figura 2.6, onde todas as entropias em função da posição obtidas para as diferentes seções são similares. Todas as figuras apresentam um único ponto de máximo e a mesma forma básica com um vale entre dois picos, o que indica a similaridade entre as dinâmicas originadas pelos mapas [as figuras 2.6(b), (c) e (d) estão invertidas em relação as outras devido a localização das respectivas seções de Poincaré no primeiro e segundo quadrantes do espaço de fases].

Com os pontos de partição dos mapas determinados pelos máximos de entropia na figura 2.6, construímos planos simbólicos, a partir de um alfabeto binário, para uma trajetória do atrator interceptando cada uma das seções de Poincaré. O plano simbólico é uma construção que permite sumarizar a organização topológica em mapas uni- e bidimensionais [44, 46, 61]. Diferenças topológicas sutis entre sistemas dinâmicos, por exemplo na organização das órbitas periódicas instáveis, podem ser identificadas com 

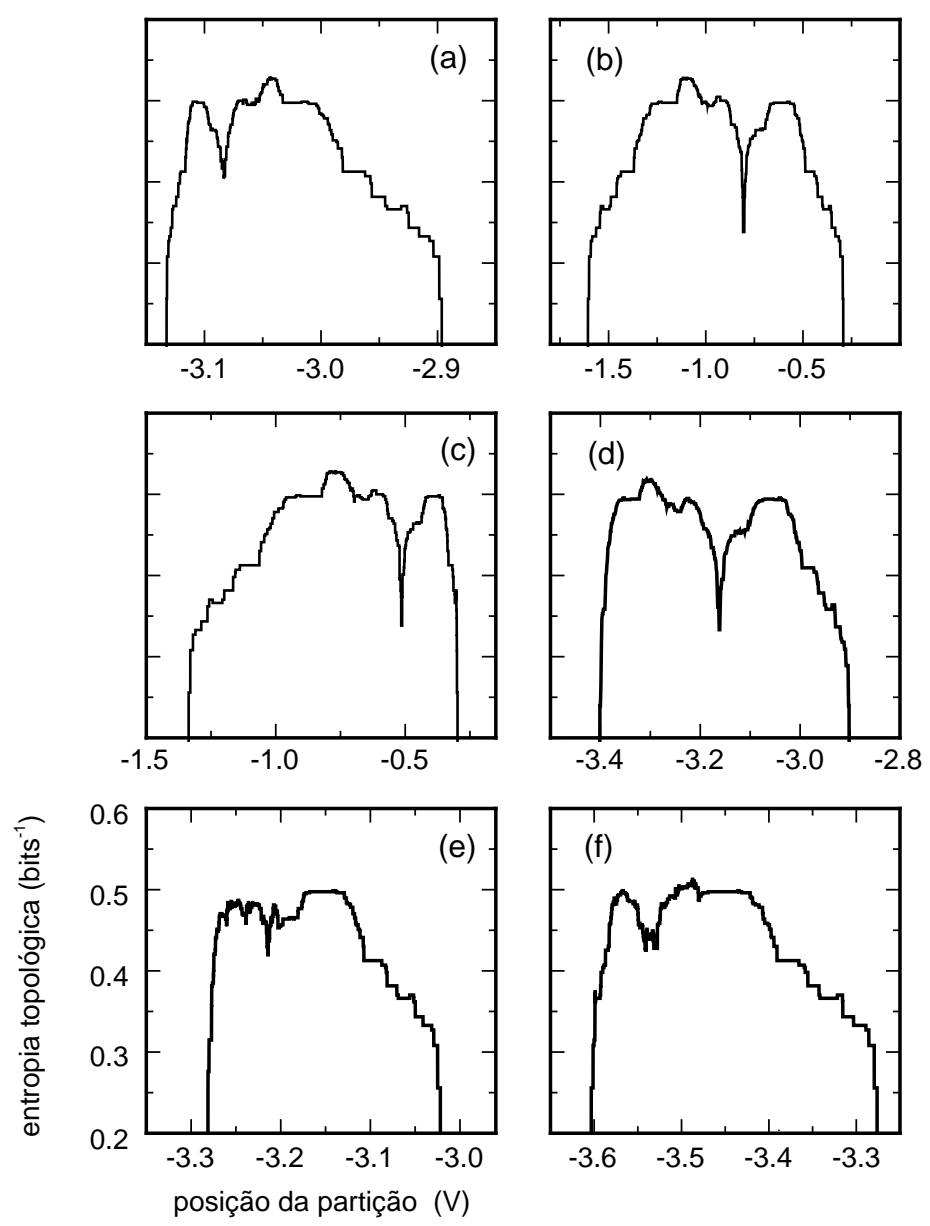

Figura 2.6: Entropia topológica em função da posição da partição para as seções de Poincaré a, b, $\ldots, \mathrm{f}$ do atrator $X_{1}$ representadas na figura 2.5 .

a aplicação dessa ferramenta.Os planos simbólicos são mostrados na figura 2.7 onde todos os planos apresentam uma distribuição bastante similar de regiões proibidas e permitidas.

Portanto, diante desses resultados, podemos concluir que a dinâmica do atrator $X_{1}$, e em particular a sua topologia, não se alteram quando a dinâmica simbólica é gerada a partir de diferentes seções de Poincaré. Isso mostra que a dinâmica do atrator $X_{1}$ é representada adequadamente quando os mapas de retorno são particionados por uma reta vertical posicionada no máximo da entropia topológica. 

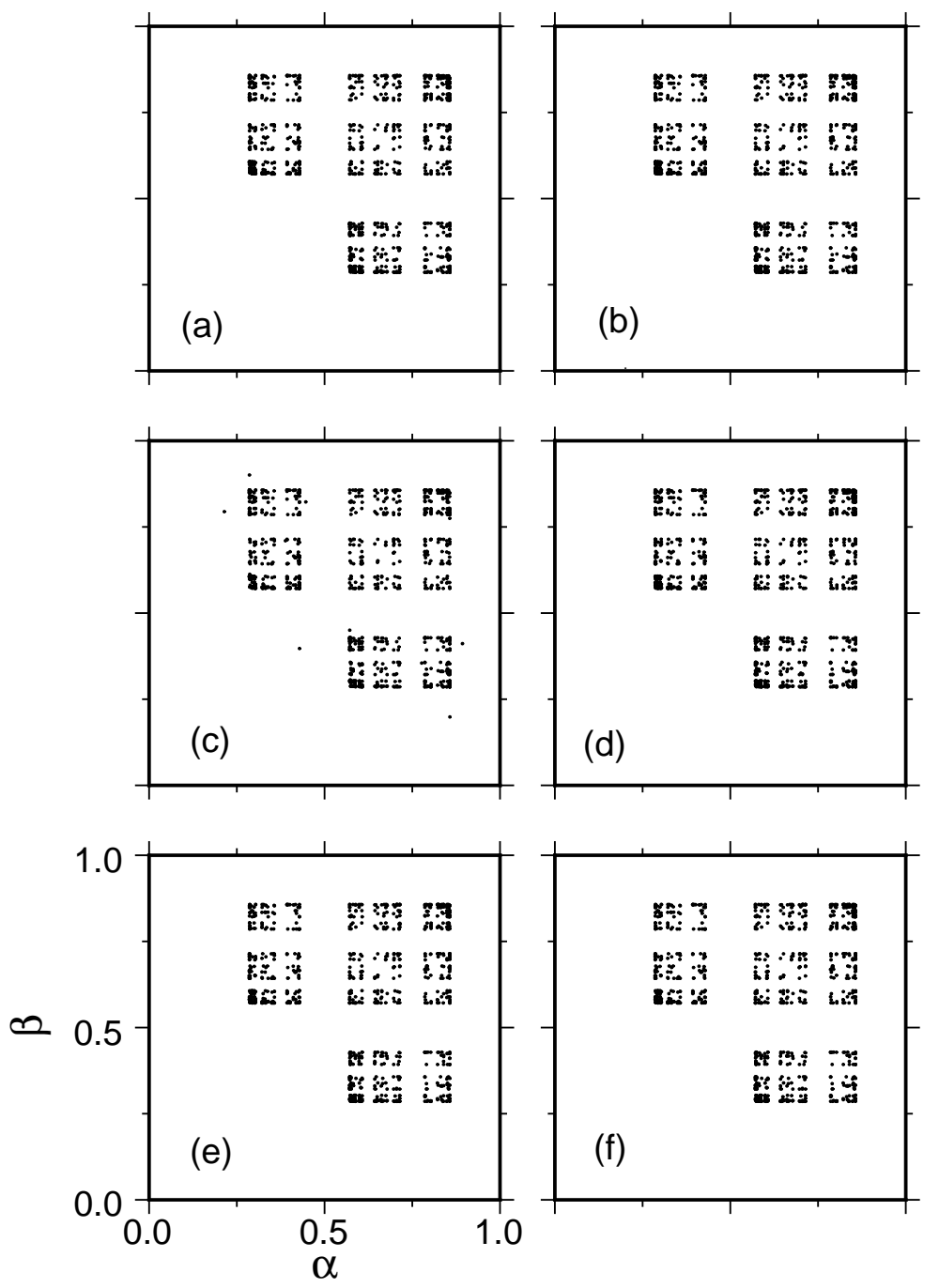

Figura 2.7: Planos simbólicos para a dinâmica simbólica gerada a partir das seções de Poincaré a,b...,f mostradas na figura 2.5, onde estão representados 1031 pontos por plano. Todos os planos, exceto o plano em (d), apresentam distribuição similar de regiões permitidas e proibidas de visitação.

\subsubsection{Comportamento dinâmico: bi- ou unidimensional?}

Os mapas de retorno obtidos por diferentes seções de Poincaré geram mapas com estruturas predominantemente bidimensionais. Apesar da dinâmica e topologia do atrator não mudar quando analisadas em diferentes seções de Poincaré, a análise efetuada não estabelece se o atrator obtido de $X_{1}$ apresenta comportamento dinâmico característico de sistema uni- ou bidimensional.

Assim, vamos comparar topologicamente os atratores reconstruídos a partir das sé- 
ries temporais do circuito com os atratores de dois tipos de mapas: o logístico [eq. (1.12)] representando um mapa unidimensional e o de Hénon, representando um mapa bidimensional, definido por

$$
\left\{\begin{array}{lcc}
x_{n+1} & = & 1-a x_{n}^{2}+y_{n} \\
y_{n+1} & = & b x_{n} .
\end{array}\right.
$$

Selecionamos três séries temporais do circuito situadas na vizinhança da janela de período três, todas com $\Delta R_{1}=0,08 \Omega: X_{1}\left(\Delta R_{2}=1,65 \Omega\right), X_{6}\left(\Delta R_{2}=1,40 \Omega\right)$ e $X_{11}$ $\left(\Delta R_{2}=1,16 \Omega\right)$. As séries experimentais foram assim escolhidas para representar a evolução dinâmica ao variarmos apenas o parâmetro $\Delta R_{2}\left(\Delta R_{1}\right.$ é mantido fixo).

Para a comparação topológica dos três sistemas, construímos planos simbólicos para o mapa de Henón, o mapa logístico e para os atratores reconstruídos à partir das séries experimentais do circuito, cujos resultados podem ser vistos na figura 2.8 e os parâmetros utilizados estão na legenda.

A semelhança topológica entre os três sistemas é caracterizada pela distribuição similar de regiões permitidas e proibidas entre os planos simbólicos para os três sistemas. Mas apesar da semelhança com o mapa logístico, que é um mapa unidimensional, as séries do circuito de Chua geram mapas de retorno bidimensionais (veja a figura 2.5). Então, na comparação com as séries experimentais, consideramos o limite de alta dissipação $[b \rightarrow 0$ na eq. (2.1)] tal que o comportamento dinâmico do mapa de Hénon é, aproximadamente, o comportamento do mapa logístico. É assim que justificamos o uso de $b=0,005 \ll 1$ na eq. (2.1). Esses resultados indicam que o circuito de Chua está muito próximo do regime de alta dissipação, da mesma maneira que o mapa de Hénon quando o parâmetro $b \rightarrow 0$.

Vamos agora comparar como a entropia topológica varia em função da posição da partição para os três sistemas: as séries experimentais de Chua, o mapa de Hénon e o logístico. Os resultados estão na figura 2.9 onde podemos ver a semelhança entre os três sistemas. Aqui, novamente, o mapa de Hénon [figura 2.9(b)] tem um comportamento similar ao do mapa logístico [figura 2.9(c)], indicando que o parâmetro $b=0,005$ é adequado para descrever as series experimentais $X_{1}, X_{6}$ e $X_{11}$ gerando sistemas dinâmicos topologicamente similares ao mapa de Hénon.

\section{A. Frentes de podas}

Frente de podas $[44,26]$ de um plano simbólico é o nome dado à linha divisória entre as regiões proibidas e permitidas de visitação para as trajetórias de um sistema 


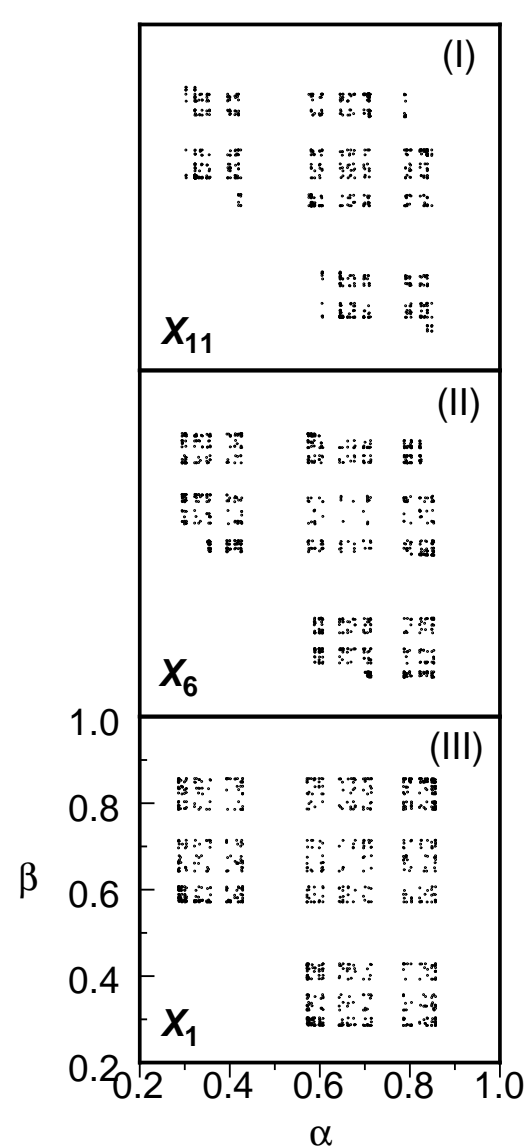

(a)

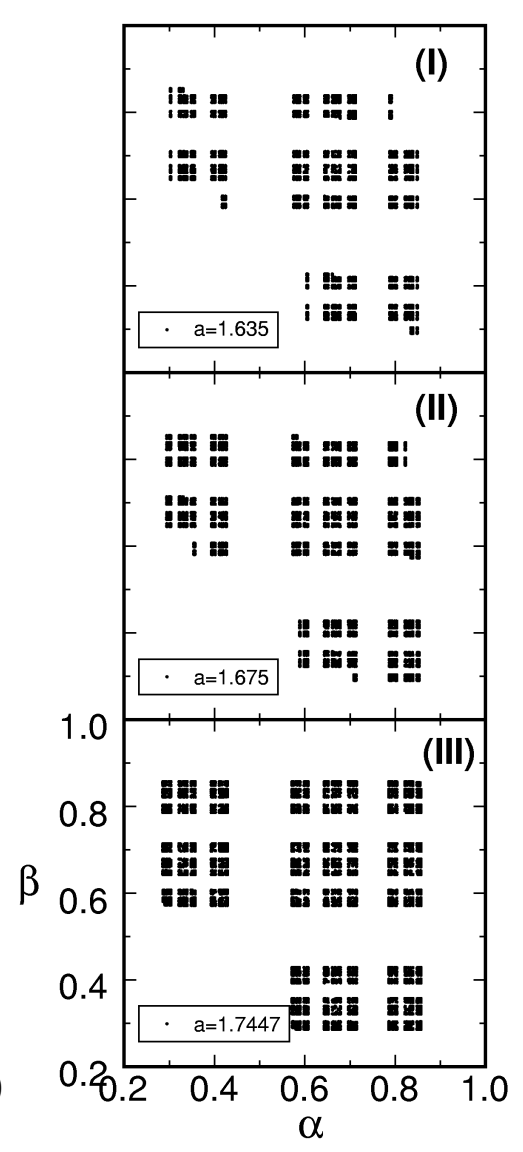

(b)

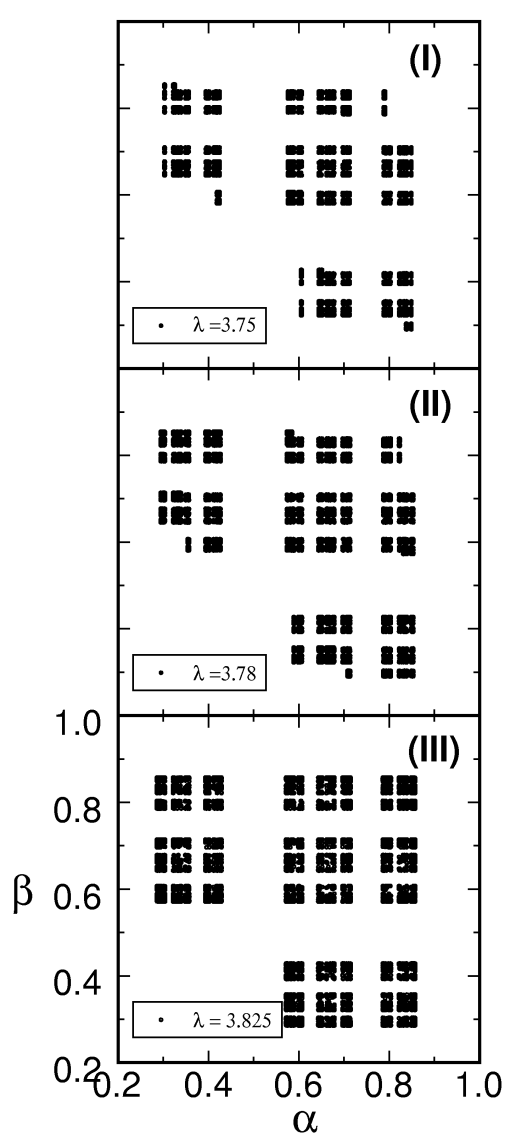

(c)

Figura 2.8: (a) Planos simbólicos construídos a partir das séries temporais $X_{11}$ (I), $X_{6}$ (II) e $X_{1}$ (III) do circuito de Chua, onde cada plano contém 1067 pontos. (b) Planos simbólicos para o mapa de Hénon com parâmetro $b=0,005$ (fixo) e $a=1,635$ (I), $a=1,675$ (II) e $a=1,7447$ (III), onde estão representados 13967 pontos por plano. (c) Planos para o mapa logístico com $\lambda=3,75$ (I), $\lambda=3,78$ (II) e $\lambda=3,825$ (III), cada um representado por 9967 pontos.

dinâmico. Como todas as regiões proibidas de um plano simbólico são imagens ou préimagens da região proibida fundamental, a frente de podas pode ser considerada como o limite de admissibilidade para uma seqüência simbólica permitida ao sistema. Em sistemas cuja dinâmica é predominantemente unidimensional a frente de podas é uma linha reta e contínua; já sistemas bidimensionais, por sua vez, apresentam frente de podas como uma função com descontinuidades [44]. A frente de podas pode, então, ser empregada para identificar a natureza uni- ou bi-dimensional de um sistema dinâmico.

Assim, construímos planos simbólicos com as frentes de podas ampliadas para o 
circuito de Chua e comparamos com as frentes de podas para o mapa de Hénon. Dessa vez, ao invés das séries experimentais, optamos por usar o circuito de Chua numericamente simulado (veja abaixo) para que não haja limitação na quantidade de pontos usados nos planos simbólicos.

O circuito de Chua, esquematizado na figura 2.1, pode ser descrito por um modelo

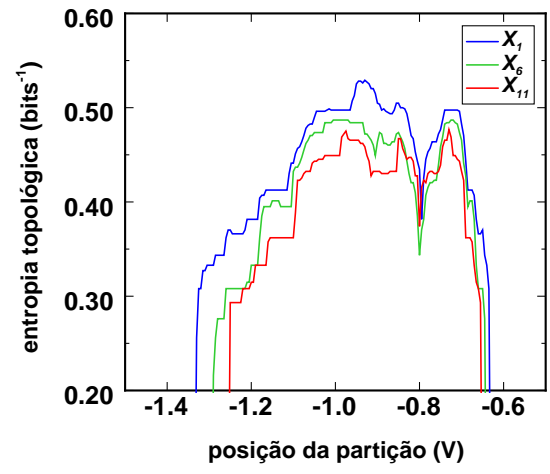

(a)

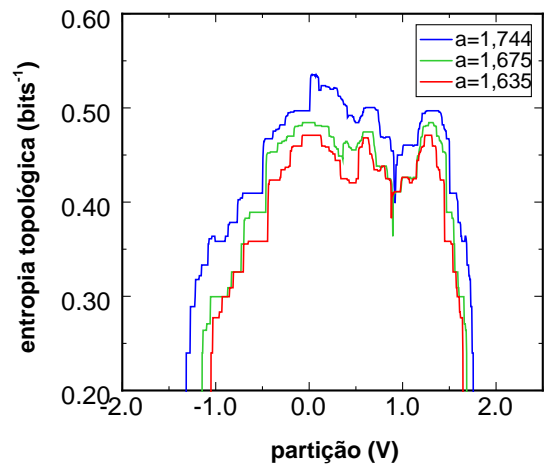

(b)

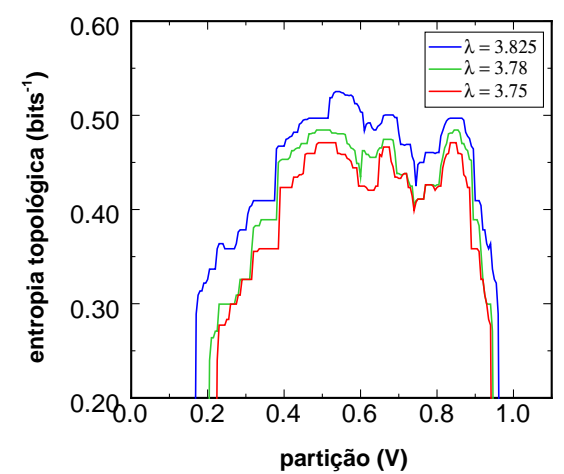

(c)

Figura 2.9: Entropia topológica em função da posição da partição para (a) série experimentais $X_{1}$, $X_{6}$ e $X_{11}$; (b) o mapa de Hénon e (c) o mapa logístico. Os parâmetros para os mapas são os mesmos utilizados na figura 2.8 . 
matemático formado pelo sistema de equações diferenciais

$$
\left\{\begin{aligned}
C_{1} \frac{d V_{C_{1}}}{d t} & =\frac{V_{C_{2}}-V_{C_{1}}}{R_{1}}-h\left(V_{C_{1}}\right), \\
C_{2} \frac{d V_{C_{2}}}{d t} & =\frac{V_{C_{1}}-V_{C_{2}}}{R_{1}}+i_{L} \\
L \frac{d i_{L}}{d t} & =-V_{C_{2}}-R_{2} i_{L}
\end{aligned}\right.
$$

onde $V_{C_{1}}$ e $V_{C_{2}}$ são as tensões sobre os capacitores $C_{1}$ e $C_{2}$, respectivamente, $i_{L}$ é a corrente elétrica sobre o indutor $L, R_{1}$ e $R_{2}$ dois resistores lineares e $R_{N L}$ o resistor não-linear. O termo

$$
h\left(V_{C_{1}}\right)=m_{0} V_{C_{1}}+\frac{1}{2}\left(m_{1}-m_{0}\right)\left(\left|V_{C_{1}}+B_{p}\right|-\left|V_{C_{1}}-B_{p}\right|\right),
$$

é a curva característica do resistor não-linear $R_{N L}$.

Na integração numérica do sistema de equações (2.2) os parâmetros utilizados foram: $C_{1}=4,7 \mathrm{nF}, C_{2}=56 \mathrm{nF}, L=9,5 \mathrm{mH}$. As resistências são dadas por $R_{1}=R_{01}-\Delta R_{1}$ e $R_{2}=R_{02}-\Delta R_{2}$ tal que $R_{01}=1,695 \mathrm{k} \Omega, \Delta R_{1}=3,02 \Omega, R_{02}=36,5 \Omega$ e $\Delta R_{2}=0,625 \Omega$. Os outros parâmetros são $m_{0}=-0,5 \mathrm{~mA} / \mathrm{V}, m_{1}=-0,8 \mathrm{~mA} / \mathrm{V}$ e $B_{p}=1,0 \mathrm{~V}$. As integrações numéricas nesse trabalho foram feitas pelo método de Runge-Kutta de $4^{\mathrm{a}}$ ordem [58]. Reescalonando o sistema eq. (2.2) obtemos um conjunto de parâmetros adimensionais [59]:

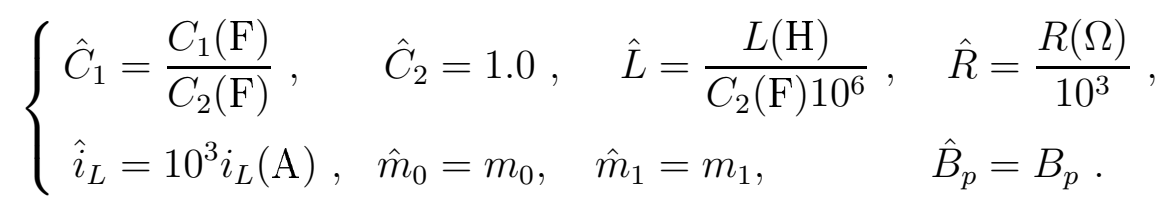

A relação entre a freqüência original, $f$, e a reescalonada, $\hat{f}$, é dada por

$$
\hat{f}=C_{2}(\mathrm{~F}) 10^{-3} f(\mathrm{~Hz})
$$

Os parâmetros acima situam o atrator simulado numericamente pelas equações (2.2) na vizinhança da janela de período três. As frentes de podas para o mapa de Hénon e o circuito de Chua simulado, assim como as ampliações das frentes podem ser vistas na figura 2.10 .

Na figura 2.10(a) temos o plano simbólico para o mapa de Hénon com parâmetros $a=1,5$ e $b=0,04$ e em (b) a ampliação da frente de podas. Podemos ver na figura (b) que, apesar do parâmetro $b=0,04 \ll 1$, a frente de podas do atrator de Henon é descontínua como esperado para um mapa bidimensional. Na figura 2.10(c) e (d), 
novamente o plano e a ampliação da frente de podas para o mapa de Hénon, os parâmetros utilizados agora foram $a=1,7447$ e $b=0,005$ e a frente de podas deixou de ser descontínua. Finalmente, na figura 2.10(e) e (f), respectivamente plano e frente de podas ampliada para o circuito numericamente simulado, a frente de podas não apresenta descontinuidades aparentando ser uma linha reta. Esses resultados reforçam a afirmação de que as séries experimentais do circuito de Chua, na vizinhança da janela de período 3, apresentam atratores cujo regime dissipativo é próximo dos atratores para o mapa de Hénon com parâmetro $b \rightarrow 0$.

Resumindo, os resultados obtidos nas duas últimas seções levam as seguintes conclusões:(1) Os mapas de retorno, obtidos de diferentes seções de Poincaré de um mesmo atrator, representam adequadamente a dinâmica do atrator quando a dinâmica simbólica é construida particionando-se os mapas pelo ponto de máximo de entropia topológica e (2) os atratores gerados pelas séries temporais situadas na vizinhança da janela de período três comportam-se como no regime de alta dissipação do mapa de Hénon onde $b \rightarrow 0$. 


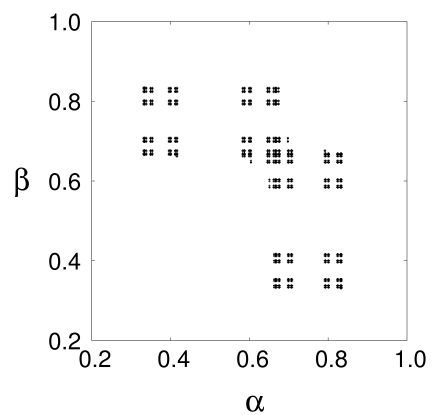

(a)

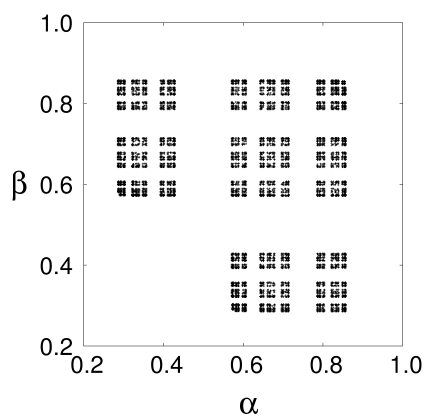

(c)

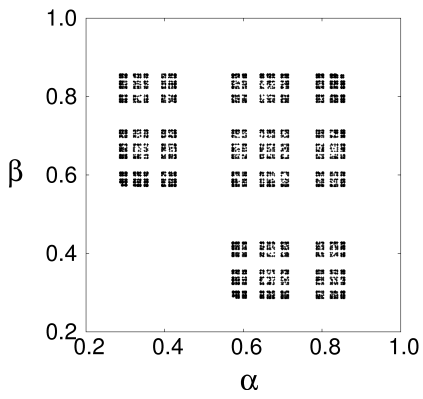

(e)

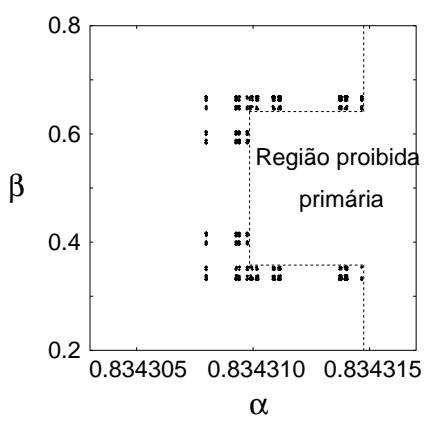

(b)

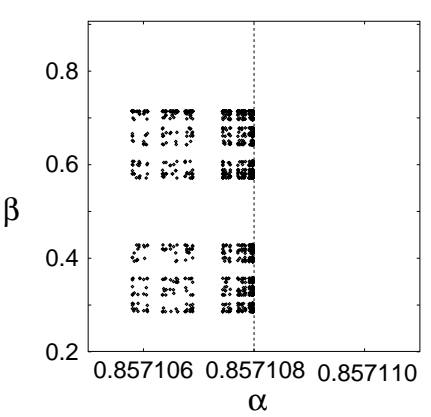

(d)

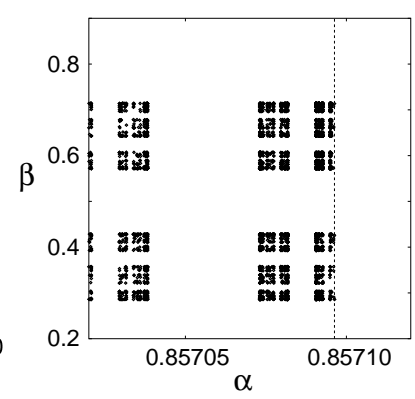

(f)

Figura 2.10: (a) Plano simbólico para o mapa de Hénon com parâmetros $a=1,5$ e $b=0,04$ e (b) ampliação da frente de podas com a região proibida primária em destaque. (c) Plano para o mapa de Hénon com $a=1,7447$ e $b=0,005$ e (d) respectiva ampliação da frente de podas. (e) Plano simbólico e (f) ampliação da frente de podas para o circuito de Chua simulado numericamente. 


\subsection{Fibras caóticas e o espaço de parâmetros}

O circuito de Chua é um sistema dinâmico frágil o que significa que uma variação dos parâmetros do sistema pode levar de um regime caótico para regular. No caso do circuito é suficiente a variação de um parâmetro para as janelas periódicas surgirem, como pode ser verificado na figura 2.2. Essa afirmação se baseia na conjectura estabelecida em Ref. [62], segundo a qual a geometria (dimensão e forma) das janelas periódicas no espaço de parâmetros é determinada pela natureza do comportamento caótico observado nas vizinhanças das janelas. Em outras palavras, as janelas periódicas que surgem no espaço de parâmetros tem codimensão $k$, onde $k$ é o número de expoentes de Lyapunov positivos do comportamento caótico presente nas vizinhanças das janelas periódicas.

A idéia de preservação do caos baseia-se justamente nesse ponto, ou seja, assim como o comportamento periódico o comportamento caótico também se sustenta ao longo de direções especiais no espaço de parâmetros às quais chamamos de fibras caóticas. Nessa e nas seções subseqüentes vamos mostrar a existência de regiões no espaço de dois parâmetros $\left(\Delta R_{1}\right.$ e $\left.\Delta R_{2}\right)$ do circuito de Chua ao longo das quais as propriedades topológicas e métricas do circuito são preservadas.

Nós selecionamos 9 séries temporais situadas antes do surgimento da janela de período três, denominadas $X_{J}, Y_{J}$ e $Z_{J}$. A posição das séries em relação ao espaço de

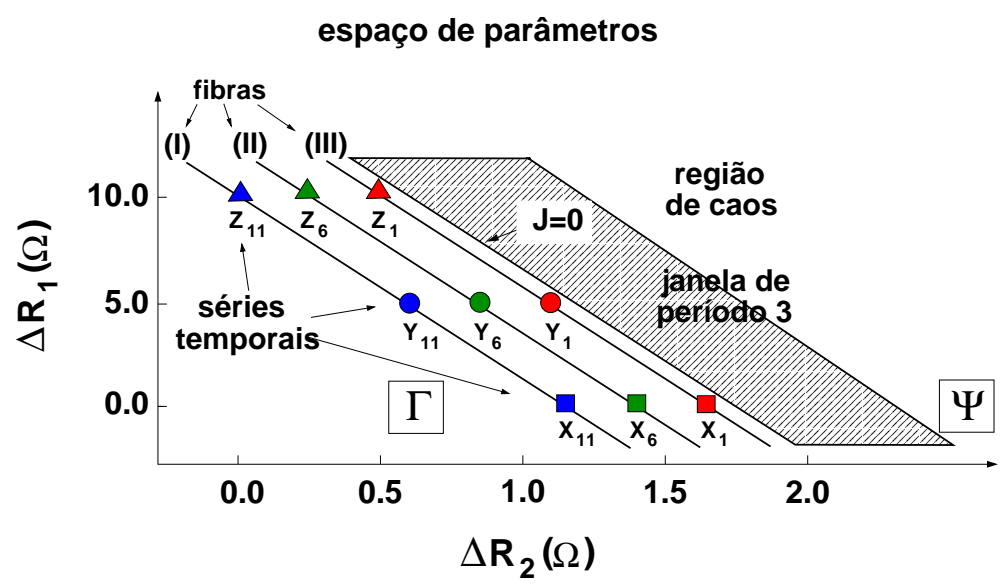

Figura 2.11: Espaço de parâmetros para o circuito de Chua e os valores dos parâmetros para as séries temporais $X_{J}, Y_{J}$ e $Z_{J}$. Para os índices $J=1,6$ e 11 os parâmetros das séries pertencem às fibras (III), (II) e (I) respectivamente. A borda da janela de período três usada como referência está indicada como $J=0$, dividindo o espaço de parâmetros em duas regiões: $\Gamma$ ( $J$ positivos) e $\Psi$ ( $J$ negativos). 
parâmetros $\Delta R_{1}$ e $\Delta R_{2}$ simplificado pode ser vista na figura 2.11. As letras indicam o valor da resistência $\Delta R_{1}: 0,08 \Omega$ para $X ; 4,6 \Omega$ para $Y$ e $9,6 \Omega$ para $Z$. O índice $J=1,6$ e 11 é o número de deslocamentos do motor de passo da resistência $\Delta R_{2}$ e representa a distância da série em relação a janela de período três $(J=0)$. A borda $J=0$ divide o espaço de parâmetros em duas regiões: $\Gamma$ onde os valores de $J$ são positivos e $\Psi$ com $J$ negativos. Cada deslocamento do motor de passo vale $\Delta p=50 \mathrm{~m} \Omega$.

Nós assumimos que existem muitas fibras na vizinhança da janela de período três alinhadas à janela, ou seja, seguindo sua geometria. E uma vez que a janela de período 3 aparece linearmente orientada no espaço de parâmetros, espera-se que as fibras caóticas também apareçam linearmente orientadas. Assim, podemos esperar que os valores dos parâmetros escolhidos, que estão linearmente relacionados, pertençam a três diferentes fibras caóticas.

\subsubsection{Caracterização métrica das séries}

Os atratores caóticos aqui estudados foram reconstruídos a partir das 9 séries temporais experimentais em dimensão de imersão $d_{E}=3$ e tempo de atraso (método de Takens) $\tau=45 \mu \mathrm{s}$, que corresponde a 18 dados. Essa dimensão é requerida para permitir o emprego de algumas técnicas topológicas de análise de atratores tal como a obtenção de invariantes topológicos [2, 27]. As projeções bidimensionais desses atratores reconstruídos podem ser vistas na figura 2.12. Na figura, os atratores em uma mesma coluna pertencem a uma mesma fibra. Assim os atratores em cada fibra/coluna apresentam as mesmas características métricas e topológicas.

Estimamos os expoentes e a dimensão de Lyapunov para as 9 séries usando o pacote TISEAN [73]. Podemos ver na tabela 2.2 que os expoentes e a dimensão de Lyapunov não fornecem informações conclusivas à respeito da existência das fibras. Apesar disso, a presença nas séries de três expoentes de Lyapunov (apenas um positivo) e a dimensão de Lyapunov $D_{K Y}<3$ satisfazem o teorema de Birman e Williams (veja seção 1.2.6) o que permite a extração de invariantes topológicos (número de ligações e o molde topológico).

\subsubsection{Retorno aproximado}

A técnica do retorno aproximado é um algoritmo para a extração de órbitas periódicas instáveis (OPI) que pode ser aplicado em séries temporais experimentais. Na aplicação dessa técnica nós observamos a variável escalar $V_{C_{1}}(t)$ do circuito e procura- 


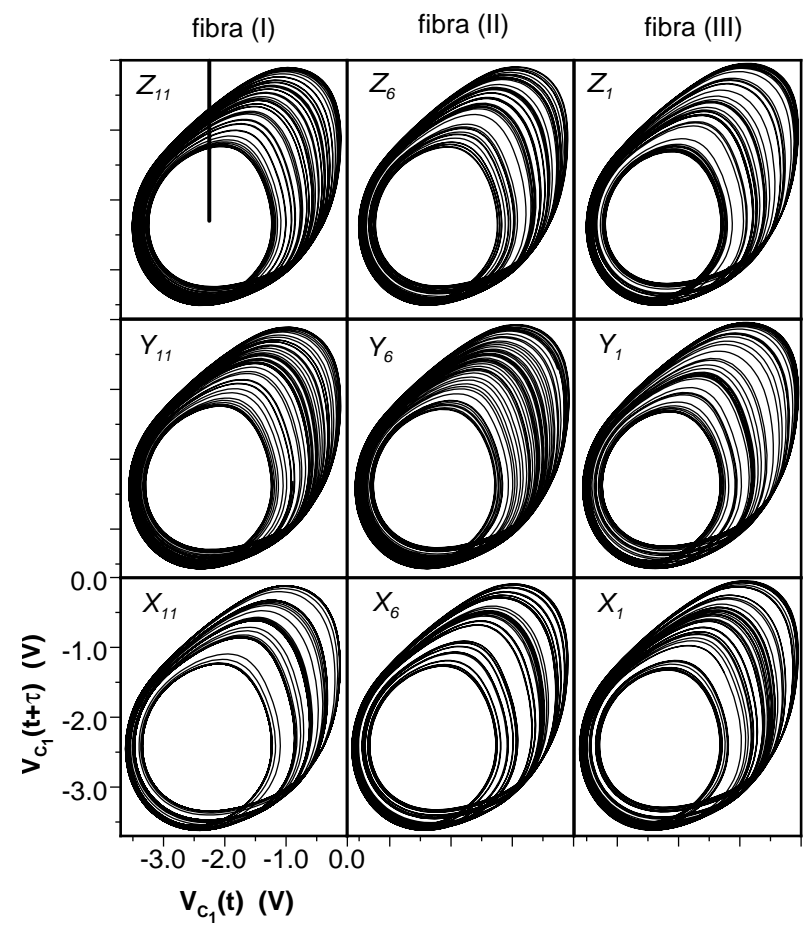

Figura 2.12: Projeção bi-dimensional dos atratores reconstruídos para parâmetros ao longo das fibras (I), (II) e (III). A projeção da seção de Poincaré usada na análise está em $V_{C_{1}}=-2,25 \mathrm{~V}$, como mostrados para o atrator obtido da série $Z_{11}$.

mos por segmentos da série tal que a diferença $\left|V_{C_{1}}(t)-V_{C_{1}}(t+T)\right|$ permaneça pequena no intervalo $t_{0} \leq t \leq t_{0}+T$. Dizemos então que esse segmento sombreia uma órbita de período $T$.

A freqüência com que uma dada OPI é detectada na série temporal (ou no atrator reconstruído) representa a contribuição da OPI à medida do atrator. Para caracterizar os atratores reconstruídos situados nas fibras nós contamos o número de vezes que uma OPI é detectada através da técnica do retorno aproximado. Assim nós percorremos a série temporal procurando pelas ocorrência das OPI para diferentes intervalos de tempo $t_{p}=i \Delta t$, ou seja, contamos todas as recorrências (ocorrência de OPI nas séries) para um dado ponto da série em função de $t_{p}$. Desse modo podemos comparar as contagens, na forma de histogramas, para diferentes atratores.

Na figura 2.13 comparamos os histogramas para as séries experimentais localizadas nas fibras. A ocorrência de um pico revela a existência de uma OPI de uma dada freqüência. O valor de limiar (a tolerância para as recorrências) foi de $\epsilon \approx$ 
Tabela 2.2: Expoentes de Lyapunov estimados para as séries temporais nas fibras (I), (II) e (III). A dimensão de Lyapunov $D_{K Y}$ é estimada como $D_{K Y}=2+\left|\lambda_{1} / \lambda_{3}\right|$ ( a conjetura de Kaplan-Yorke).

\begin{tabular}{cccccc}
\hline fibra & série temporal & $\lambda_{1}$ & $\lambda_{2}$ & $\lambda_{3}$ & $D_{K Y}$ \\
\hline$(\mathrm{I})$ & $X_{1}$ & $0.01362(8)$ & $-0.00463(7)$ & $-0.0896(2)$ & 2.101 \\
& $Y_{1}$ & $0.01371(8)$ & $-0.00504(9)$ & $-0.0897(4)$ & 2.098 \\
& $Z_{1}$ & $0.01416(2)$ & $-0.00444(2)$ & $-0.0895(6)$ & 2.103 \\
\hline$(\mathrm{II})$ & $X_{6}$ & $0.01342(2)$ & $-0.00503(5)$ & $-0.0870(2)$ & 2.095 \\
& $Y_{6}$ & $0.01367(4)$ & $-0.00440(5)$ & $-0.0869(2)$ & 2.107 \\
& $Z_{6}$ & $0.01305(9)$ & $-0.00541(3)$ & $-0.0901(2)$ & 2.087 \\
\hline$(\mathrm{III})$ & $X_{11}$ & $0.01257(7)$ & $-0.00519(9)$ & $-0.0831(2)$ & 2.086 \\
& $Y_{11}$ & $0.01298(5)$ & $-0.00496(8)$ & $-0.0864(2)$ & 2.095 \\
& $Z_{11}$ & $0.01234(5)$ & $-0.00488(10)$ & $-0.0861(2)$ & 2.089 \\
\hline
\end{tabular}

0,05\%×máxima amplitude da série temporal.

Na figura 2.13 podemos observar que todos os histogramas apresentam o mesmo tempo de ciclo $T=86 \Delta t(\Delta t=2,5 \mu \mathrm{s})$. O tempo $T$ é aproximadamente o período característico do circuito de Chua. Contudo, é a altura dos picos dos histogramas que caracteriza uma série temporal em uma dada fibra. Podemos ver na fibra (I) a predominância do quinto pico para todas as séries. Na fibra (II) vemos a similaridade entre as alturas do segundo, quarto e quinto picos. E, por fim, na fibra (III) observamos a predominância do terceiro pico, indicando a emergência da janela de período três a partir de $J=0$.

\subsubsection{Espectro de órbitas e números de ligações}

As características das OPI existentes podem ser determinadas pela aplicação da dinâmica simbólica a trajetória (ou a segmentos de trajetórias) de um atrator. Na verdade, as OPI existentes são consideradas como uma aproximação para o atrator. Órbitas de baixo período revelam a estrutura global do atrator enquanto que órbitas de períodos mais altos dizem respeito a detalhes finos dessa estrutura. Assim, as características topológicas do conjunto de órbitas encontradas podem ser usadas para caracterizar os atratores nas fibras caóticas.

Para construir a dinâmica simbólica devemos primeiro observar que os mapas de 


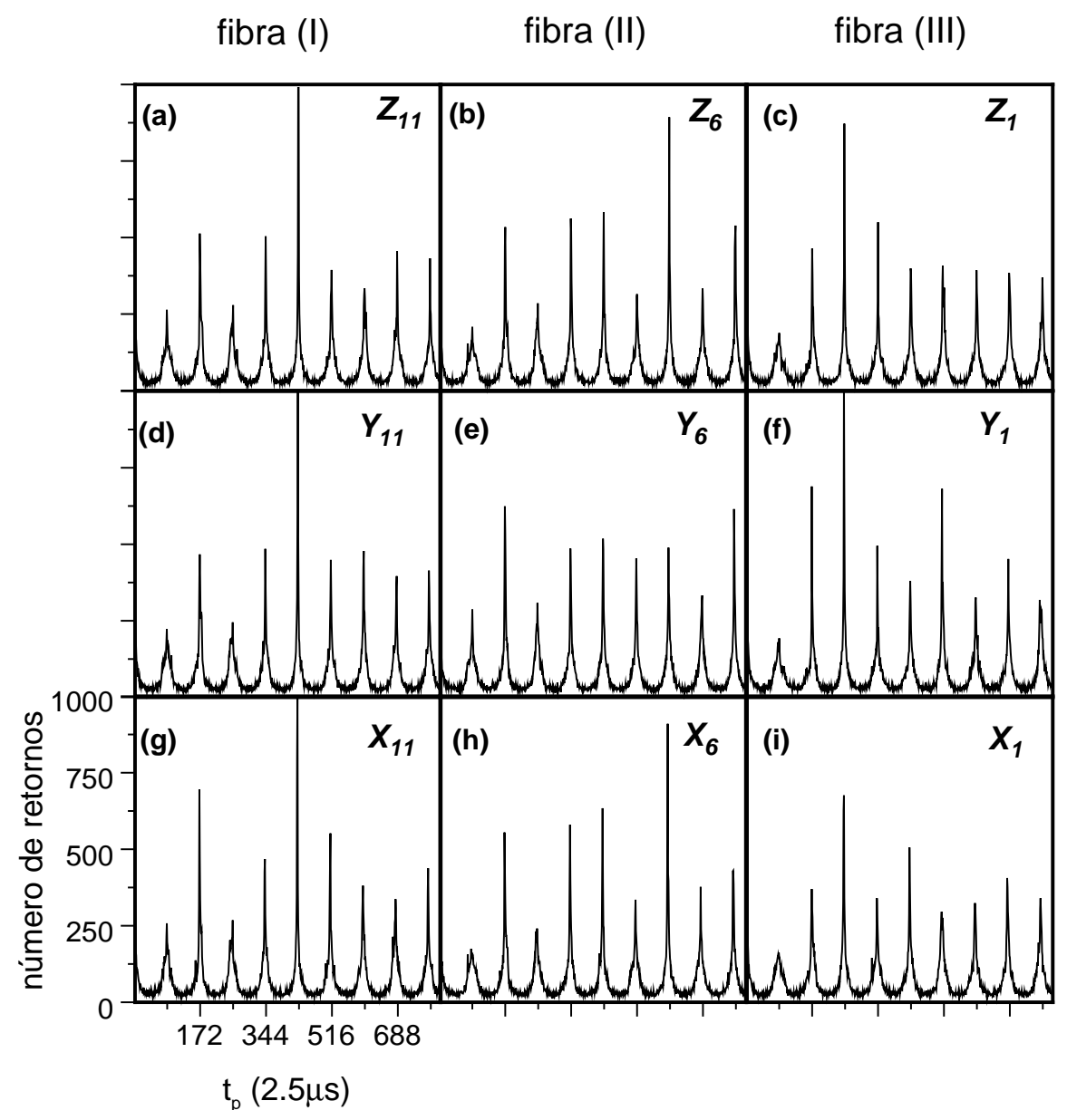

Figura 2.13: Histogramas para o retorno fechado para as séries temporais $V_{C_{1}}(t)$ situadas ao longo das fibras caóticas. A fibra correspondente à cada conjunto está indicada acima.

primeiro retorno, mostrados na figura 2.14, são, aproximadamente, unimodais. Os mapas de primeiro retorno foram obtidos pela seção de Poincaré definida para o atrator reconstruído $Z_{11}$ mostrado na figura 2.12. Nos mapas as coordenadas são $\left(V_{C_{1}}^{(n)}, V_{C_{1}}^{(n+1)}\right)$ tal que $V_{C_{1}}^{(n)}=V_{C_{1}}(n T+\tau)$ onde $T$ é o tempo entre duas interseç̧ões na seção de Poincaré e $\tau$ o tempo da atraso da reconstrução do atrator. Os mapas são particionados através do ponto de máximo $y_{c}$ em duas regiões: a região $\mathbf{0}$ com curvatura positiva e a região 1 com curvatura negativa. Uma órbita periódica (ou trajetória) é codificada, de acordo com a região visitada, pela cadeia binária $s_{0} s_{1} \ldots s_{n-1}$ com $n$ símbolos onde $s_{i}=0$ (respectivamente 1) se $V_{C_{1}}^{(n)}<y_{c}$ (respectivamente $V_{C_{1}}^{(n)}>y_{c}$ ).

As órbita periódicas encontradas pelo método do retorno aproximado são identificadas da maneira descrita acima. Uma órbita é dita de período $p$ se sua representação simbólica $s_{0} s_{1} \ldots s_{p-1}$ contiver $p$ símbolos. 


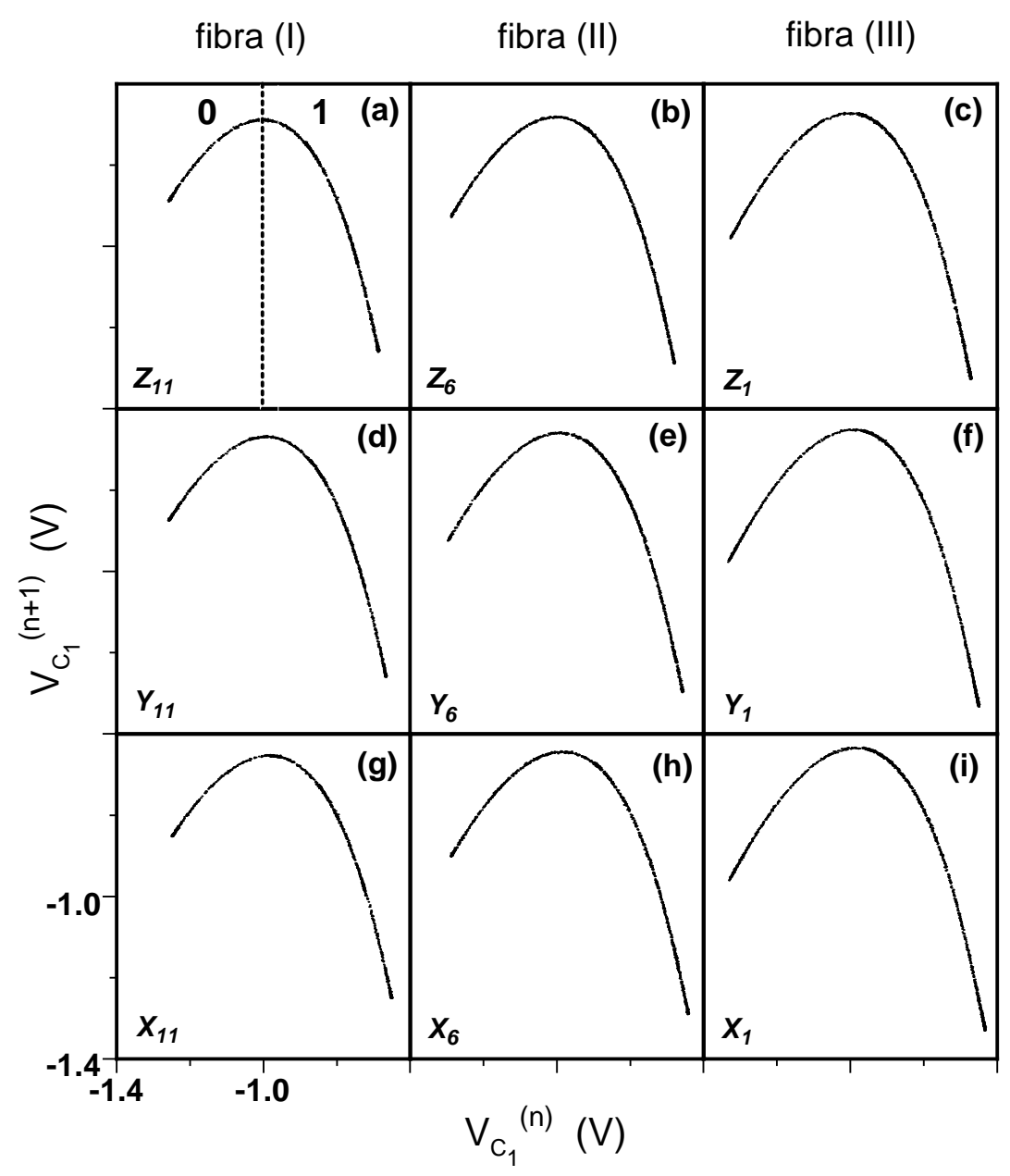

Figura 2.14: Mapas de primeiro retorno obtidos pela seção de Poincaré $V_{C_{1}}(t)=-2.25 \mathrm{~V}$ para os atratores reconstruídos a partir das séries temporais no espaço de parâmetros. Todos os mapas se assemelham aos mapas unimodais. Em (a) é mostrado a partição pelo ponto crítico, dividindo o mapa em dois ramos identificados por 0 , à esquerda, e 1 , à direita.

Após a extração e identificação das órbitas pela dinâmica simbólica, o invariante topológico chamado número de ligações pode ser obtido pelo procedimento já descrito na seção 1.2.6. Assim, nas tabelas 2.3, 2.4 e 2.5 nós determinamos o espectro de OPI de pequeno período (até 8) e os números de ligações (de auto-ligações) para pares de órbitas (e órbitas com ela mesma) para os atratores reconstruídos a partir das séries temporais. As informações contidas em uma tabela foram obtidas simultaneamente para as três séries temporais em cada uma das fibras. Logo, cada tabela contém as informações referente a uma fibra: a tabela 2.3 se refere às séries $X_{11}, Y_{11}$ e $Z_{11}$ na fibra (I); a tabela 2.4 se refere às séries $X_{6}, Y_{6}$ e $Z_{6}$ na fibra (II) e tabela 2.5 se refere às séries 
Tabela 2.3: Espectro, números de ligações e auto-ligações das OPI extraídas dos atratores reconstruídos a partir das séries $X_{11}, Y_{11} \mathrm{e}$ $Z_{11}$ na fibra caótica (I). Nos espaços não preenchidos os valores não puderam ser determinados corretamente.

\begin{tabular}{|c|c|c|c|c|c|c|c|c|c|c|c|c|c|}
\hline nome & órbitas & 1 & 2 & 4 & $5 \mathrm{a}$ & $5 b$ & $6 a$ & $6 \mathrm{~b}$ & $7 \mathrm{a}$ & $7 \mathrm{~b}$ & $8 a$ & $8 b$ & $8 \mathrm{c}$ \\
\hline 1 & 1 & 0 & & & & & & & & & & & \\
\hline 2 & 10 & 1 & 1 & & & & & & & & & & \\
\hline 4 & 1011 & 2 & 3 & 5 & & & & & & & & & \\
\hline $5 \mathrm{a}$ & 10110 & 2 & 4 & 8 & 8 & & & & & & & & \\
\hline $5 \mathrm{~b}$ & 10111 & 2 & 4 & 8 & 10 & 8 & & & & & & & \\
\hline $6 a$ & 101110 & 3 & 4 & 8 & . & 9 & 14 & & & & & & \\
\hline $6 \mathrm{~b}$ & 101111 & 3 & 5 & 8 & . & . & . & 12 & & & & & \\
\hline $7 a$ & 1011011 & 2 & 6 & 10 & . & . & . & . & 17 & & & & \\
\hline $7 \mathrm{~b}$ & 1011111 & 3 & 6 & 12 & . & . & . & . & . & 17 & & & \\
\hline $8 \mathrm{a}$ & 10111110 & 3 & 6 & . & . & . & . & . & . & . & 24 & & \\
\hline $8 \mathrm{~b}$ & 10111010 & 3 & 5 & . & . & . & . & . & . & . & . & 22 & \\
\hline $8 c$ & 10111111 & 4 & 7 & . & . & . & . & . & . & . & . & . & 22 \\
\hline
\end{tabular}

$X_{1}, Y_{1}$ e $Z_{1}$ na fibra (III).

A variação dos parâmetros de controle, em geral, modifica o espectro de órbitas de um dado atrator. Contudo, o espectro de órbitas, indicado pela seqüência simbólica na segunda coluna das tabelas, são idênticos para as séries cujos parâmetros pertencem a uma dada fibra. E, assim como para o espectro de OPI, os números de ligações também são idênticos para as séries situadas em uma mesma fibra. Os resultados das tabelas podem ser interpretados como uma assinatura topológica das fibras, tal que as propriedades topológicas das OPI não mudam para atratores em uma mesma fibra.

Os números de (auto-)ligações de uma determinada ordem de órbita (órbitas de mesmo período e mesma seqüência simbólica) não se alteram para variações dos parâmetros na vizinhança da janela de período 3 no espaço de dois parâmetros. Ou seja, para tais órbitas, sua seqüência simbólica e organização topológica permanecem inalteradas em todo domínio de existência da órbita. Esse fato mostra que o molde topológico, e conseqüentemente a dinâmica dos atratores [15], não se alteram do ponto de vista da estrutura global dos atratores. Logo, os números de ligações e as órbitas presentes no 
Tabela 2.4: Espectro, números de ligações e auto-ligações das OPI extraídas dos atratores reconstruídos a partir das séries $X_{6}, Y_{6}$ e $Z_{6}$ na fibra caótica (II). Nos espaços não preenchidos os valores não puderam ser determinados corretamente.

\begin{tabular}{|c|c|c|c|c|c|c|c|c|c|c|c|c|c|c|c|}
\hline nome & órbitas & 1 & 2 & 4 & $5 \mathrm{a}$ & $5 \mathrm{~b}$ & $6 a$ & $6 \mathrm{~b}$ & $7 \mathrm{a}$ & $7 \mathrm{~b}$ & $7 \mathrm{c}$ & $7 \mathrm{~d}$ & $8 \mathrm{a}$ & $8 \mathrm{~b}$ & $8 \mathrm{c}$ \\
\hline 1 & 1 & 0 & & & & & & & & & & & & & \\
\hline 2 & 10 & 1 & 1 & & & & & & & & & & & & \\
\hline 4 & 1011 & 2 & 3 & 5 & & & & & & & & & & & \\
\hline $5 \mathrm{a}$ & 10110 & 2 & 4 & 8 & 8 & & & & & & & & & & \\
\hline $5 \mathrm{~b}$ & 10111 & 2 & 4 & 8 & 10 & 8 & & & & & & & & & \\
\hline $6 \mathrm{a}$ & 101110 & 3 & 4 & 8 & . & 9 & 14 & & & & & & & & \\
\hline $6 \mathrm{~b}$ & 101111 & 3 & 5 & 8 & . & . & . & 12 & & & & & & & \\
\hline $7 \mathrm{a}$ & 1011011 & 2 & 6 & 10 & . & . & . & . & 17 & & & & & & \\
\hline $7 \mathrm{~b}$ & 1011111 & 3 & 6 & 12 & . & . & . & . & . & 17 & & & & & \\
\hline $7 \mathrm{c}$ & 1011010 & 3 & 5 & 11 & . & . & . & . & . & . & 17 & & & & \\
\hline $7 \mathrm{~d}$ & 1011110 & 5 & 5 & 10 & . & . & . & . & . & . & . & 18 & & & \\
\hline $8 a$ & 10111110 & 3 & 6 & . & . & . & . & . & . & . & . & . & 24 & & \\
\hline $8 \mathrm{~b}$ & 10111010 & 3 & 5 & . & . & . & . & . & . & . & . & . & . & 22 & \\
\hline $8 \mathrm{c}$ & 10111111 & 4 & 7 & & . & . & . & . & . & . & . & . & . & . & 22 \\
\hline
\end{tabular}

espectro não contribuem para distinguir a presença de três fibras diferentes.

Entretanto, existe uma característica importante entre os espectros de OPIs, que pode ser usada para identificar a existência de três fibras diferentes. Essa característica é dada pelas órbitas podadas entre os espectros. Uma órbita é dita podada se sua seqüência simbólica, apesar de prevista pelo modelo simbólico usado (a árvore binária), não é encontrada no espectro de órbitas do atrator. Dizemos que as órbitas podadas são proibidas de ocorrer no sistema dinâmico. Assim, nos espectros para a fibra (I) e (II), tabelas 2.3 e 2.4 respectivamente, a órbita de período três (101) é proibida, enquanto que na fibra (III) é permitida (veja tabela 2.5). As órbitas de período 7 (1011010) e (1011110) são proibidas no espectro para a fibra (I), mas são permitidas nos espectros para as fibras (II) e (III). 
Tabela 2.5: Espectro, números de ligações e auto-ligações das OPI extraídas dos atratores reconstruídos a partir das séries $X_{1}, Y_{1}$ e $Z_{1}$ na fibra caótica (III). Nos espaços não preenchidos os valores não puderam ser determinados corretamente.

\begin{tabular}{|c|c|c|c|c|c|c|c|c|c|c|c|c|c|c|c|c|c|c|}
\hline nome & órbitas & 1 & 2 & 3 & 4 & $5 \mathrm{a}$ & $5 \mathrm{~b}$ & $6 \mathrm{a}$ & $6 \mathrm{~b}$ & $7 \mathrm{a}$ & $7 \mathrm{~b}$ & $7 \mathrm{c}$ & $7 \mathrm{~d}$ & $8 \mathrm{a}$ & $8 \mathrm{~b}$ & $8 \mathrm{c}$ & $8 \mathrm{~d}$ & $8 \mathrm{e}$ \\
\hline 1 & 1 & 0 & & & & & & & & & & & & & & & & \\
\hline 2 & 10 & 1 & 1 & & & & & & & & & & & & & & & \\
\hline 3 & 101 & 1 & 2 & 2 & & & & & & & & & & & & & & \\
\hline 4 & 1011 & 2 & 3 & 4 & 5 & & & & & & & & & & & & & \\
\hline $5 \mathrm{a}$ & 10110 & 2 & 4 & 5 & 8 & 8 & & & & & & & & & & & & \\
\hline $5 \mathrm{~b}$ & 10111 & 2 & 4 & 5 & 8 & 10 & 8 & & & & & & & & & & & \\
\hline $6 \mathrm{a}$ & 101110 & 3 & 4 & 6 & 8 & . & 9 & 14 & & & & & & & & & & \\
\hline $6 \mathrm{~b}$ & 101111 & 3 & 5 & 6 & 8 & . & . & . & 12 & & & & & & & & & \\
\hline $7 \mathrm{a}$ & 1011011 & 2 & 6 & 7 & 10 & . & . & . & . & 17 & & & & & & & & \\
\hline $7 \mathrm{~b}$ & 1011111 & 3 & 6 & 7 & 12 & . & . & . & . & . & 17 & & & & & & & \\
\hline $7 \mathrm{c}$ & 1011010 & 3 & 5 & 7 & 11 & . & . & . & . & . & . & 17 & & & & & & \\
\hline $7 \mathrm{~d}$ & 1011110 & 5 & 5 & 7 & 10 & & . & . & . & . & & & 18 & & & & & \\
\hline $8 \mathrm{a}$ & 10111110 & 3 & 6 & . & . & . & . & . & . & . & & . & & 24 & & & & \\
\hline $8 \mathrm{~b}$ & 10111010 & 3 & 5 & & . & $\cdot$ & . & . & . & . & $\cdot$ & & . & . & 22 & & & \\
\hline $8 \mathrm{c}$ & 10111111 & 4 & 7 & . & . & . & . & . & e & . & . & & . & . & & 22 & & \\
\hline $8 \mathrm{~d}$ & 10110111 & 3 & 6 & & . & . & . & . & . & . & $\cdot$ & . & . & . & . & . & 20 & \\
\hline $8 \mathrm{e}$ & 10110110 & 3 & 6 & . & . & . & . & . & . & . & . & & . & . & . & . & . & 20 \\
\hline
\end{tabular}

\subsubsection{Planos simbólicos}

Construímos planos simbólicos para as 9 séries situadas nas três fibras através da partição dos mapas na figura 2.14 (exemplificado na séries temporal $Z_{11}$ ) e aplicando a dinâmica simbólica às trajetórias dos atratores. O resultado pode ser visto na figura 2.15. Podemos notar que os planos simbólicos para uma mesma fibra apresentam distribuições de regiões permitidas e proibidas com estrutura bastante similar. Nos planos a estrutura de vazios (regiões não permitidas) se deve ao mecanismo de podas de órbitas que age no atrator. Essa estrutura é particular em cada fibra e é visível a presença de três estruturas distintas.

Em particular, na fibra (I) as seqüências (101), (1011011), (1011110), (10110111) 


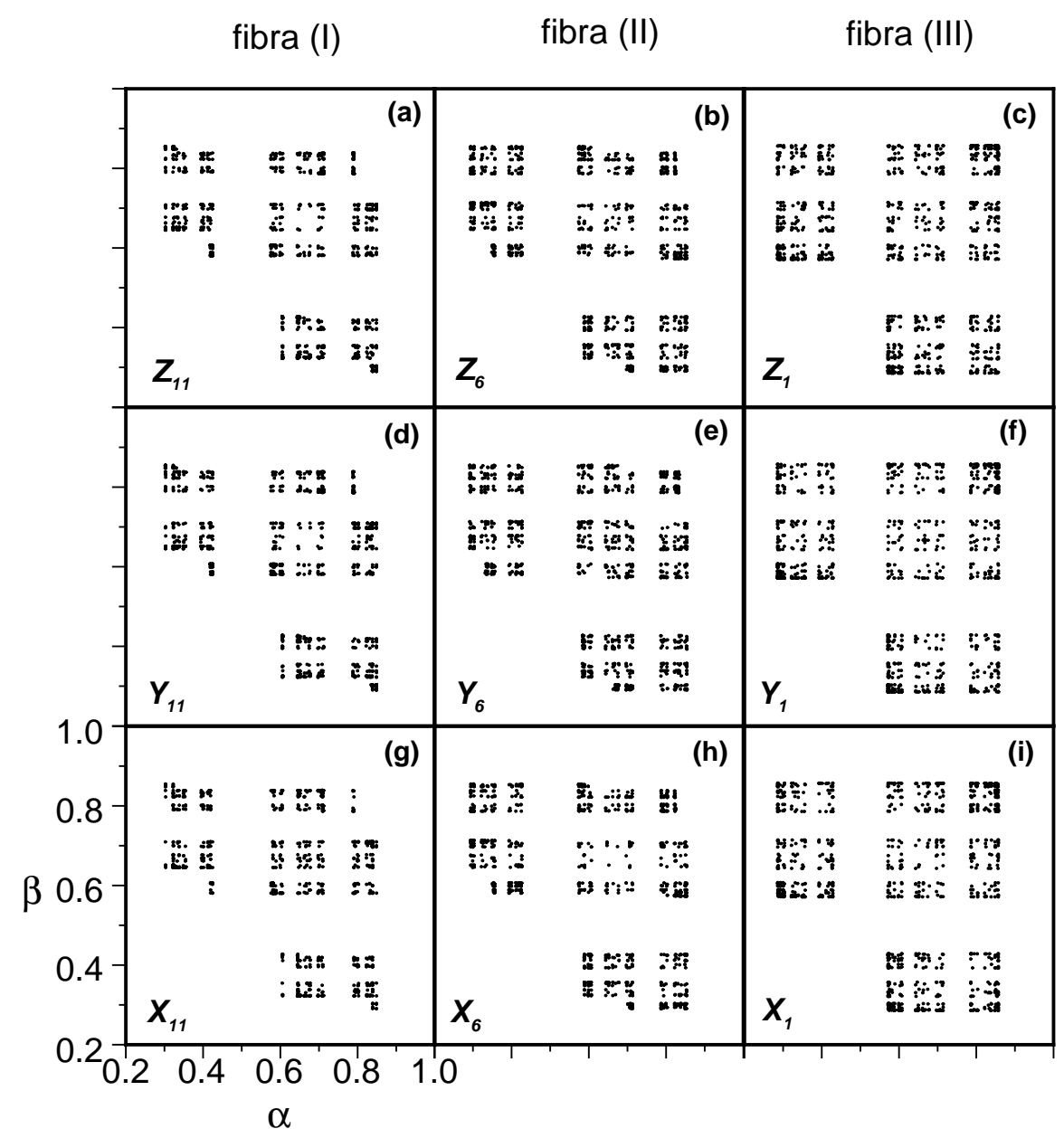

Figura 2.15: Planos simbólicos para a fibra (I) (à esquerda), para a fibra (II) (no centro) e para a fibra (III) (à direita). A estrutura de vazios (regiões não permitidas) muda para planos simbólicos em diferentes fibras. Cada plano contém 1067 pontos.

e (10110110) são todas proibidas (não estão presentes na tabela 2.3) provocando as regiões vazias à esquerda e à direita dos planos, observadas nas figuras 2.15(a), (d) e (g). Na fibra (II) somente as seqüências (101), (10110111) e (10110110) são proibidas (veja tabela 2.4) e a estrutura dos planos é ligeiramente diferente [veja figuras 2.15(b), (e) e (f)] com as regiões à direita e à esquerda um pouco mais preenchidas em relação a fibra (I). Na fibra (III) todas as seqüências acima são permitidas e a estrutura dos planos muda novamente [veja nas figuras 2.15(c), (f) e (i)]. Agora, as regiões à esquerda e à direita são ainda mais preenchidas em relação aos planos nas fibras (I) e (II). 


\subsubsection{Entropia topológica}

Estimamos a entropia topológica $h_{T}(S)$, como definida na eq.(1.26), para os nove atratores nas três fibras, variando o comprimento das seqüências $S=s_{1} s_{2} \ldots s_{p}$ de $p=3$ até $p=10$. O resultado pode ser visto na figura 2.16. Caso as seqüências simbólicas usadas fossem suficientemente longas, as estimativas de $h_{T}(S)$ calculadas para atratores com parâmetros situados ao longo de uma dada fibra, convergiriam para um único valor para $p$ suficientemente grande. Entretanto, as séries usadas contém apenas $\sim 1100$ símbolos fato que afeta a convergência de $h_{T}(S)$ já entre $p=8$ ou $p=9$. Apesar disso, nós podemos notar a tendência de convergência similar, quando variamos $p$, para os atratores situados em cada uma das fibras, indicando a preservação da informação topológica para atratores situados sobre uma dada fibra.

\section{A. Experimental $\times$ simulado}

Com o propósito de verificar a convergência para um único valor e a preservação ao longo das fibras estimamos a entropia topológica $h_{T}(S)$, definida pela eq.(1.26), a partir de séries simbólicas obtidas por simulação numérica do circuito de Chua variandose $\Delta R_{1}$ e $\Delta R_{2}$, onde $R_{01}=1,389 \mathrm{k} \Omega, R_{02}=36,0 \Omega$ são fixos e demais parâmetros os mesmos usados na seção 2.4.2. Uma vez que em uma simulação numérica não há a limitação da quantidade de dados que há em um experimento, a convergência da entropia pode ser claramente estabelecida através do emprego de séries numéricas. A entropia topológica foi estimada para as séries numéricas da mesma forma que para as séries experimentais: particionando os mapas de retorno dos atratores e construindo seqüências simbólicas através da aplicação de uma dinâmica simbólica binária.

Na figura 2.17 podemos ver a entropia topológica $h_{T}(S)$ estimada para as séries numéricas em função do comprimento $p$ das seqüências, de $p=2$ até $p=22$ bits. Os parâmetros $\Delta R_{1}$ e $\Delta R_{2}$ usados situam as séries em três retas distintas no espaço de parâmetros de modo que pertençam à três fibras, alinhadas à janela de período três, em uma configuração similar ao espaço de parâmetros para as séries experimentais (veja a figura 2.11). Os resultados da figura 2.17 mostram que a entropia topológica estimada para atratores em uma dada fibra converge, de fato, para um único valor e que é preservada quando os parâmetros são variados ao longo dessa fibra caótica. 


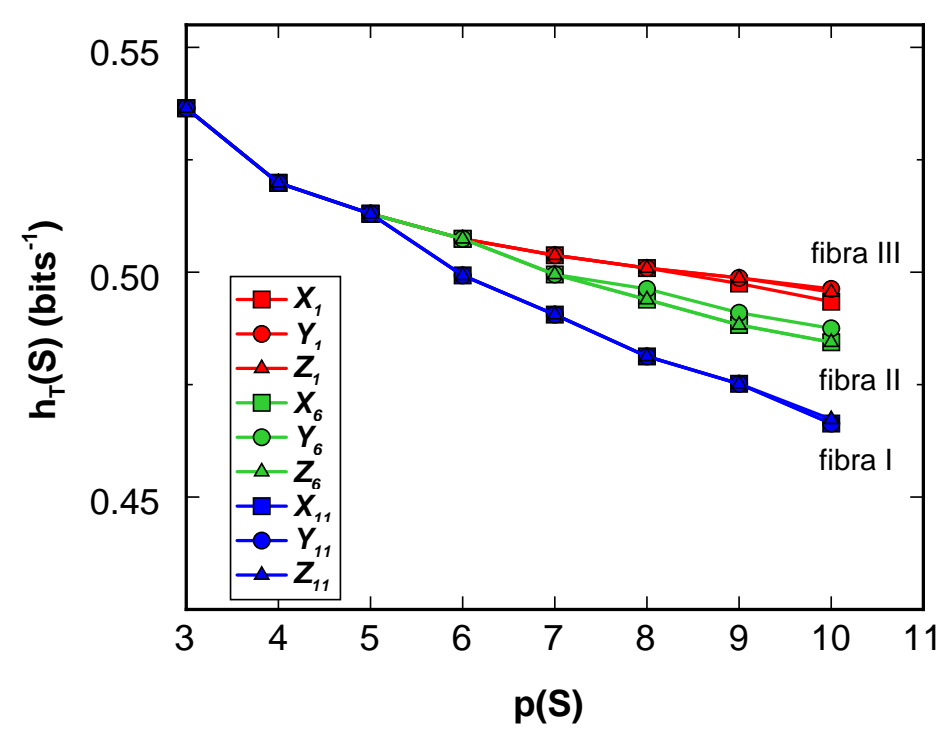

Figura 2.16: Entropia topológica dos atratores reconstruídos, estimada à partir das seqüências simbólicas, em função do comprimento $p$ das seqüências.

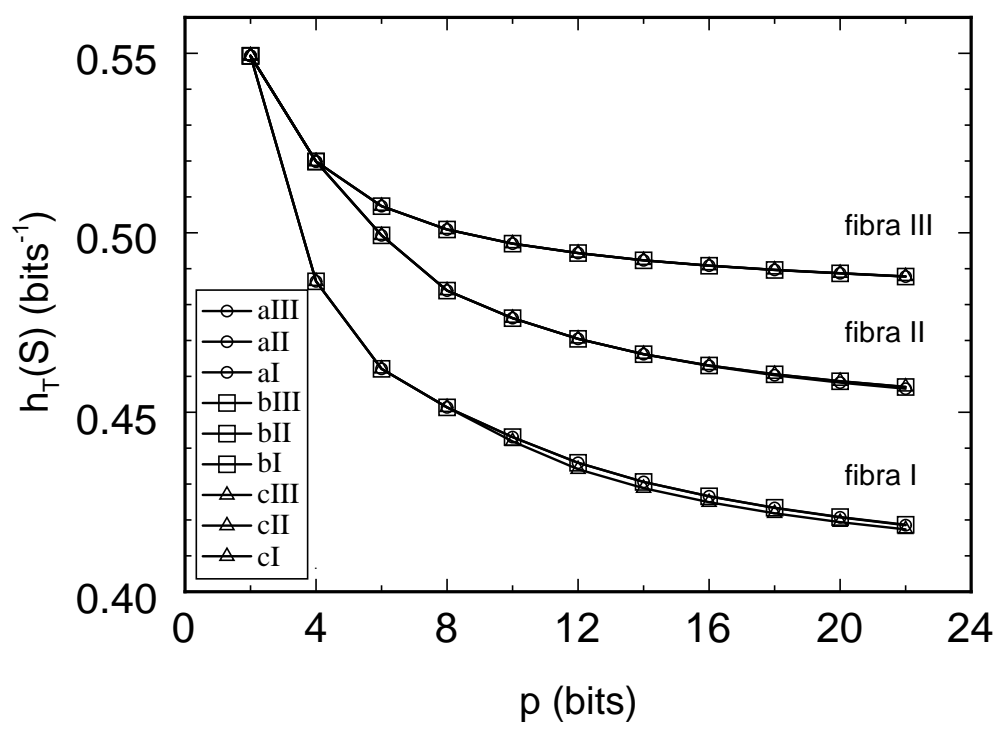

Figura 2.17: Entropia topológica dos atratores numericamente simulados, estimada a partir das seqüências simbólicas, em função do comprimento $p$ das seqüências. Os parâmetros são: séries a com $\Delta R_{1}=3,023 \Omega$ e $\Delta R_{2}=[0,3527 ; 0,4884 ; 0,6240] \Omega$ para as series nas fibras (I), (II) e (III); séries b com $\Delta R_{1}=2,635 \Omega$ e $\Delta R_{2}=[0,4341 ; 0,5697 ; 0,7054] \Omega$ em (I), (II) e (III) e séries c com $\Delta R_{1}=2,248 \Omega$ e $\Delta R_{2}=[0,5155 ; 0,6512 ; 0,7868] \Omega$ em (I), (II) e (III). Os outros parâmetros são os mesmos já usados na seção 2.4.2. 


\subsection{Caracterização topológica dos atratores no cir- cuito de Chua}

Nessa seção, abordaremos a topologia dos atratores do circuito de Chua ao redor da janela periódica de período quatro na região $\Psi$ do espaço de parâmetros. A janela de período quatro não é uma janela estendida como a de período três e apresenta estruturas secundárias alongadas, separadas por regiões de comportamento caótico, conforme pode ser visto na figura 1.16. Em particular, é próximo à janela de período quatro que ocorre a transição entre três estados caóticos no circuito de Chua: o atrator do tipo Rössler que muda, ao variarmos o parâmetro $\Delta R_{2}$, para o atrator do tipo Rössler dobrado que, por sua vez, muda para o atrator duplo-rolo. A transição entre os atratores do tipo Rössler e Rössler dobrado para um modelo matemático do circuito de Chua com uma abordagem através da dinâmica simbólica pode ser visto em [37, 72].

Inicialmente, analisaremos os mapas de primeiro retorno para os atratores na região de transição entre os três estados caóticos. A seguir, construiremos modelos geométricos para os atratores naquela região, a partir dos quais obteremos os moldes topológicos correspondentes a cada um dos atratores, assim como um molde generalizado para os estados dinâmicos do circuito após o surgimento do atrator duplo-rolo.

\subsubsection{Atratores e mapas de retorno}

No diagrama de bifurcações para o conjunto de séries temporais $X$, que pode ser visto na figura 2.18, a janela de período quatro ocorre duas vezes, intercalada por uma

região de caos. É nessa região de caos que ocorre a transição entre os estados caóticos no circuito: até a primeira janela de período quatro a dinâmica é caracterizada pelo atrator do tipo Rössler; na segunda janela a dinâmica passa a ser descrita pelo atrator do tipo Rössler dobrado. Após o termino da segunda janela periódica a dinâmica transita do atrator Rössler dobrado para duplo-rolo. Na figura 2.19 temos 7 atratores situados na região $\Psi$ do espaço de parâmetros ( $J$ negativos), ao redor da janela de período quatro, reconstruídos a partir das séries temporais $X$. Na reconstrução empregamos o método de Takens com tempo de atraso de $\tau=45,0 \mu \mathrm{s}$, correspondendo a 18 pontos de dados. Identificamos os atratores por $X_{J}, J=-17,-27,-30,-35,-38,-42$ e -47 , da mesma forma que as séries usadas na análise das fibras caóticas: a letra $X$ indica o valor de $\Delta R_{1}$ para os atratores, enquanto que o índice $J$ o valor de $\Delta R_{2}$ (veja a legenda da figura 2.19). 


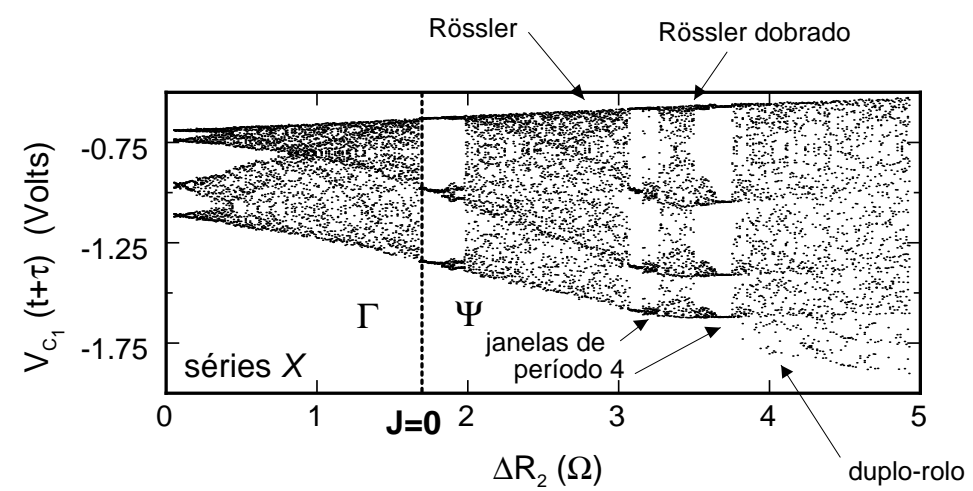

Figura 2.18: Diagrama de bifurcações para as séries temporais $X$ mostrando a localização aproximada dos atratores do tipo Rössler, Rössler dobrado e duplo-rolo nas vizinhanças das duas janelas de período quatro. A linha pontilhada $(J=0)$ indica o ponto de referência na borda esquerda da janela de período três, separando o espaço de parâmetros em duas regiões: $\Gamma$ ( $J$ positivo) e $\Psi$ ( $J$ negativo).

Uma maneira eficiente de revelar as mudanças topológicas experimentadas pelos atratores na região $\Psi$ do espaço de parâmetros é através dos mapas de primeiro retorno. Os mapas de primeiro retorno em atratores cuja dinâmica é caracterizada por processos de estiramento e dobras, como nos mapas logístico e Hénon, apresentam ramos delimitados pelos pontos onde as dobras ocorrem. Em mapas unidimensionais as dobras ocorrem nos pontos críticos [36, 38, 39]. Em mapas bidimensionais elas ocorrem nos pontos de tangências homoclínicas primárias entre as variáveis estável e instável do sistema dinâmico $[44,65,66,67]$. Tais pontos são usados como partição para a aplicação da dinâmica simbólica, particionando o atrator de um sistema dinâmico em várias regiões com topologias diferentes. Logo, um mapa de primeiro retorno pode ser empregado para encontrar regiões topologicamente diferentes em atratores.

Na figura 2.20 podemos ver os mapas de primeiro retorno para os 7 atratores na região $\Psi$ do espaço de parâmetros. Os mapas nas figuras 2.20 de (a) à (f) foram construídos através das intersecções das trajetórias dos atratores com a seção de Poincaré $P_{V_{C_{1}}}^{(-)}$dada por

$P_{V_{C_{1}}}^{( \pm)}=\left\{\left[V_{C_{1}}(t), V_{C_{1}}(t+\tau), V_{C_{1}}(t+2 \tau)\right] \in \mathbb{R}^{3} \mid V_{C_{1}}(t)= \pm 2,5 \mathrm{~V}, V_{C_{1}}(t+\tau) \lessgtr \pm 2,5 \mathrm{~V}\right\}$.

O mapa de retorno na figura 2.20 (g) foi construído usando $P_{V_{C_{1}}}^{(+)}$e $P_{V_{C_{1}}}^{(-)}$simultaneamente para capturar a dinâmica do atrator nos domínios $D^{+}$e $D^{-}$do espaço de fases. Fazendo uso da anti-simetria apresentada pelo atrator duplo-rolo (simetria ímpar) [37] o mapa 

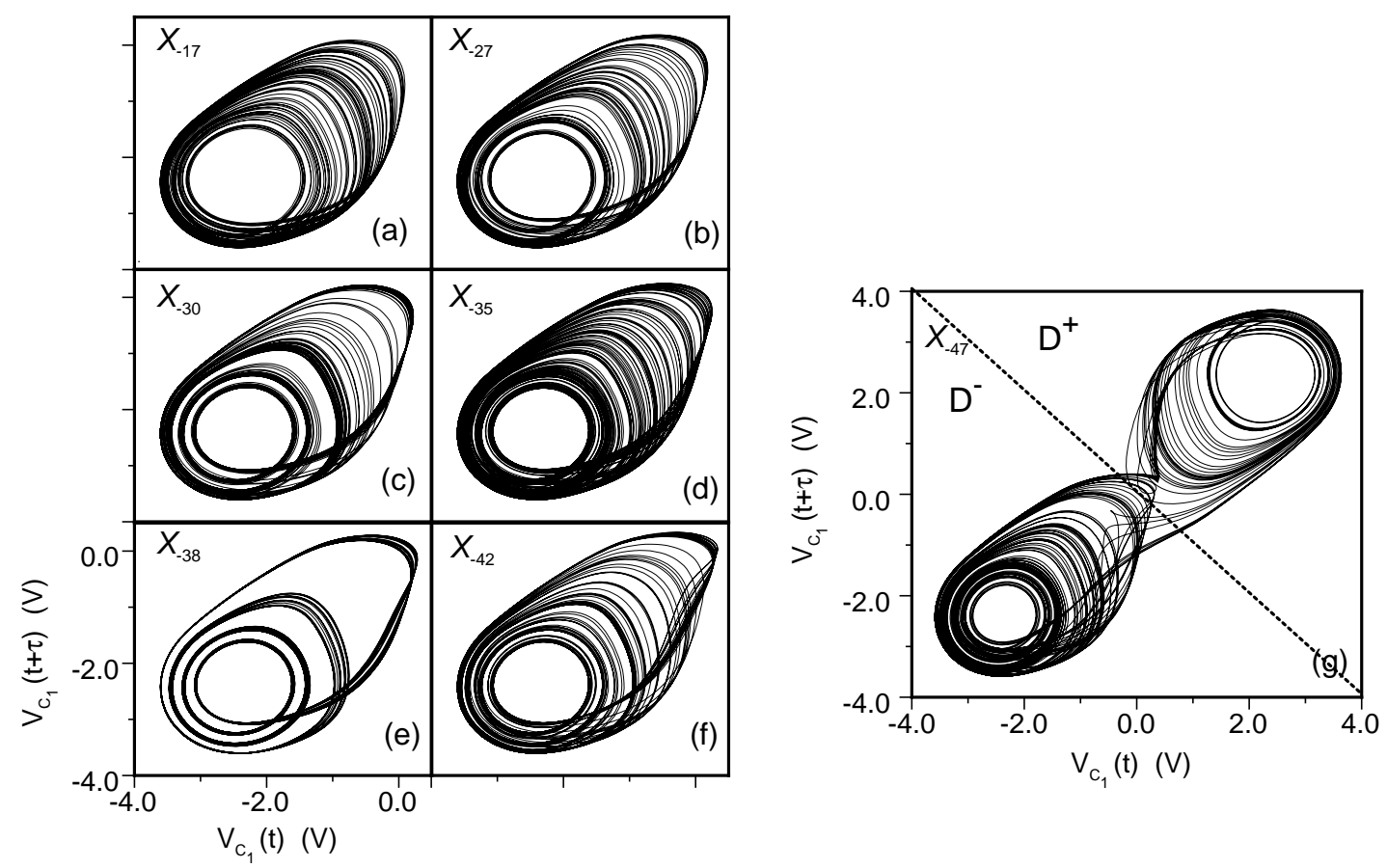

Figura 2.19: Atratores reconstruídos a partir do conjunto de séries $X$ (parâmetro $\Delta R_{1}=0,08 \Omega$ )

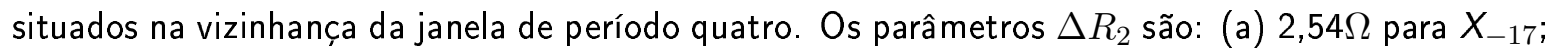
(b) $3,03 \Omega$ para $X_{-27} ;$ (c) $3,18 \Omega$ para $X_{-30}$; (d) $3,43 \Omega$ para $X_{-35}$; (e) $3,57 \Omega$ para $X_{-38}$; (f) $3,77 \Omega$ para $X_{-42}$ e (g) $4,02 \Omega$ para $X_{-47}$.

de retorno obtido em $D^{+}$sobrepõe-se ao mapa em $D^{-}$.

Como os mapas de retorno na figura 2.20(a) à (g) são aproximadamente unidimensionais a partição foi feita nos pontos críticos. Nos mapas (a) à (d) da figura 2.20, aproximadamente unimodais, a partição está nos pontos de máximo. Esses mapas correspondem aos atratores do tipo Rössler que apresentam uma única dobra. Nos mapas (e) e (f) da figura 2.20, aproximadamente bimodais, as duas partições estão nos pontos de máximo e de mínimo. Os atratores correspondentes são os do tipo Rössler dobrado e tem esse nome porque apresentam uma segunda dobra, visível no canto inferior direito da figura 2.20(f). E por fim no mapa (g), aproximadamente tri-modal, as partições estão nos dois pontos de máximo e no de mínimo. Esse mapa corresponde ao atrator duplo-rolo com três dobras visíveis, que são mostradas nas figuras $2.20(\mathrm{~g})$ e na sua ampliação (h).

As partições nos mapas de primeiro retorno na figura 2.20 separam os ramos com curvatura positiva dos ramos com curvatura negativa. Cada ramo está associado a 

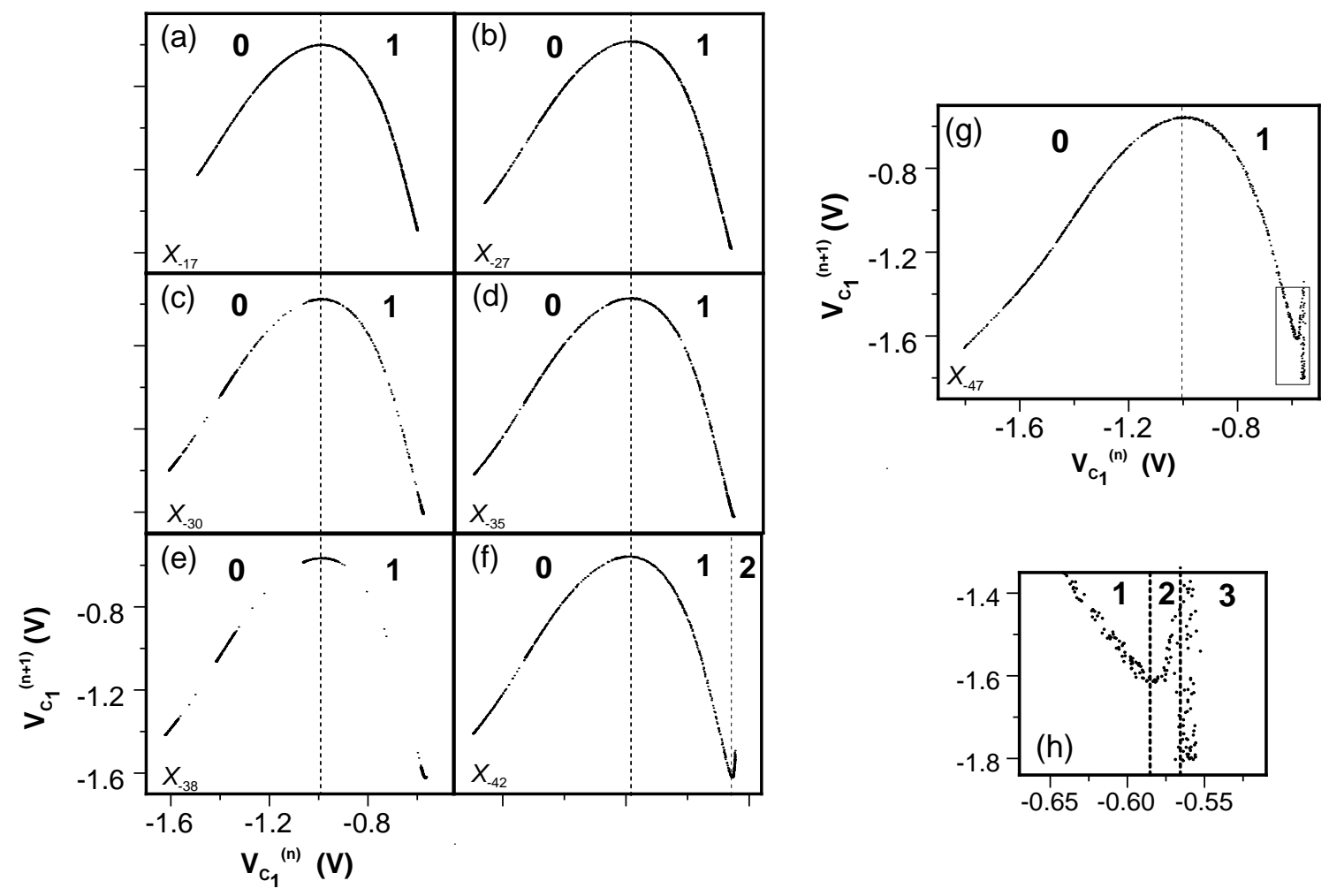

Figura 2.20: Mapas de primeiro retorno para os atratores reconstruídos à partir das séries $X_{J}$, $J=-17,-27,-30,-35,-38,-42$ e -47 . Os mapas são particionados pelos pontos críticos e seus ramos identificados por símbolos de acordo com a curvatura: $\mathbf{0}$ e $\mathbf{2}$ para ramos com curvatura positiva e $\mathbf{1}$ e $\mathbf{3}$ para ramos com curvatura negativa.

uma região topológica do atrator. Assim, as partições nos mapas de retorno para o atrator do tipo Rössler [figuras 2.20(a) até (d)] estabelecem duas regiões topológicas: a primeira, associada ao ramo com curvatura positiva e identificada pelo símbolo $\mathbf{0}$, é a região de estiramento das trajetórias; a segunda, associada ao ramo com curvatura negativa e símbolo 1, é a região em que as trajetórias dobram. Os mapas para o atrator Rössler dobrado [figuras 2.20(e) e (f)] são particionados em três regiões: uma região de estiramentos das trajetórias, identificadas por 0; uma dobra, identificada por $\mathbf{1}$ e uma segunda dobra, identificada por 2. Por fim, o mapa para o atrator duplo-rolo é particionado em quatro regiões: uma região de estiramentos, identificada por $\mathbf{0}$, e três regiões de dobras, identificadas por $\mathbf{1}, 2$ e 3. 


\subsubsection{Retratos para os atratores}

As projeções bidimensionais dos atratores reconstruídos na figura 2.19 e os mapas de retorno correspondentes na figura 2.20 permitem a obtenção de retratos ou modelos geométricos para a dinâmica que origina os atratores. Os retratos descrevem a evolução dinâmica das trajetórias em um dado atrator, estabelecendo quais são as regiões topológicas que as trajetórias podem percorrer. O retrato, a projeção da direção do fluxo sobre a direção instável (ao longo da direção estável), é garantida pelo teorema de Birman-Williams (veja a seção 1.2.6).

Os retratos para os 7 atratores do conjunto $X_{J}$ podem ser vistas na figura 2.21. O retrato na figura 2.21(a) corresponde aos atratores tipo Rössler, reconstruídos das séries $J=-35,-30,-27$ e -17 . O retrato na figura 2.21(b) corresponde aos atratores Rössler dobrado reconstruídos das séries $J=-42$ e -38 . E o retrato na figura 2.21(c) corresponde ao atrator duplo-rolo (série $J=-47$ ).

As dobras a que o fluxo sujeita um atrator provoca torções nas trajetórias. Nos retratos na figura 2.21, as torções são representadas por rotações de $\pm \pi$ radianos. As torções são dadas pelo numeral que identifica uma dada região topológica no mapa de retorno ou no retrato. Assim, vemos na figura 2.21 que regiões identificadas por numeral par $(\mathbf{0}, \mathbf{2}, \ldots)$ ou não apresentam rotações (o caso da região $\mathbf{0}$ ) ou apresentam número par de rotações. As regiões identificadas por numeral ímpar $(\mathbf{1}, \mathbf{3}, \ldots)$ apresentam número ímpar de rotações.

Além de torções o fluxo provoca entrelaçamento entre as trajetórias de um atrator. Os entrelaçamentos podem ser vistos nos retratos, embora não seja muito fácil expressalos em forma de rotações a partir da observação direta dos retratos.

\subsubsection{Moldes topológicos}

Todas as informações contidas em um retrato de um atrator podem ser sumarizadas em um molde topológico. Entretanto, o molde é mais preciso que o retrato pois além de estabelecer as regiões topológicas de um atrator, suas torções e entrelaçamentos, o molde organiza as regiões de uma forma hierárquica. Devido a esse fato, as órbitas imersas em um atrator são representadas no molde de forma organizada, o que permite a definição de invariantes topológicos associados às órbitas.

Os moldes são representados de duas formas: gráfica, através de diagramas, e algébrica, através de matrizes $[2,3,15,18,27,48,49,64]$. Na figura 2.22 podemos ver 

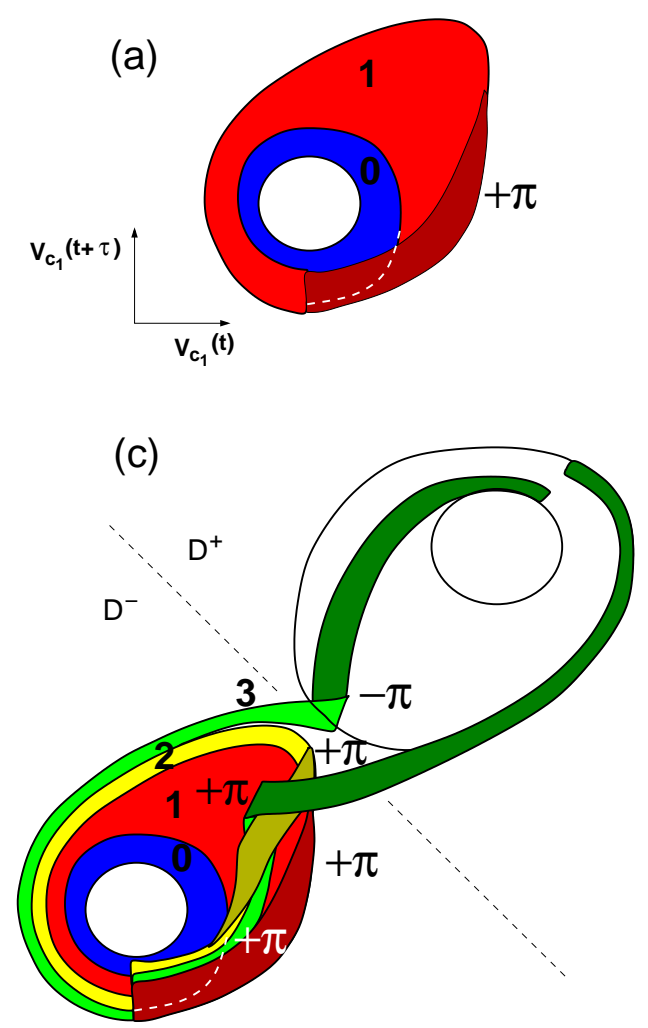

(b)

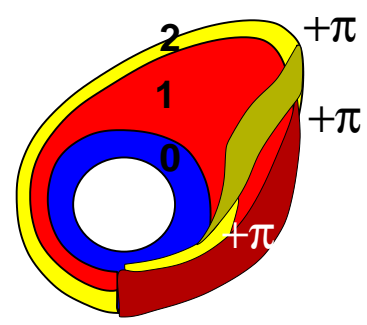

região 0

região $1 \square$ face superior

face inferior

região $2 \square$ face superior

face inferior

região $3 \square$ face superior

face inferior

Figura 2.21: Retratos para os três tipos de atratores encontrados nas séries temporais $X_{J}$, obtidos projetando-se o atrator no plano definido por $x y=V_{C_{1}}(t) V_{C_{1}}(t+\tau)$. (a) Rössler, com duas regiões topológicas: a região $\mathbf{0}$, um estiramento sem torções e a região $\mathbf{1}$, uma dobra com torção de $\pi$ rad. (b) Rössler dobrado, com a região $\mathbf{0}$ de estiramento e duas dobras: região $\mathbf{1}$ com torção de $\pi$ rad e região 2 com torção de $2 \pi$ rad. (c) Duplo-rolo com a região 0 de estiramento sem torções e três dobras: região $\mathbf{1}$ (torção de $\pi \mathrm{rad}$ ); região $\mathbf{2}$ (torção de $2 \pi$ rad) e região $\mathbf{3}$ (torção de $\pi \mathrm{rad}$ ). Essas regiões topológicas são idênticas nos domínios $D^{-}$e $D^{+}$.

os moldes topológicos para os atratores das séries $X_{J}$ em sua forma padrão. Assim como os retratos, os moldes representam a dinâmica dos atratores presentes na região $\Psi$ do espaço de parâmetros, obtidos a partir das séries temporais $X_{J}$. Logo, o molde da figura 2.22(a) corresponde aos atratores gerados pelas séries $J=-35,-30,-27$ e -17 , enquanto que o molde da figura 2.22(b) corresponde às séries $J=-42 \mathrm{e}-38 \mathrm{e}$, por fim, o molde da figura $2.22(\mathrm{c})$ corresponde à série $J=-47$.

Os moldes na figura 2.22 mostram como evolui a dinâmica do circuito de Chua quando variamos o parâmetro $\Delta R_{2}$. O atrator de Rössler com duas regiões topológicas, a região 0 de estiramento (zero torções), e a região 1 de dobra das trajetórias (uma torção $=+1 \pi$ radianos), sofre uma transição para o atrator Rössler-dobrado com o 
(a)

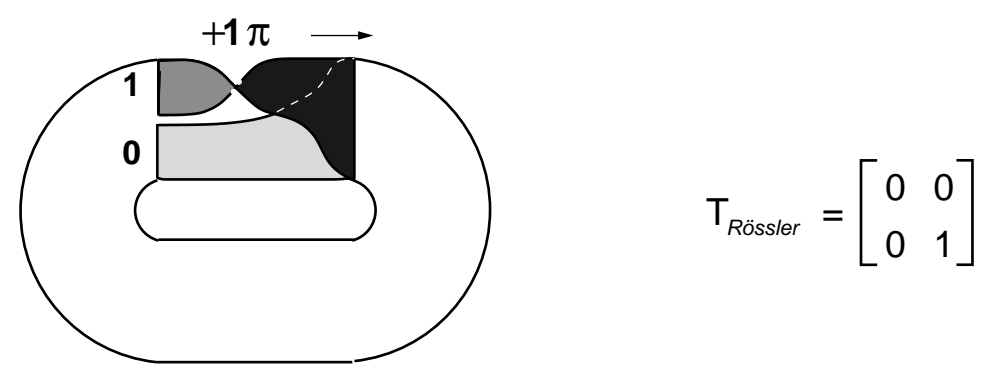

(b)

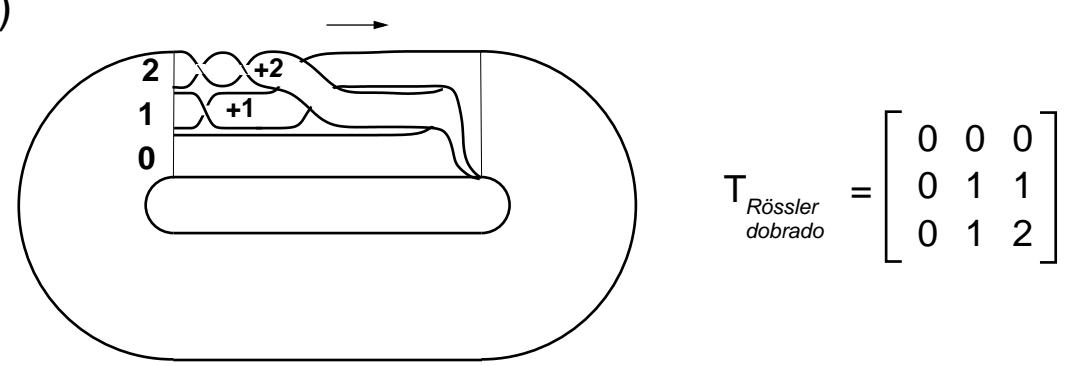

(c)

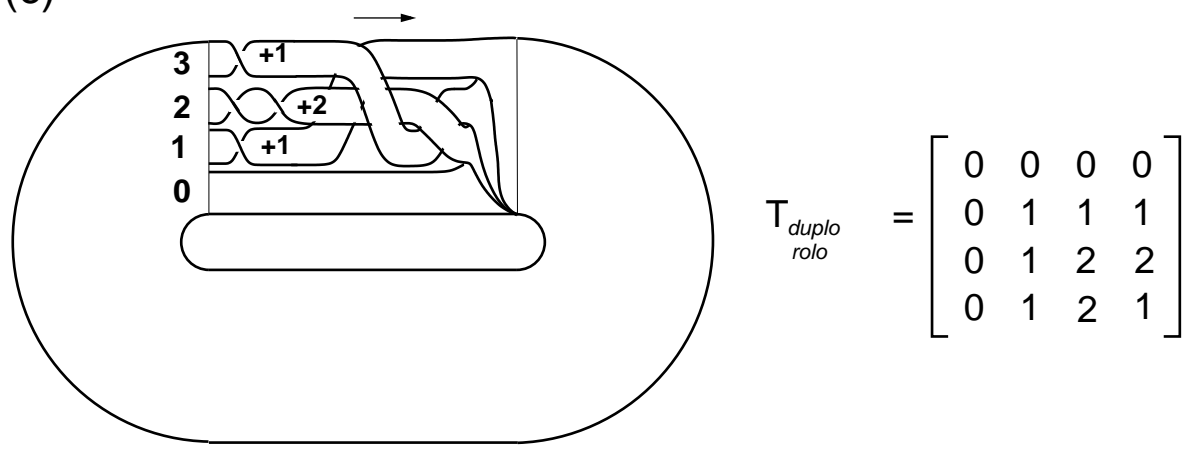

Figura 2.22: Moldes topológicos, nas formas gráfica e algébrica, para os três tipos de atratores encontrados na vizinhança da janela de período quatro: (a) Rössler, (b) Rössler dobrado e (c) duplo-rolo.

acréscimo de uma nova região topológica. Agora, além das regiões de estiramento e dobra anteriores surge uma segunda região de dobra, a região $\mathbf{2}$, com duas torções $(+2 \pi$ radianos $)$. O atrator duplo-rolo surge após uma crise por fusão [56] dos dois atratores coexistentes, derivados do atrator Rössler dobrado, cada um em sua bacia de atração. Esse atrator apresenta visível uma quarta região topológica de largura muito estreita, a dobra chamada de região 3 , mas com uma torção de $+\pi$ radianos apenas.

$\mathrm{Na}$ crise que da origem ao atrator duplo-rolo os dois atratores que se fundem são idênticos e estão simetricamente posicionados em seu domínio de existência: o atrator situado em $D^{-}$é anti-simétrico ao atrator situado em $D^{+}$. É devido a essa simetria, uma simetria conhecida como ímpar, que podemos simplificar o molde para o duplo-rolo 
de 8 para 4 ramos. Uma extensa discussão a respeito de sistemas apresentando simetria ímpar e a construção de moldes para atratores pode ser encontrada em [45, 61].

\subsubsection{Verificação dos moldes topológicos}

Um molde topológico descreve corretamente a dinâmica de um atrator caótico se os invariantes topológicos obtidos através do molde forem idênticos aos extraídos do atrator. Para validar um molde devemos então comparar os invariantes extraídos diretamente do atrator com os invariantes calculados a partir do molde. Para validar os moldes na figura 2.22 vamos utilizar apenas um único atrator como representante de cada molde: o atrator gerado pela série $X_{-27}$ será usado para validar o molde $T_{\text {Rössler }}$; o atrator gerado por $X_{-42}$ para validar $T_{\text {Rössler dobrado }}$ e o atrator gerado por $X_{-47}$ para validar $T_{\text {duplo-rolo }}$.

\section{A. Atrator $X_{-27}$}

Consideremos o atrator na figura 2.19(d) gerado pela série temporal $X_{-27}$. O molde topológico para esse atrator, $T_{X_{20}}$, deve ser igual ao molde $T_{\text {Rössler }}$. Então a matriz de elos

$$
T_{X_{-27}}=\left[\begin{array}{cc}
t_{00} & t_{01} \\
t_{10} & t_{11}
\end{array}\right]=\left[\begin{array}{ll}
0 & 0 \\
0 & 1
\end{array}\right]
$$

e a matriz de inserção

$$
I_{X_{-27}}=\left[\begin{array}{ll}
0 & m
\end{array}\right]=\left[\begin{array}{ll}
0 & 1
\end{array}\right],
$$

apresentam quatro elementos desconhecidos: $t_{00}, t_{01}=t_{10}, t_{11}$ e $m$, que pode valer -1 ou 1 se o ramo 1 estiver acima ou abaixo do ramo $\mathbf{0}$, respectivamente, na linha de inserção. Então, quatro equações envolvendo os elementos das matrizes são suficientes para verificarmos $T_{X_{-27}}$ e $I_{X_{-27}}$. Aplicando a eq.(1.41) ao cálculo dos números de ligações dos pares de órbitas $(1,10),(10,101)$ e $(1,100)$ temos

$$
\begin{aligned}
\lg (1,10) & =\frac{1}{2}\left(t_{10}+t_{11}+1\right)=1 \\
\lg (10,101) & =\frac{1}{2}\left(3 t_{10}+2 t_{11}+t_{00}+2\right)=2 \\
l g(1,100) & =\frac{1}{2}\left(2 t_{10}+t_{11}+1\right)=1 \\
m & =t_{01}+t_{11}
\end{aligned}
$$

tal que $\lg (1,10)=1, \lg (10,101)=2$ e $\lg (1,100)=1$ foram obtidos diretamente das órbitas identificadas no atrator reconstruído $X_{-27}$, como pode ser visto na fi- 
gura 2.23(a),(b) e (c). O espectro de órbitas para esse atrator pode ser visto na tabela 2.6. A equação para $m$ [eq.(2.11)] é dada em termos das permutações do ramo $\mathbf{1}$ no interior do molde, de acordo com as regras exposta na referência [18]. Combinando as eqs.(2.8) e (2.10) temos

$$
t_{10}=\lg (1,100)-\lg (1,10)=0 .
$$

Substituindo $t_{10}$ em eq.(2.8) vem

$$
t_{11}=1-t_{10}=1 \text {. }
$$

A eq.(2.9) fornece o valor de $t_{00}$

$$
t_{00}=2-2 t_{11}-3 t_{10}=0
$$

que, levando em eq.(2.11), juntamente com resultado de eq.(2.13) temos

$$
m=t_{01}+t_{11}=1
$$

Esses resultados concordam com os elementos das matrizes em eq.(2.6) e em eq.(2.7).

Tabela 2.6: Espectro de OPIs, até o período 8, encontradas no atrator reconstruído $X_{-27}$ através do método de retorno aproximado. A tolerância para os retornos foi de $\epsilon=1 \% \times$ maior amplitude da série.

\begin{tabular}{ccr|ccc}
\hline nome & período & órbita & nome & período & órbita \\
\hline 1 & $\mathrm{~T}$ & 1 & $5 \mathrm{c}$ & $5 \mathrm{~T}$ & 10011 \\
2 & $2 \mathrm{~T}$ & 10 & $5 \mathrm{~d}$ & $5 \mathrm{~T}$ & 10010 \\
$3 \mathrm{a}$ & $3 \mathrm{~T}$ & 100 & $6 \mathrm{a}$ & $6 \mathrm{~T}$ & 100101 \\
$3 \mathrm{~b}$ & $3 \mathrm{~T}$ & 101 & $6 \mathrm{~b}$ & $6 \mathrm{~T}$ & 101110 \\
$4 \mathrm{a}$ & $4 \mathrm{~T}$ & 1001 & $6 \mathrm{c}$ & $6 \mathrm{~T}$ & 101111 \\
$4 \mathrm{~b}$ & $4 \mathrm{~T}$ & 1011 & $6 \mathrm{~d}$ & $6 \mathrm{~T}$ & 100111 \\
$4 \mathrm{c}$ & $4 \mathrm{~T}$ & 1000 & $6 \mathrm{e}$ & $6 \mathrm{~T}$ & 100110 \\
$5 \mathrm{a}$ & $5 \mathrm{~T}$ & 10110 & $6 \mathrm{f}$ & $6 \mathrm{~T}$ & 101011 \\
$5 \mathrm{~b}$ & $5 \mathrm{~T}$ & 10111 & & & \\
\hline
\end{tabular}




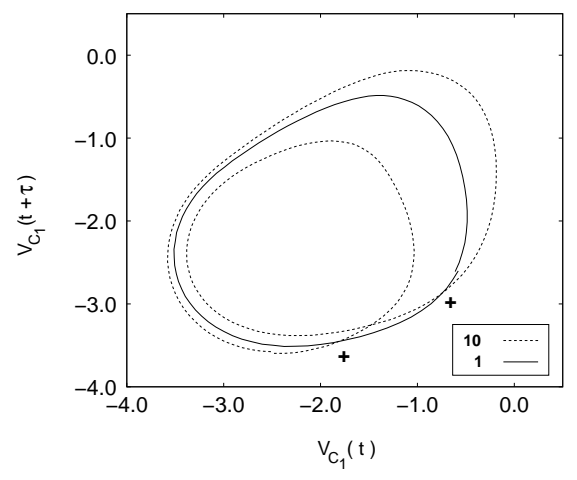

(a)

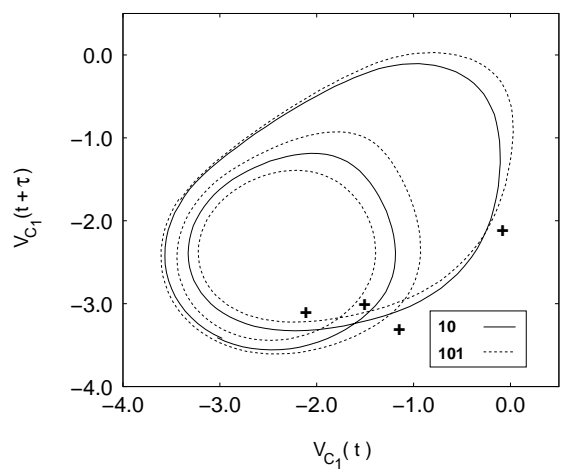

(b)

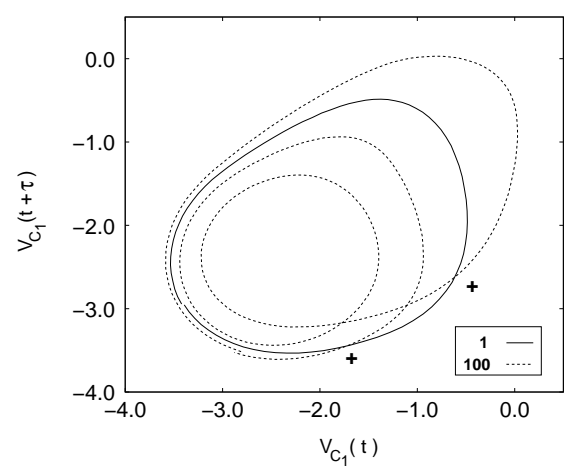

(c)

Figura 2.23: Números de ligações $l g\left(\mathcal{O}_{1}, \mathcal{O}_{2}\right)$ de pares de OPIs $\mathcal{O}_{1}$ e $\mathcal{O}_{2}$ identificadas no atrator reconstruído $X_{-27}$. (a) $\lg (1,10)=\frac{1}{2}(+1+1)=+1$ para as órbitas $\overline{1}$ e $\overline{10}$. (b) $\lg (1,100)=$ $\frac{1}{2}(+1+1)=+1$ para as órbitas $\overline{1}$ e $\overline{100}$. (c) $l g(1,101)=\frac{1}{2}(+1+1+1+1)=+2$ para as órbitas $\overline{1}$ e $\overline{101}$.

\section{B. Atrator $X_{-42}$}

O molde para o atrator na figura $2.19(\mathrm{f}), T_{X_{-42}}$, reconstruído a partir da série $X_{-42}$, deve ser igual ao molde $T_{\text {Rössler dobrado }}$ Então, a matriz

$$
T_{X_{-42}}=\left[\begin{array}{ccc}
t_{00} & t_{01} & t_{02} \\
t_{10} & t_{11} & t_{12} \\
t_{20} & t_{21} & t_{22}
\end{array}\right]=\left[\begin{array}{lll}
0 & 0 & 0 \\
0 & 1 & 1 \\
0 & 1 & 2
\end{array}\right]
$$

e a matriz de inserção correspondente

$$
I_{X_{-42}}=\left[\begin{array}{lll}
0 & m_{1} & m_{2}
\end{array}\right]=\left[\begin{array}{lll}
0 & 2 & 1
\end{array}\right] \text {, }
$$


apresentam 8 elementos desconhecidos: $t_{00}, t_{10}=t_{01}, t_{20}=t_{02}, t_{11}, t_{21}=t_{12}, t_{22}, m_{1}$ e $m_{2}$. Necessitamos, então, de 8 equações para verificarmos se a dinâmica do molde $T_{X_{-42}}$ com a matriz de inserção $I_{X_{-42}}$ descreve corretamente a dinâmica do atrator $X_{-42}$. Utilizando novamente a eq.(1.41) para o cálculo dos números de ligações aos pares de órbitas $(10,100),(10,1000),(10,2000),(10,200),(101,2000)$ e $(200,200)$ temos as equações

$$
\begin{aligned}
\operatorname{alg}(200) & =\frac{1}{2}\left(t_{22}+4 t_{20}+2\right)=2 \\
\lg (10,100) & =\frac{1}{2}\left(t_{11}+3 t_{10}+3 t_{00}+3\right)=2 \\
l g(10,1000) & =\frac{1}{2}\left(t_{11}+4 t_{10}+3 t_{00}+3\right)=2 \\
l g(10,2000) & =\frac{1}{2}\left(3 t_{10}+3 t_{00}+t_{12}+t_{20}+3\right)=2 \\
l g(10,200) & =\frac{1}{2}\left(t_{12}+2 t_{10}+2 t_{00}+3\right)=2 \\
l g(101,2000) & =\frac{1}{2}\left(6 t_{10}+3 t_{00}+2 t_{12}+t_{20}+4\right)=3 \\
m_{1} & =t_{11}-t_{10}+t_{12} \\
m_{2} & =t_{22}-t_{20}-t_{21} .
\end{aligned}
$$

Os números de ligações foram determinados diretamente das órbitas extraídas do atrator $X_{-42}$ e podem ser vistos na figura $2.24(\mathrm{a}) \ldots(\mathrm{f})$. O espectro de órbitas pode ser visto na tabela 2.7. E novamente, para as eqs.(2.24) e (2.25) utilizamos as regras de permutação dos ramos demonstradas na referência [18]. Combinando as eqs.(2.20) e (2.19) temos

$$
t_{10}=\lg (10,1000)-\lg (10,100)=0 .
$$

Combinando as eqs.(2.23) e (2.21) com o resultado anterior

$$
t_{12}=\lg (101,2000)-\lg (10,2000)-1=1 .
$$

Substituindo esse resultado na eq.(2.22) temos

$$
t_{00}=1-t_{12}-2 t_{10}=0 .
$$

As eqs.(2.19) e (2.21) fornecem os valores de $t_{11}$ e $t_{20}$

$$
t_{11}=1-3 t_{10}-3 t_{00}=1
$$

e

$$
t_{20}=1-3 t_{10}-3 t_{00}-t_{12}=0,
$$


que substituindo em eq.(2.18) resulta

$$
t_{22}=2-4 t_{20}=2
$$

Finalmente, os valores de $m_{1}$ e $m_{2}$ são

$$
m_{1}=t_{11}-t_{10}+t_{12}=2
$$

$\mathrm{e}$

$$
m_{2}=t_{22}-t_{20}-t_{21}=1 \text {. }
$$

Esses resultados concordam com os elementos das matrizes nas eqs.(2.16) e (2.17).

Tabela 2.7: Espectro de OPIs, até o período 6, encontradas no atrator reconstruído $X_{-42}$ através do método de retorno aproximado. A tolerância para os retornos foi de $\epsilon=1 \% \times$ maior amplitude da série.

\begin{tabular}{ccr|ccc}
\hline nome & período & órbita & nome & período & órbita \\
\hline 1 & \multicolumn{1}{c}{$\mathrm{T}$} & 1 & $5 \mathrm{c}$ & $5 \mathrm{~T}$ & 20011 \\
2 & $2 \mathrm{~T}$ & 10 & $5 \mathrm{~d}$ & $5 \mathrm{~T}$ & 20010 \\
$3 \mathrm{a}$ & $3 \mathrm{~T}$ & 100 & $6 \mathrm{a}$ & $6 \mathrm{~T}$ & 101111 \\
$3 \mathrm{~b}$ & $3 \mathrm{~T}$ & 101 & $6 \mathrm{~b}$ & $6 \mathrm{~T}$ & 100110 \\
$3 \mathrm{c}$ & $3 \mathrm{~T}$ & 200 & $6 \mathrm{c}$ & $6 \mathrm{~T}$ & 100101 \\
$4 \mathrm{a}$ & $4 \mathrm{~T}$ & 1001 & $6 \mathrm{~d}$ & $6 \mathrm{~T}$ & 101111 \\
$4 \mathrm{~b}$ & $4 \mathrm{~T}$ & 1011 & $6 \mathrm{e}$ & $6 \mathrm{~T}$ & 100111 \\
$4 \mathrm{c}$ & $4 \mathrm{~T}$ & 1000 & $6 \mathrm{f}$ & $6 \mathrm{~T}$ & 100010 \\
$4 \mathrm{~d}$ & $4 \mathrm{~T}$ & 2000 & $6 \mathrm{~g}$ & $6 \mathrm{~T}$ & 101110 \\
\hline $5 \mathrm{a}$ & $5 \mathrm{~T}$ & 10011 & $6 \mathrm{~h}$ & $6 \mathrm{~T}$ & 200111 \\
\hline $5 \mathrm{~b}$ & $5 \mathrm{~T}$ & 10010 & $6 \mathrm{i}$ & $6 \mathrm{~T}$ & 200100 \\
& & & $6 \mathrm{j}$ & $6 \mathrm{t}$ & 200110 \\
\hline
\end{tabular}

\section{Atrator $X_{-47}$}

Consideremos finalmente o atrator na figura $2.19(\mathrm{~g})$ gerado pela série temporal $X_{-47}$. O molde topológico para esse atrator, $T_{X_{-47}}$, deve ser igual ao molde $T_{\text {duplo-rolo }}$. Assim, 
a matriz

$$
T_{X_{-47}}=\left[\begin{array}{cccc}
t_{00} & t_{01} & t_{02} & t_{03} \\
t_{10} & t_{11} & t_{12} & t_{13} \\
t_{20} & t_{21} & t_{22} & t_{23} \\
t_{30} & t_{31} & t_{32} & t_{33}
\end{array}\right]=\left[\begin{array}{llll}
0 & 0 & 0 & 0 \\
0 & 1 & 1 & 1 \\
0 & 1 & 2 & 2 \\
0 & 1 & 2 & 1
\end{array}\right]
$$

e a matriz de inserção

$$
I_{X_{-47}}=\left[\begin{array}{llll}
0 & m_{1} & m_{2} & m_{3}
\end{array}\right]=\left[\begin{array}{llll}
0 & 3 & 1 & 2
\end{array}\right]
$$

apresentam 13 elementos desconhecidos: $t_{00}, t_{10}=t_{01}, t_{20}=t_{02}, t_{30}=t_{03}, t_{11}, t_{21}=t_{12}$, $t_{22}, t_{31}=t_{13}, t_{32}=t_{23}, t_{33}, m_{1}, m_{2}$ e $m_{3}$. Então 13 equações são necessárias para verificar se a dinâmica gerada pelo molde $T_{X_{-47}}$ corresponde àquela gerada pelo atrator $X_{-47}$. Aplicando a eq.(1.41) aos pares de órbitas $(300301,1),(200100,10),(30030,200)$, $(100,10),(200,200),(30030,30030),(301,301),(10,10),(100,100)$ e $(2000,2000)$ temos as equações

$$
\begin{aligned}
\operatorname{alg}(30030) & =\frac{1}{2}\left(4 t_{33}+12 t_{30}+9 t_{00}+8\right)=6 \\
\operatorname{alg}(301) & =\frac{1}{2}\left(t_{33}+2 t_{31}+2 t_{30}+2 t_{10}+t_{11}+t_{00}\right)=2 \\
\operatorname{alg}(200) & =\frac{1}{2}\left(t_{22}+4 t_{20}+4 t_{00}+2\right)=2 \\
\operatorname{alg}(10) & =\frac{1}{2}\left(t_{11}+2 t_{10}+t_{00}+1\right)=1 \\
\operatorname{alg}(100)= & \frac{1}{2}\left(t_{11}+4 t_{10}+4 t_{00}+3\right)=2 \\
\operatorname{alg}(2000)= & \frac{1}{2}\left(t_{22}+6 t_{20}+9 t_{00}+4\right)=3 \\
\lg (300301,1)= & \frac{1}{2}\left(2 t_{31}+3 t_{10}+t_{11}+1\right)=2 \\
\lg (200100,10)= & \frac{1}{2}\left(t_{21}+t_{20}+5 t_{10}+4 t_{00}+t_{11}+6\right)=4 \\
\lg (30030,200) & =\frac{1}{2}\left(2 t_{32}+3 t_{20}+4 t_{30}+6 t_{00}+6\right)=5 \\
\lg (100,10) & =\frac{1}{2}\left(t_{11}+3 t_{10}+2 t_{00}+3\right)=2 \\
m_{1} & =\frac{t_{11}+t_{12}+t_{13}}{m_{2}}= \\
m_{3} & =\left(t_{33}+2\right)-t_{31} . \\
t_{21} & \\
&
\end{aligned}
$$


Os números de ligações, determinados diretamente das órbitas identificadas no atrator, estão nas figuras 2.25, 2.26 e 2.27. O espectro de órbitas está na tabela 2.8. Utilizamos para as eqs.(2.46), (2.47) e (2.48) as regras demonstradas na referência [18]. Combinando as eq.(2.40) com as eqs.(2.45) e (2.39) temos

$$
\begin{aligned}
t_{10}+2 t_{00} & =0, \\
2 t_{10}+3 t_{00} & =0,
\end{aligned}
$$

tais que combinadas resultam em

$$
t_{00}=0 \text { e } t_{10}=0
$$

Substituindo esses resultados na eq.(2.45) temos

$$
t_{11}=1-3 t_{10}-2 t_{00}=1 \text {. }
$$

Combinando agora as eqs.(2.41) e (2.38) vem

$$
t_{20}=-\frac{5}{2} t_{00}=0 \text {. }
$$

Substituindo $t_{20}, t_{00}, t_{10}$ e $t_{11}$ nas eqs.(2.41), (2.43) e (2.42) resulta

$$
\begin{gathered}
t_{22}=2-6 t_{20}-9 t_{00}=2 \\
t_{21}=2-t_{20}-5 t_{10}-4 t_{00}-t_{11}=1
\end{gathered}
$$

$\mathrm{e}$

$$
t_{31}=\frac{1}{2}\left(3-t_{11}-3 t_{10}\right)=1 .
$$

As eqs.(2.36) e (2.37) levam à

$$
\begin{aligned}
4 t_{33}+12 t_{30} & =4 \\
t_{33}+2 t_{30} & =1
\end{aligned}
$$

tal que combinadas levam aos valores de $t_{30}$ e $t_{33}$

$$
t_{30}=0 \text { e } t_{33}=1
$$

A eq. (2.44) da o valor de $t_{32}$

$$
t_{32}=\frac{1}{2}\left(4-3 t_{20}-4 t_{30}-6 t_{00}\right)=2 .
$$


Finalmente, os valores de $m_{1}, m_{2}$ e $m_{3}$ são

$$
\begin{gathered}
m_{1}=1+1+1=3, \\
m_{2}=2-1=1
\end{gathered}
$$

$\mathrm{e}$

$$
m_{3}=3-1=2
$$

Esses resultados concordam com os elementos das matrizes nas eqs.(2.34) e (2.35).

Tabela 2.8: Espectro de OPIs, até o período 6, encontradas no atrator reconstruído $X_{-47}$ através do método de retorno aproximado. A tolerância para os retornos foi de $\epsilon=1 \% \times$ maior amplitude da série.

\begin{tabular}{ccr|ccc}
\hline nome & período & órbita & nome & período & órbita \\
\hline 1 & $\mathrm{~T}$ & 1 & $5 \mathrm{a}$ & $5 \mathrm{~T}$ & 10100 \\
2 & $2 \mathrm{~T}$ & 10 & $5 \mathrm{~b}$ & $5 \mathrm{~T}$ & 10011 \\
$3 \mathrm{a}$ & $3 \mathrm{~T}$ & 100 & $5 \mathrm{c}$ & $5 \mathrm{~T}$ & 10110 \\
$3 \mathrm{~b}$ & $3 \mathrm{~T}$ & 101 & $5 \mathrm{~d}$ & $5 \mathrm{~T}$ & 10010 \\
$3 \mathrm{c}$ & $3 \mathrm{~T}$ & 200 & $5 \mathrm{e}$ & $5 \mathrm{~T}$ & 10111 \\
$3 \mathrm{~d}$ & $3 \mathrm{~T}$ & 301 & $5 \mathrm{f}$ & $5 \mathrm{~T}$ & 20010 \\
$4 \mathrm{a}$ & $4 \mathrm{~T}$ & 1001 & $5 \mathrm{~g}$ & $5 \mathrm{~T}$ & 20011 \\
$4 \mathrm{~b}$ & $4 \mathrm{~T}$ & 1011 & $5 \mathrm{~h}$ & $5 \mathrm{~T}$ & 30030 \\
$4 \mathrm{c}$ & $4 \mathrm{~T}$ & 1000 & $6 \mathrm{a}$ & $6 \mathrm{~T}$ & 200101 \\
$4 \mathrm{~d}$ & $4 \mathrm{~T}$ & 2000 & $6 \mathrm{~b}$ & $6 \mathrm{~T}$ & 200100 \\
$4 \mathrm{e}$ & $4 \mathrm{~T}$ & 2001 & $6 \mathrm{c}$ & $6 \mathrm{~T}$ & 300301 \\
\hline
\end{tabular}




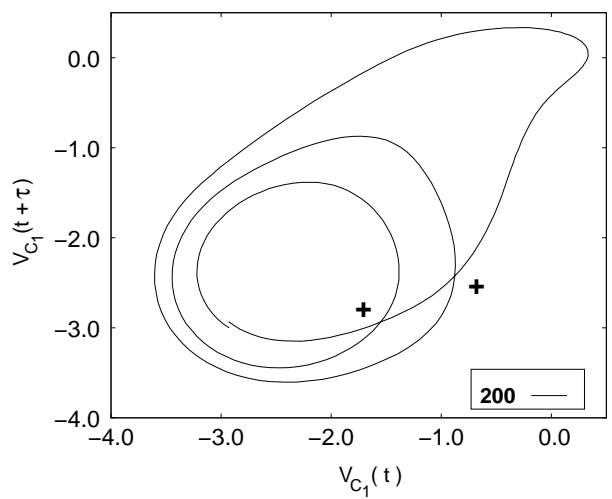

(a)

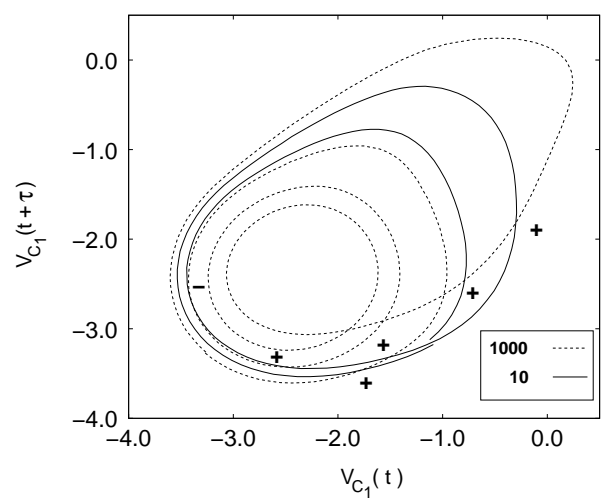

(c)

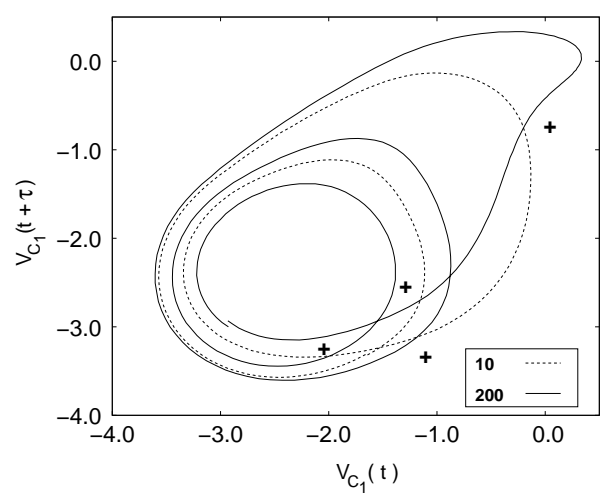

(e)

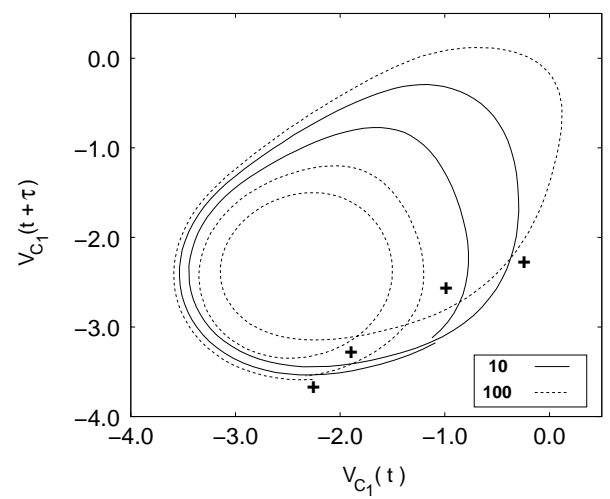

(b)

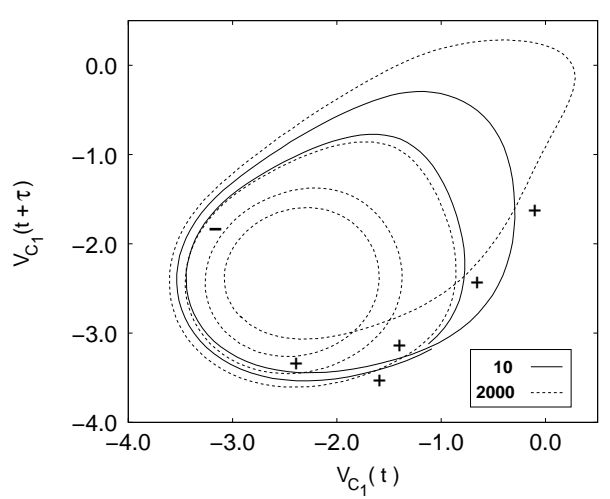

(d)

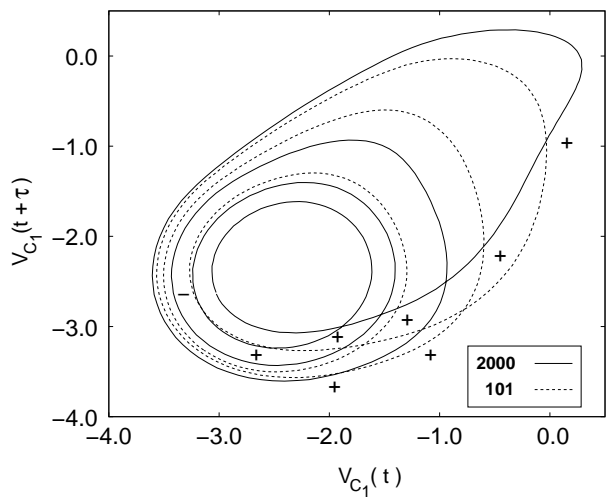

(f)

Figura 2.24: Números de ligações $\lg \left(\mathcal{O}_{1}, \mathcal{O}_{2}\right)$ de pares de OPIs $\mathcal{O}_{1}$ e $\mathcal{O}_{2}$ extraídas do atrator reconstruído $X_{-42}$. (a) $\operatorname{alg}(200)=+2$; (b) $\lg (10,100)=+2$; (c) $\lg (10,1000)=+2$; (d) $\lg (10,2000)=+2$; (e) $\lg (10,200)=+2$; (f) $\lg (101,2000)=+3$. 


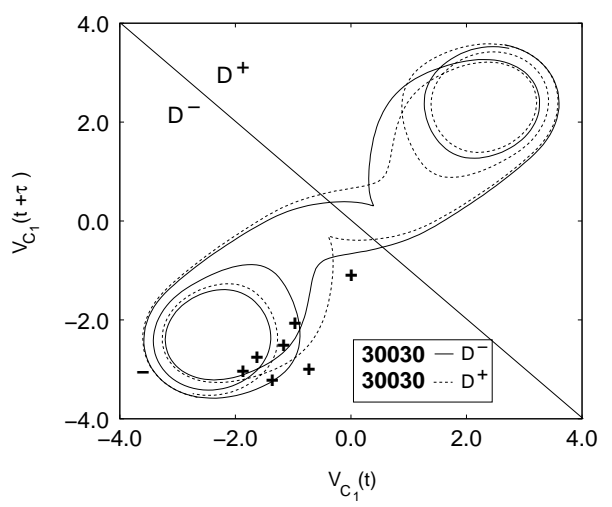

(a)

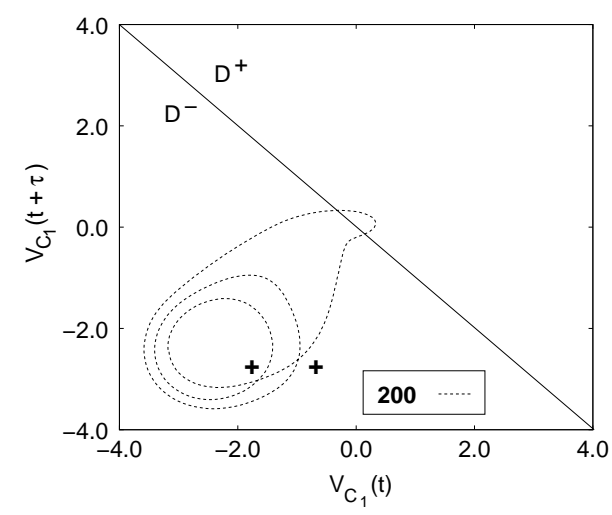

(c)

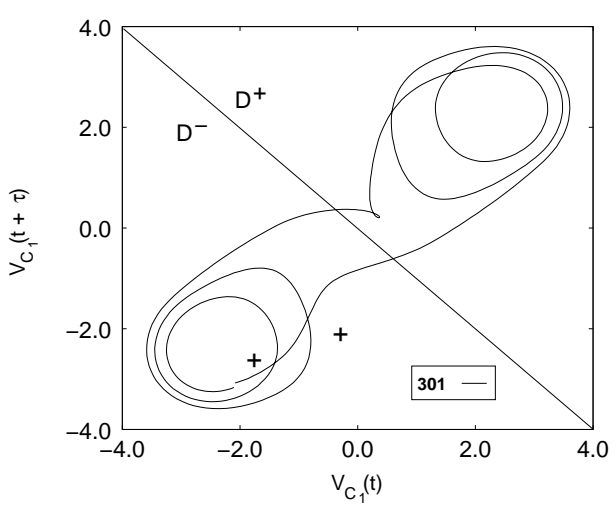

(b)

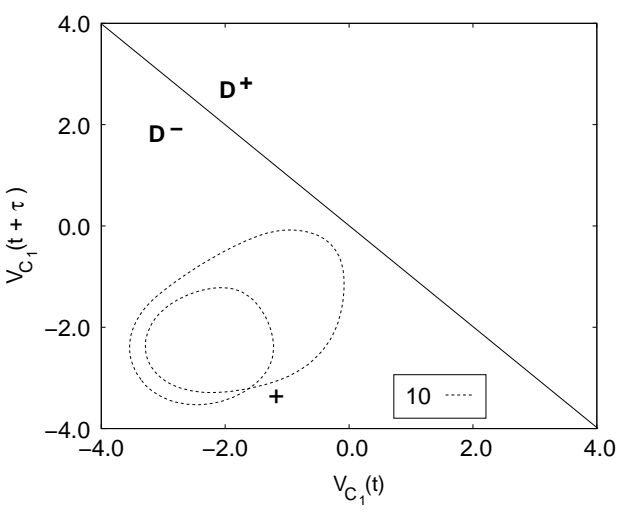

(d)

Figura 2.25: Números de ligações $\lg \left(\mathcal{O}_{1}, \mathcal{O}_{2}\right)$ de pares de OPls $\mathcal{O}_{1}$ e $\mathcal{O}_{2}$ extraídas do atrator reconstruído $X_{-47}$. (a) $\operatorname{alg}(30030)=+6$; (b) $\operatorname{alg}(301)=+2$; (c) $\operatorname{alg}(200)=+2$; (d) $\lg (10)=$ +1 . 


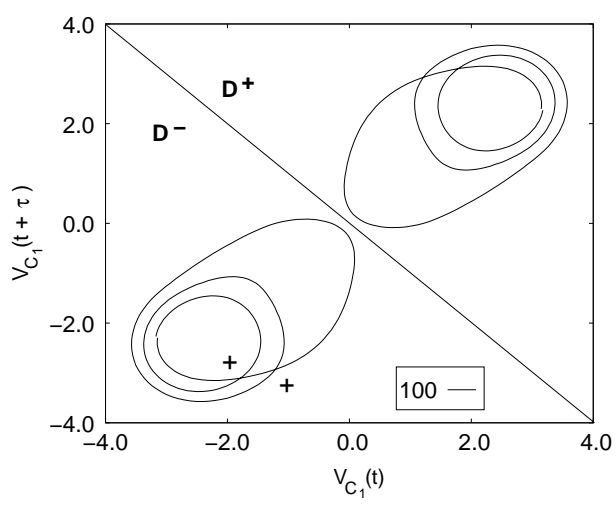

(a)

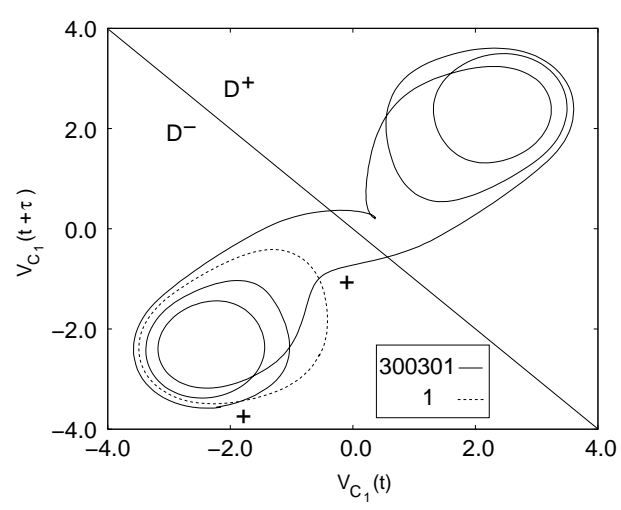

(c)

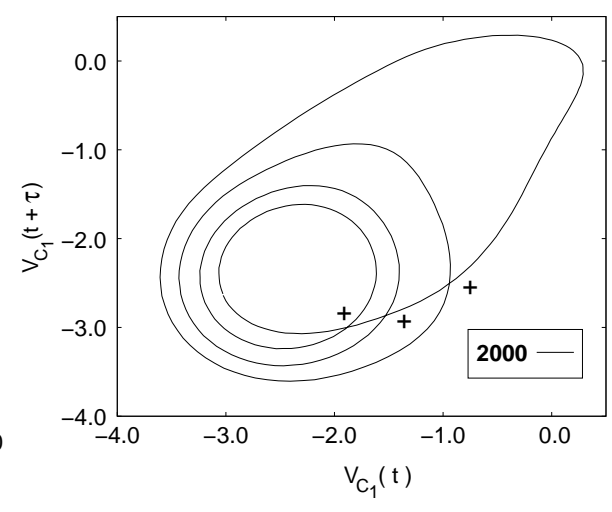

(b)

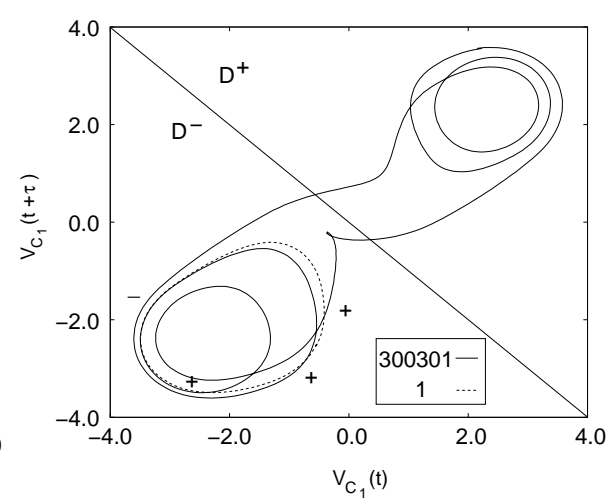

(d)

Figura 2.26: Números de ligações $\lg \left(\mathcal{O}_{1}, \mathcal{O}_{2}\right)$ de pares de OPIs $\mathcal{O}_{1}$ e $\mathcal{O}_{2}$ extraídas do atrator reconstruído $X_{-47}$. (a) $\operatorname{alg}(100)=+2$; (b) $\operatorname{alg}(2000)=+3$. Em (c) e (d) temos o número de ligações entre as órbitas $\overline{300301}$ e $\overline{1}, \lg (300301,1)=+2$, computado como metade da soma dos cruzamentos ocorridos em $D^{-}$e $D^{+}$. 


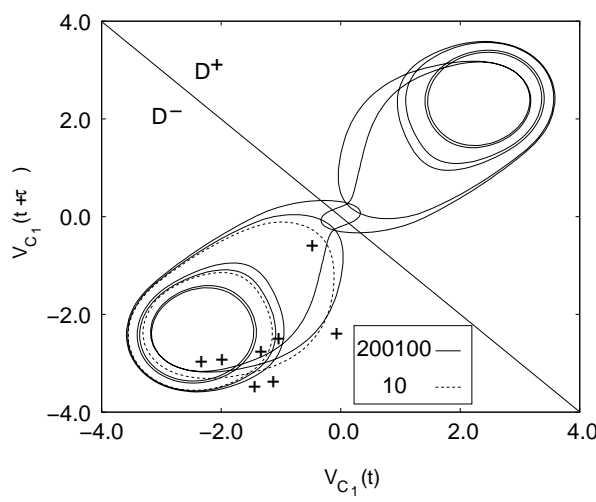

(a)

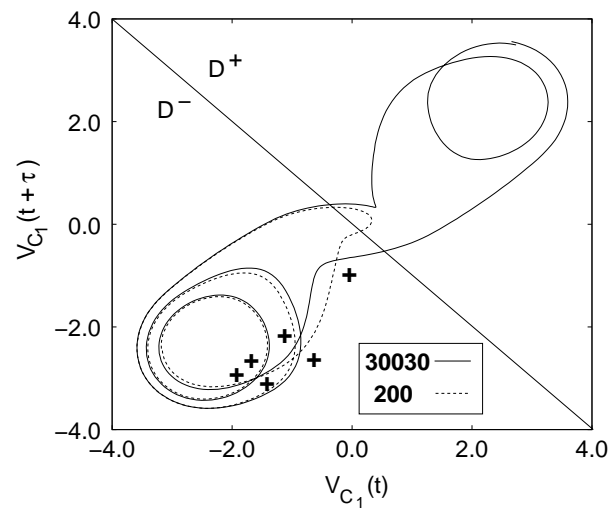

(c)

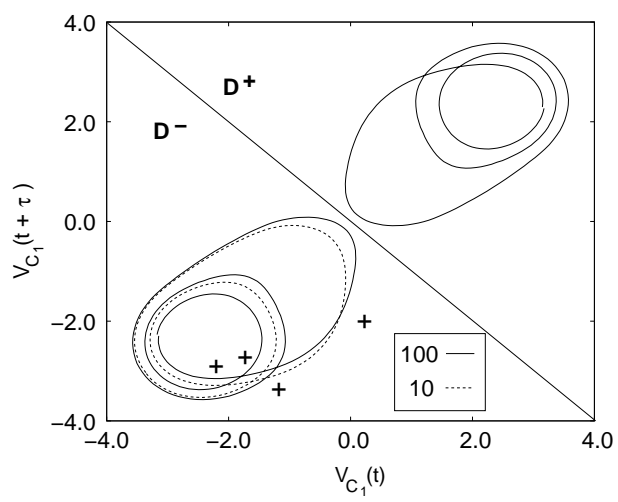

(b)

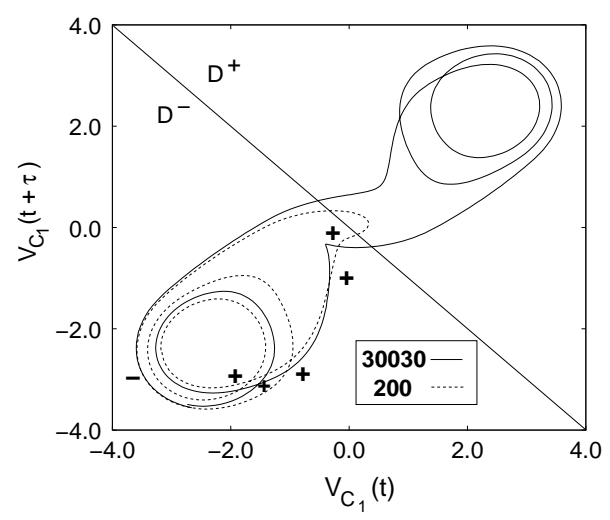

(d)

Figura 2.27: Números de ligações $\lg \left(\mathcal{O}_{1}, \mathcal{O}_{2}\right)$ de pares de OPIs $\mathcal{O}_{1}$ e $\mathcal{O}_{2}$ extraídas do atrator reconstruído $X_{-47}$. (a) $\lg (200100,10)=+4$; (b) $\lg (10,100)=+2$. Em (c) e (d) temos o número de ligações entre as órbitas $\overline{30030}$ e $\overline{200}, \lg (30030,200)=+2$, computado como metade da soma dos cruzamentos ocorridos em $D^{-}$e $D^{+}$ 


\subsubsection{O molde topológico e a crise por fusão}

\section{A. Crise por fusão}

No circuito de Chua o atrator duplo-rolo surge após uma crise interna conhecida como crise por fusão [56] entre dois atratores do tipo Rössler dobrado. A crise ocorre quando os dois atratores Rössler dobrados colidem com a fronteira entre suas respectivas bacias de atração e com o ponto de sela. Esse fenômeno pode ser observado através da simulação numérica do circuito de Chua [eq. (2.2)]. Nas figuras 2.28(a), (b) e (c) vemos como a bacia de atração e os atratores no circuito de Chua evoluem ao variarmos o parâmetro $\Delta R_{2}$ próximo da crise. Na figura $2.28(\mathrm{a})\left(\Delta R_{2}=1,899 \Omega\right)$ os atratores

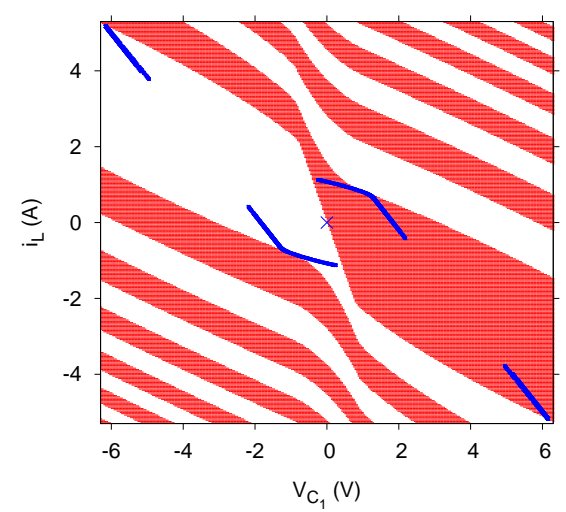

(a)

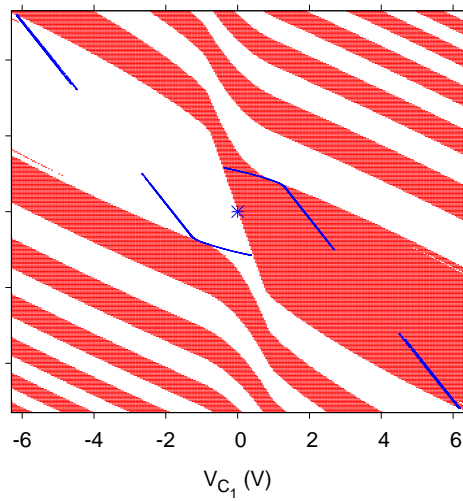

(b)

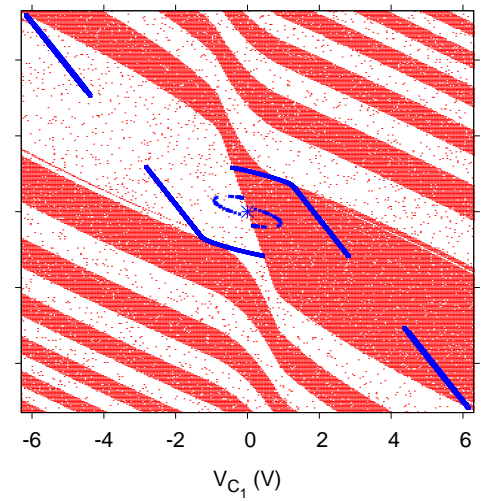

(c)

Figura 2.28: Seção no plano $V_{C_{1}}$ vs $i_{L}$ mostrando em corte os dois atratores Rössler-dobrados coexistentes e suas respectivas bacias de atração para uma simulação do circuito de Chua (parâmetros $R_{01}=1695 \Omega$ e $R_{02}=36,5 \Omega$ ). Em (a) $\Delta R_{1}=3,798 \Omega$ e $\Delta R_{2}=1,899 \Omega$ antes de ocorrer a crise por fusão. Em (b) $\Delta R_{2}=2,170 \Omega$ e os atratores estão próximos da fronteira entre as bacias onde se localiza o ponto fixo de sela $(0,0,0)$. $\operatorname{Em}\left(\right.$ c) $\Delta R_{2}=2,313 \Omega$ e os atratores tocam a fronteira entre as bacias e o ponto de sela $(0,0,0)$.

estão longe da fronteira entre as bacias. Ao variarmos o parâmetro $\Delta R_{2}$ os atratores se aproximam da fronteira e suas bacias mudam ligeiramente, como pode ser observado na figura $2.28(\mathrm{~b})$ onde $\Delta R_{2}=2,170 \Omega$. Muito próximo da crise $\left(\Delta R_{2}=2,313 \Omega\right)$ a mudança nas bacias é bem visível na figura 2.28(c), onde podemos observar o surgimento de estruturas alongadas tocando os atratores. Essas estruturas correspondem às tangências entre a variável estável, aproximadamente na fronteira das bacias de atração, e a variedade instável, aproximadamente ao longo dos atratores, associadas ao 


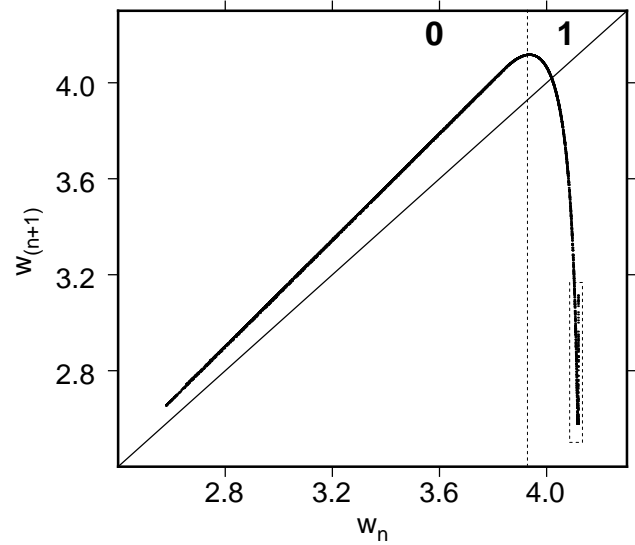

(a)

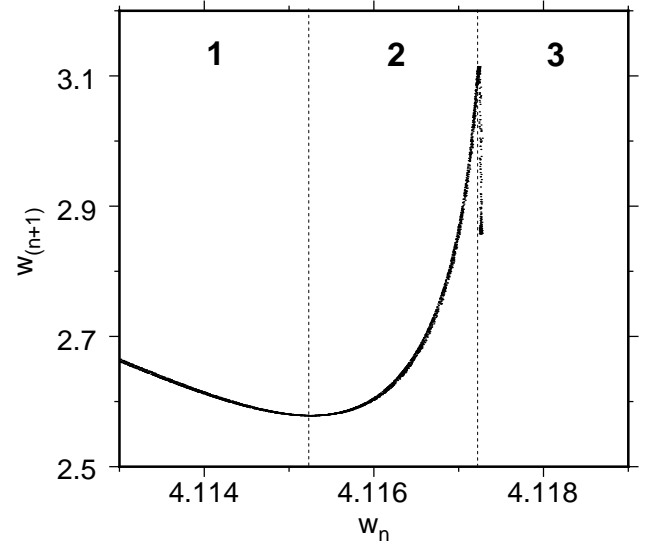

(b)

Figura 2.29: (a) Mapa de retorno para o circuito de Chua obtido pela integração numérica do sistema (2.2), com parâmetros $\Delta R_{1}=3,798 \Omega$ e $\Delta R_{2}=2,314 \Omega$ e coordenadas $w_{n+1}$ vs $w_{n}$ onde $w_{n}=\left|V_{C_{2}}^{(n)}\right|+1,25\left|i_{L}^{(n)}\right|$. (b) Ampliação mostrando o surgimento do quarto ramo.

ponto fixo de sela $(0,0,0)$ localizado na fronteira entre as bacias [74], visível no centro das figuras 2.28(a), (b) e (c). No momento em que a crise ocorre, os dois atratores colidem também com o ponto de sela $(0,0,0)$, como podemos observar no centro da figura $2.28(\mathrm{c})$.

\section{B. Regiões topológicas e molde com n-ramos}

O comportamento dinâmico do circuito de Chua muda a medida que aumentamos o parâmetro $\Delta R_{2}$ em direção à crise, com o acréscimo de novas regiões topológicas acessíveis aos atratores. Assim, vemos que os atratores do tipo Rössler, formados por duas regiões topológicas, a região de estiramento $\mathbf{0}$ (zero torções) e a dobra 1 (1 torção $=+\pi$ rad), mudam para os atratores Rössler dobrados antes da crise por fusão ocorrer. Os atratores Rössler dobrados apresentam, em conformidade com seu mapa de primeiro retorno, três regiões topológicas: a região $\mathbf{0}$, a região de dobra 1 e a uma segunda região de dobra 2 com 2 torções. Após o parâmetro crítico para o qual ocorre a crise por fusão, $\Delta R_{2}^{\text {fusão }} \approx 2,313 \Omega$, esses dois atratores fundem-se e geram o atrator duplo-rolo, adicionando uma nova região topológica: uma região de dobra 3 com 1 torção interligando os domínios $D^{+}$e $D^{-}$dos atratores Rössler dobrados.

Cada nova região topológica acrescentada ao molde topológico é assinalada no mapa 
de primeiro retorno como um novo ramo. A cada ramo atribuímos a paridade de sua respectiva letra simbólica, de acordo com o número de torções de $\pi$ rad da região topológica associada. Isso mostra que há uma relação direta entre os ramos dos mapas de retorno e os ramos nos moldes para o circuito de Chua.

O momento em que a região topológica 3 surge no circuito pode ser visto no mapa de retorno na figura 2.29(a) e (b) como o quarto ramo que emerge. Essa figura foi obtida a partir da integração numérica do circuito de Chua com $\Delta R_{2}=2,314 \Omega$ e os outros parâmetros idênticos aos da seção anterior. A figura 2.29(b), uma ampliação da figura 2.29(a), mostra que o ramo 3 é muito pequeno (relativamente aos outros ramos), e que também é decrescente com paridade ímpar.

Após a crise a complexidade da estrutura de regiões topológicas nos atratores aumenta à medida que o parâmetro $\Delta R_{2}$ aumenta, com o acréscimo de uma nova região topológica com torção de $+(n-2) \pi$ rad para cada ramo $n(n \geq 4)$ que emerge no mapa de retorno. Desse modo, os ramos alternam entre paridade par e ímpar e no molde são re-inseridos seguindo a ordem dada por uma estrutura espiral como mostra a figura 2.30. Nós temos observado que esse fenômeno ocorre após o surgimento do quarto ramo $(n=4)$ no mapa de primeiro retorno, ou seja, após a crise que dá origem ao atrator duplo-rolo, observada na simulação numérica.

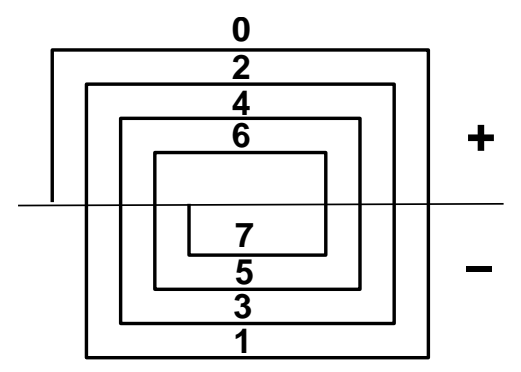

Figura 2.30: Estrutura em espiral que mostra como as regiões topológicas nos atratores do circuito de Chua são re-inseridos após a crise por fusão. O número de torções cresce para o interior da espiral e define a paridade, onde ramos com paridade par alternam com ramos com paridade ímpar.

Para ilustrar o sucessivo acréscimo de ramos, a figura 2.31(a) e sua ampliação (b), mostram o mapa de primeiro retorno para o circuito de Chua, integrado numericamente, no regime dinâmico caracterizado pelo atrator duplo-rolo com parâmetro $\Delta R_{2}=2,992 \Omega>\Delta R_{2}^{\text {fusão. }}$. Podemos observar na figura 2.31 (b) que os ramos se sucedem alternando sua paridade, onde um ramo crescente é seguido por um ramo decrescente. A figura (b) mostra ramos largos acompanhados de uma sucessão de ramos 
muito estreitos e difíceis de observar. Os ramos estreitos são ainda afetados pelo caráter bidimensional do mapa de retorno, como pode ser visto na ampliação do mapa na figura $2.31(\mathrm{c})$.

Reunindo os resultados acima, propomos um molde topológico para o circuito de Chua, na forma de uma matriz quadrada de ordem $n$ (com $n$ ramos), válido na região $\Psi$ do espaço de parâmetros, após a janela de período quatro, ou seja,

$$
T_{\text {Chua }}^{(n)}=\left[\begin{array}{ccccccccc}
0 & 0 & 0 & 0 & 0 & \ldots & 0 & 0 & 0 \\
0 & 1 & 1 & 1 & 1 & \ldots & 1 & 1 & 1 \\
0 & 1 & 2 & 2 & 2 & \ldots & 2 & 2 & 2 \\
0 & 1 & 2 & 1 & 1 & \ldots & 1 & 1 & 1 \\
0 & 1 & 2 & 1 & 2 & \ldots & 2 & 2 & 2 \\
\ldots & \ldots & \ldots & \ldots & \ldots & \ldots \ldots \ldots \\
0 & 1 & 2 & 1 & 2 & \ldots & (n-5) & (n-5) & (n-5) \\
0 & 1 & 2 & 1 & 2 & \ldots & (n-5) & (n-4) & (n-4) \\
0 & 1 & 2 & 1 & 2 & \ldots & (n-5) & (n-4) & (n-3)
\end{array}\right]
$$

Podemos notar que as matrizes para os atratores do tipo Rössler $T_{X_{-27}}$ [eq.(2.6)] e Rössler dobrado $T_{X_{-42}}$ [eq.(2.16)] são sub-matrizes de $T_{\text {Chua }}^{(n)}$, de modo que o molde dado pela relação (2.64) preserva, em sua estrutura, a topologia encontrada nos atratores Rössler e Rössler dobrado. A relação (2.64) é válida para $n \geq 4$ ramos, enquanto as bifurcações no circuito de Chua originarem novas regiões topológicas nos atratores e não houver aniquilamentos de regiões topológicas (aniquilamento de ramos nos moldes) na região $\Psi$ do espaço de parâmetros para o circuito. 


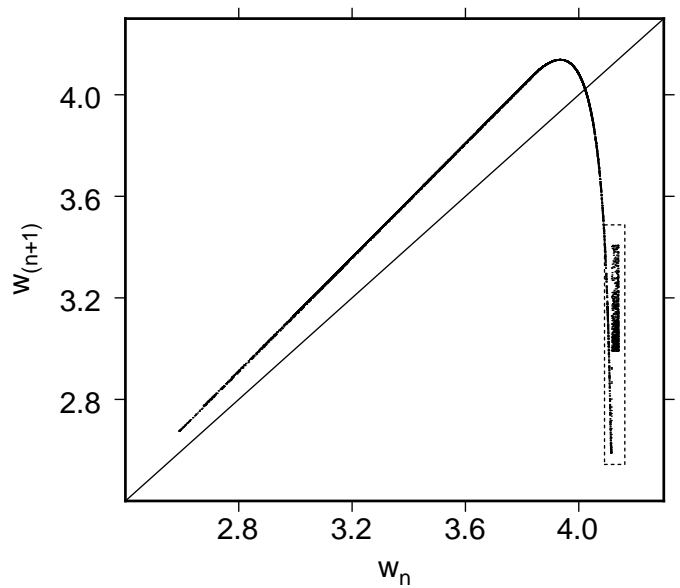

(a)

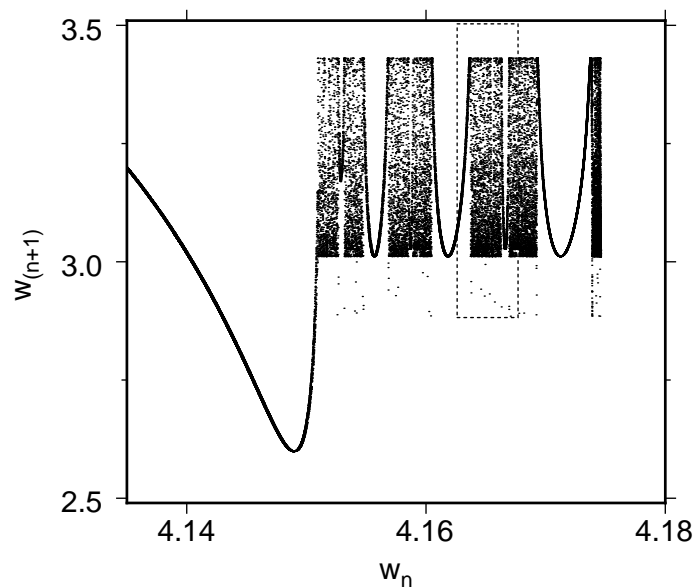

(b)

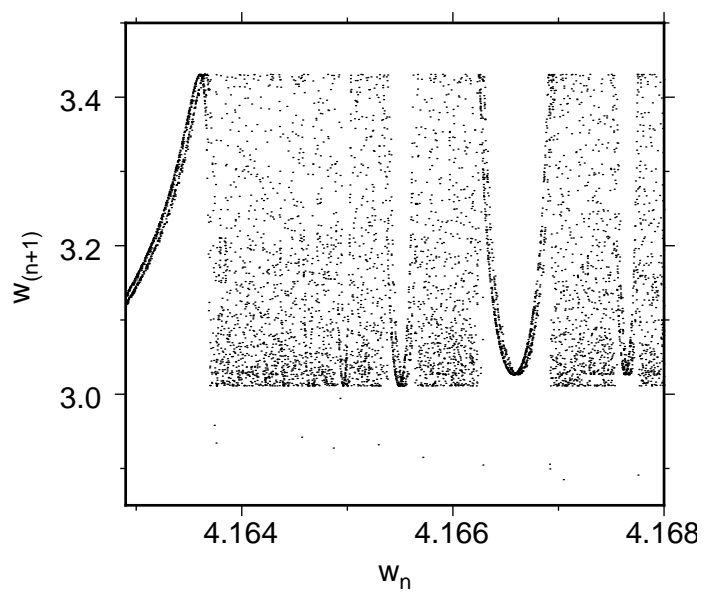

(c)

Figura 2.31: (a) Mapa de retorno $w_{n+1}$ vs $w_{n}$ para o circuito de Chua obtido pela integração numérica do sistema (2.2) com parâmetros $\Delta R_{1}=3,7985 \Omega$ e $\Delta R_{2}=2,992 \Omega>\Delta R_{2}^{\text {fusão. }}$. (b) Ampliação da região no interior do retângulo em (a) mostrando múltiplos ramos no mapa de retorno, cada um alternando sua paridade em relação ao anterior. (c) Ampliação do retângulo em (b) mostrando a presença de diversos ramos de largura muito estreita e exibindo estruturas bidimensionais. 


\subsection{Topologia das janelas periódicas no espaço de parâmetros}

O espaço de parâmetros $\left(\Delta R_{2}, \Delta R_{1}\right)$ para o circuito experimental de Chua, que pode ser visto na figura 1.16, apresenta estruturas periódicas em forma de janelas. As órbitas que compõe o interior das janelas podem ser estudadas através da dinâmica simbólica aplicada aos mapas bimodais unidimensionais. As bifurcações das órbitas que formam as janelas, quando interpretadas através de mapas bimodais, originam estruturas no espaço de parâmetros conhecidas como "swallow-tails" [25, 26], semelhantes aos camarões ("shrimps") definidos em [23]. Nessa seção mostraremos que essas estruturas estão presentes no circuito experimental de Chua.

\subsubsection{Dinâmica simbólica das órbitas no interior das janelas}

A dinâmica simbólica para as órbitas periódicas no interior das janela foi obtida através da localização das sucessivas intersecções dessas órbitas em uma seção de Poincaré e sobrepondo-as aos ramos do mapa de retorno dos atratores caóticos, cujos valores dos parâmetros de controle os situam vizinhos às janelas, ou seja, atratores localizados imediatamente fora das janelas [64]. As regiões analisadas situam-se nas bordas das janelas, como mostrado no espaço de parâmetros na figura 2.32. As figuras 2.34, 2.35, 2.36 e 2.37 mostram a aplicação desse procedimento para as regiões I, II, III e IV, respectivamente.

No diagrama de bifurcações para o circuito, figuras 2.2 e 2.18, podemos observar o acúmulo de pontos ao longo de determinadas direções, formando estruturas que compõe o esqueleto do diagrama. Essas regiões se formam pela acumulação das iteradas do sistema dinâmico ao redor dos pontos críticos $x_{C_{i}}, i=1,2, \ldots$, do mapa de retorno. Para um mapa de retorno de um sistema unidimensional, as tangências entre as linhas que formam o esqueleto mostram as localizações das janelas periódicas no diagrama de bifurcações [36], e a aproximação das tangências provoca a acumulação de pontos ao redor da órbita periódica da janela. Esse fenômeno é observado quando surgem as janelas de período três e de período quatro nos diagramas de bifurcações do circuito, conforme vemos nas figuras 2.2 e 2.18. Sendo assim, podemos esperar que as órbitas periódicas no interior das janelas sejam suportadas por mapas unidimensionais cujas curvas, em uma primeira aproximação, podem ser obtidas dos atratores caóticos vizinhos às janelas periódicas. 


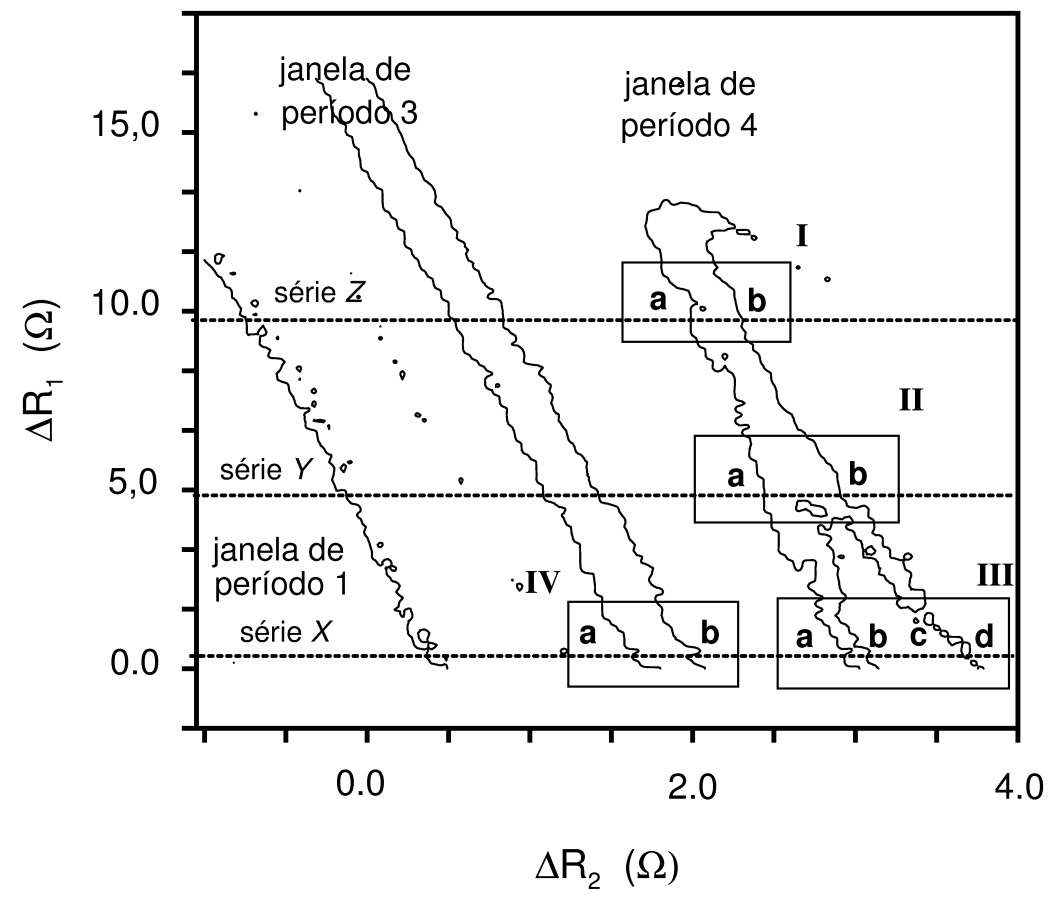

Figura 2.32: Espaço de parâmetros para o circuito de experimental de Chua destacando as regiões I, II e III localizadas nas bordas da janela de período quatro e região IV nas bordas da janela de período três.

A acumulação das iteradas dos mapas em torno das órbitas de período três e quatro nas vizinhanças das duas janelas podem ser quantificadas através dos histogramas de retorno aproximado, que foram discutidos nas seções 1.2.2 e 2.5.2. Procuramos, então, pelos retornos que geram ciclos de períodos que sejam múltiplos de $T=86 \times(2,5 \mu \mathrm{s})$ para três séries temporais nas bordas da janela de período quatro: $X_{-35}, Y_{-39}$ e $Z_{-30}$. Os resultados estão na figura 2.33, onde o quarto pico dos histogramas, indicando um ciclo de período $4 T$, é maior que os demais. Resultado similar a este foi obtido para a borda da janela de período três (veja figura 2.13).

A sobreposição das órbitas periódicas das janelas sobre os mapas de retorno dos atratores situados nas bordas das janelas permite a codificação simbólica, uma vez estabelecida as partições e os moldes topológicos dos atratores. Uma órbita é identificada por uma seqüência $\overline{s_{1} s_{2} \ldots s_{n}}$, composta por um alfabeto de três símbolos $s_{i}=\{0,1,2\}$, representando o itinerário $1 \rightarrow 2 \rightarrow \ldots \rightarrow n$ da órbita no mapa de retorno [o numeral no itinerário corresponde a intersecção com a seção de Poincaré $P_{V_{C_{1}}}^{(-)}$, eq. (2.5)]. As figuras $2.34,2.35,2.36$ e 2.37 mostram que os mapas de retorno para as bordas nas regiões I, II, III e IV são, aproximadamente, unidimensionais e de dois tipos: unimodal 


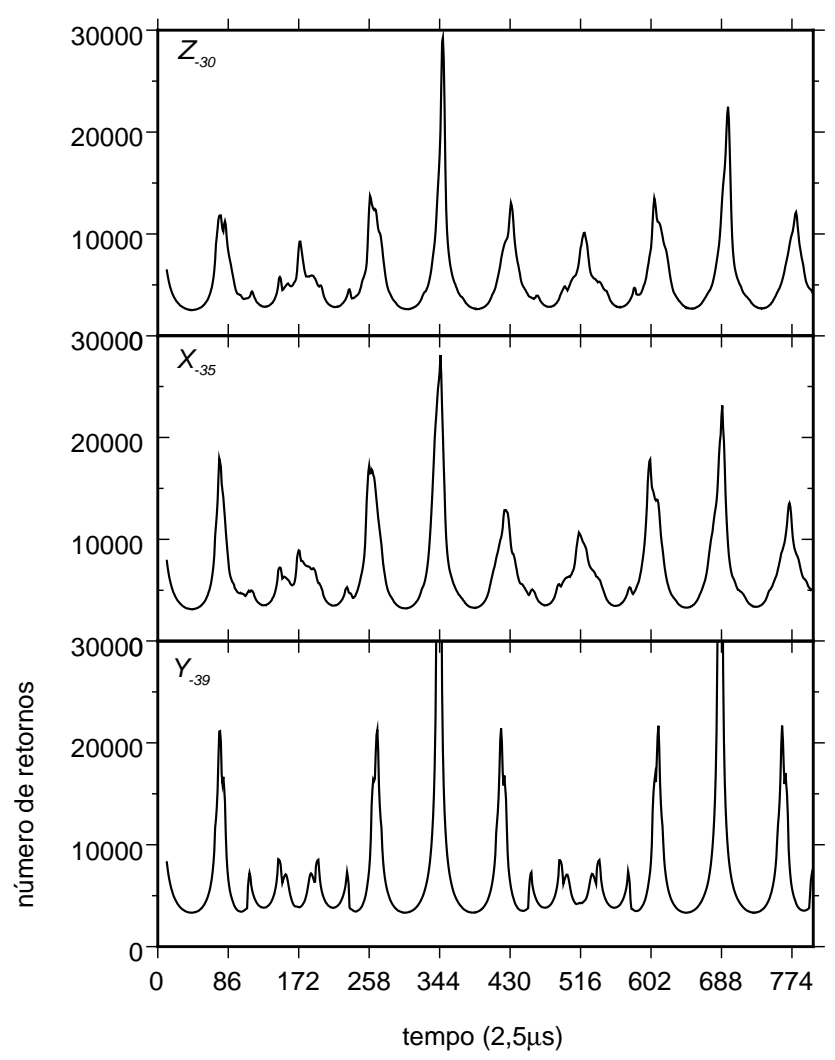

Figura 2.33: Histogramas de retorno aproximado em três pontos das bordas da janela de período quatro. A grande contagem para o quarto pico mostra o acumulo das iteradas dos mapas ao redor da órbita de período quatro.

e bimodal. Logo, esses mapas podem ser particionados pelos pontos críticos $\left(x_{C_{1}}\right.$ para o ponto de máximo e $x_{C_{2}}$ para o ponto de mínimo). As dinâmicas associadas a estes dois mapas são devidas aos atratores do tipo Rössler e Rössler-dobrado, cujos moldes topológicos foram estabelecidos na seção 2.6.3.

Para a janela de período quatro $(n=4)$, as bordas a e $\mathbf{b}$ nas regiões I e II [figuras 2.34(A) e (B) e 2.35(A) e (B), respectivamente] fornecem as seqüências simbólicas $\overline{1001}$ e $\overline{2001}$. A região III compreende as bordas a, b, c e d [figuras 2.36(A), (B), (C) e (D)] e fornecem as seqüências $\overline{1001}, \overline{1000}, \overline{2000}$ e $\overline{2000}$, respectivamente. Por fim, para a janela de período 3, as bordas a e b da região IV [figuras 2.37(A) e (B), respectivamente] fornecem as seqüências $\overline{101}$ e $\overline{100}$. As seqüências simbólicas para as bordas das janelas de períodos três e quatro, obtidas como descrito acima, estão reunidas no espaço de parâmetros esquemático na figura 2.38. 

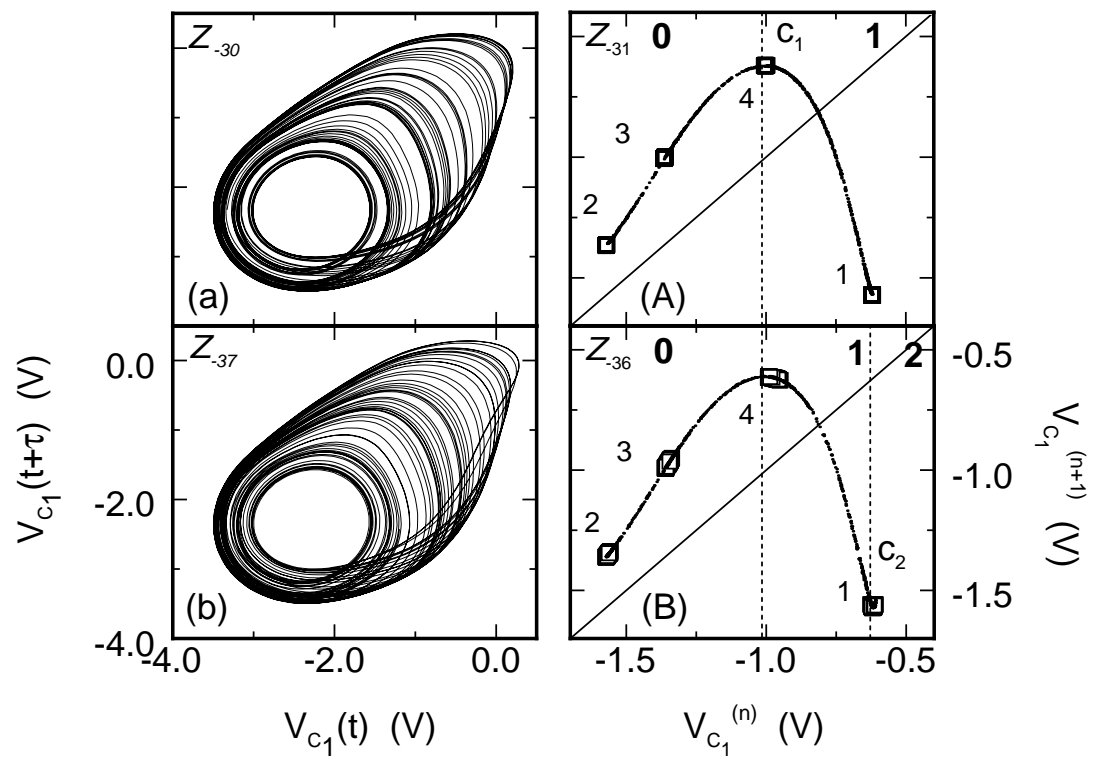

Figura 2.34: Atratores em (a) e (b) situados nas bordas a e b da região I, reconstruídos a partir das séries $Z_{J}, J=-30$ e $-37\left(J=\right.$ número de deslocamentos do motor de passo $\Delta R_{2}$, veja seção 2.6.1). Órbitas periódicas $\overline{1001}$ (A) e $\overline{2001}$ (B), sobrepostas aos mapas de retorno para os atratores em (a) e (b), respectivamente.

\subsubsection{Bifurcações e as janelas periódicas}

Podemos entender como ocorrem as mudanças das órbitas no interior das janelas de período três e de período quatro analisando o que acontece com suas representações simbólicas ao cruzarem as regiões de super estabilidade. Por simplicidade, exemplificaremos o processo para um sistema definido por um mapa unimodal (com um único ponto crítico).

Em um mapa unimodal as órbitas periódicas são criadas, em geral, por dois tipos de bifurcações: (1) sela-nó que origina um par de órbitas de período $n$, uma estável e outra instável ou (2) duplicação de período originando uma órbita estável de período $2 n$, enquanto que a órbita de período $n$ torna-se instável. Imediatamente após uma bifurcação sela-nó as duas órbitas criadas apresentam o mesmo itinerário, dado pela seqüência simbólica $\overline{s_{1} s_{2} \ldots s_{n}}$, com número ímpar de símbolos $\mathbf{1}$ e parâmetro topológico (definido na seção 1.2.5) $\kappa\left(\overline{s_{1} s_{2} \ldots s_{n}}\right)=\gamma\left(\overline{s_{1} s_{2} \ldots s_{n}}\right)$. As órbitas com esse itinerário existem enquando o mapa apresentar $\kappa \geqslant \gamma\left(\overline{s_{1} s_{2} \ldots s_{n}}\right)$. Ao variarmos o parâmetro de controle a órbita estável atravessa a região de super estabilidade, de modo que o ponto periódico mais próximo do ponto crítico do mapa cruza o ponto crítico e muda 

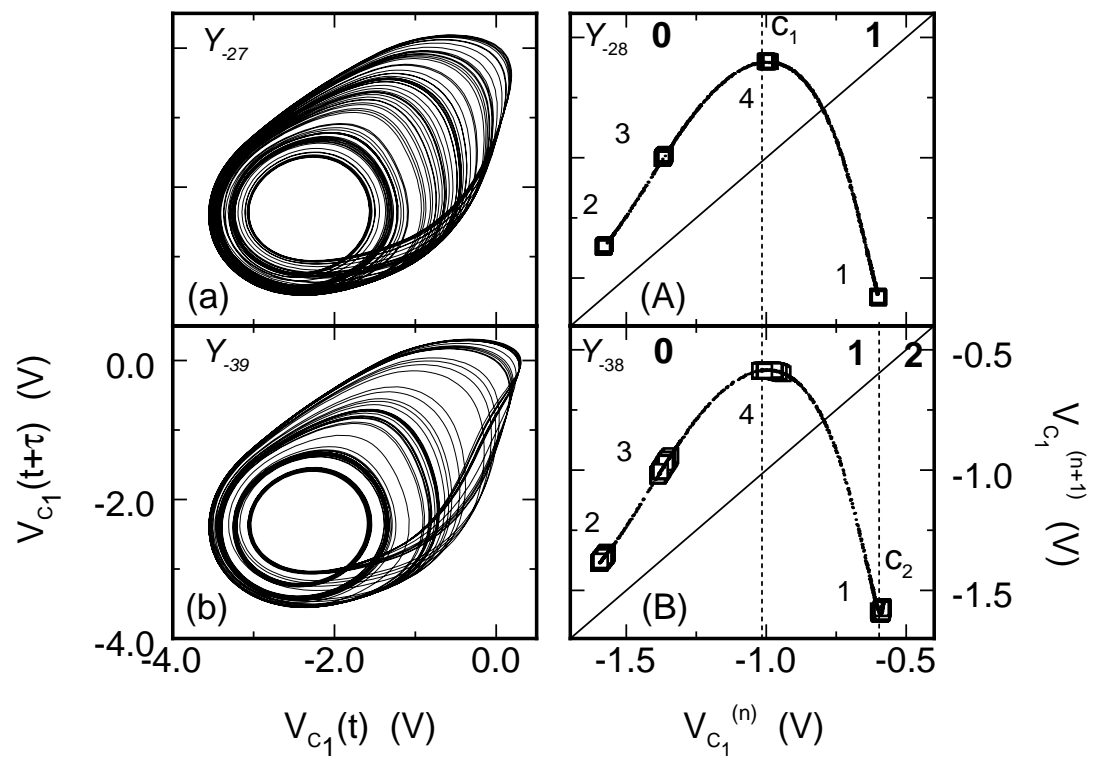

Figura 2.35: Atratores em (a) e (b) situados nas bordas a e b da região II, reconstruídos a partir das séries $Y_{J}, J=-27$ e -39 . Órbitas periódicas $\overline{1001}$ (A) e $\overline{2001}$ (B), sobrepostas aos mapas de retorno para os atratores em (a) e (b), respectivamente.

a dinâmica simbólica da órbita para $\overline{s_{1} s_{2} \ldots s_{n-1}\left(1-s_{n}\right)}$. O parâmetro topológico da órbita estável é agora $\kappa\left(\overline{s_{1} s_{2} \ldots\left(1-s_{n}\right)}\right)$, assumindo que $\overline{s_{1} s_{2} \ldots s_{n}}$ é a permutação cíclica com maior valor de $\gamma$. Assim o intervalo de parâmetros topológicos

$$
\left[\kappa\left(\overline{s_{1} s_{2} \ldots s_{n}}\right), \kappa\left(\overline{s_{1} s_{2} \ldots s_{n-1}\left(1-s_{n}\right)}\right)\right]
$$

definido pelas duas órbitas é dito inacessível ao sistema (não há outras representações das órbitas com valores intermediários de $\kappa$ ) e esta relacionado com intervalo do parâmetro de controle entre a bifurcação sela-nó e o ponto super-estável, ou seja, o intervalo onde a órbita periódica $\overline{s_{1} s_{2} \ldots s_{n-1}\left(1-s_{n}\right)}$ é estável.

A duplicação de período da órbita também leva a um intervalo inacessível de parâmetros $\kappa$. Após sua passagem pelo ponto crítico, a órbita estável $\overline{s_{1} s_{2} \ldots\left(1-s_{n}\right)}$ bifurca e muda sua representação simbólica para $\overline{s_{1} s_{2} \ldots\left(1-s_{n}\right) s_{1} s_{2} \ldots s_{n}}$, levando ao intervalo inacessível

$$
\left[\kappa\left(\overline{s_{1} s_{2} \ldots s_{n-1}\left(1-s_{n}\right)}\right), \kappa\left(\overline{s_{1} s_{2} \ldots s_{n-1}\left(1-s_{n}\right) s_{1} \ldots s_{n}}\right)\right]
$$

que corresponde ao intervalo do parâmetro de controle onde a órbita $\overline{s_{1} s_{2} \ldots\left(1-s_{n}\right)}$ é super-estável até onde a órbita $\overline{s_{1} s_{2} \ldots s_{n-1}\left(1-s_{n}\right) s_{1} \ldots s_{n}}$ é super-estável. 

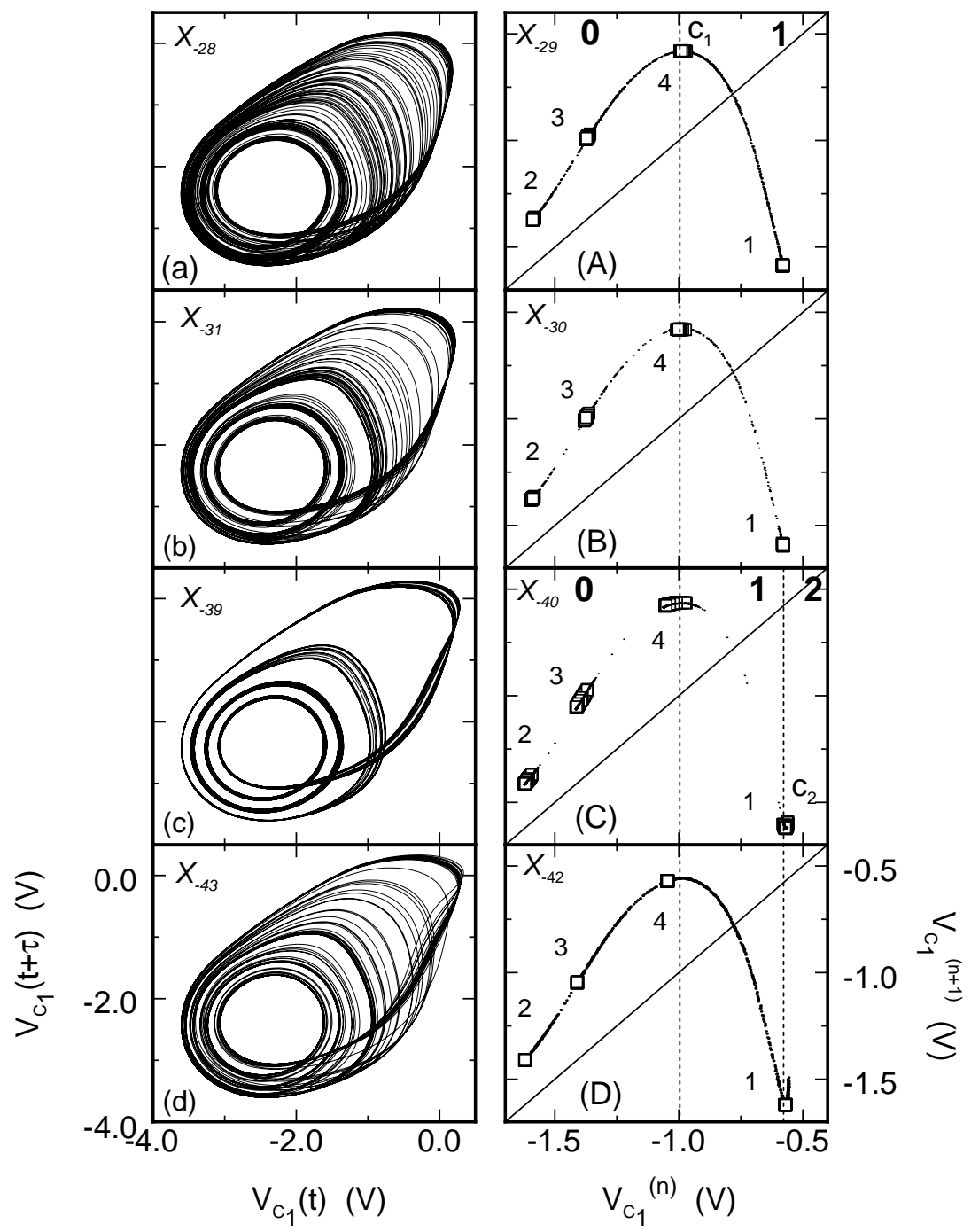

Figura 2.36: Atratores em (a), (b), (c) e (d) situados nas bordas a e b, c e d da região III, reconstruídos à partir das séries $X_{J}, J=-28,-31,-39$ e -43 . Órbitas periódicas $\overline{1001}(\mathrm{~A})$, $\overline{1000}$ (B), $\overline{2000}$ (C) e $\overline{2000}$ (D), sobrepostas aos mapas de retorno para os atratores em (a), (b), (c) e (d), respectivamente.

Esse processo pode ser generalizado para mapas bimodais com dois parâmetros topológicos $\kappa_{1}$ e $\kappa_{2}$ (associados aos dois pontos críticos $x_{C_{1}}$ e $x_{C_{2}}$ ) e aplicado nas diferentes representações simbólicas das órbitas estáveis encontradas nas janelas de período três e quatro no espaço de parâmetros do circuito de Chua.

$\mathrm{Na}$ figura 2.38, a representação esquemática do espaço de parâmetros, vemos as mudanças que as órbitas periódicas sofrem no interior das janelas de período três e quatro com a variação dos parâmetros $\Delta R_{1}$ e $\Delta R_{2}$. Na janela de período quatro, a 

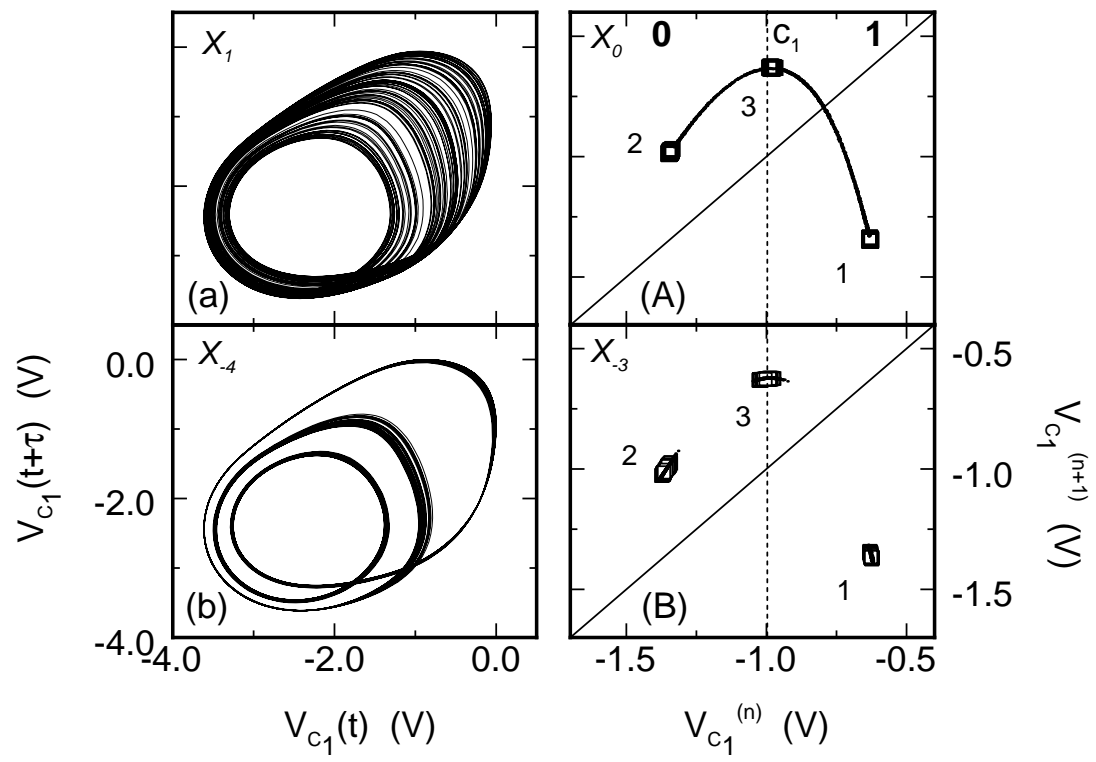

Figura 2.37: Atratores em (a) e (b) situados nas bordas a e b da região IV (janela de período 3), reconstruídos a partir das séries $X_{J}, J=1 \mathrm{e}-4$. Órbitas periódicas $\overline{101}$ (A) e $\overline{100}$ (B), sobrepostas aos mapas de retorno para os atratores em (a) e (b), respectivamente.

órbita representada por $\overline{1001}$ muda para $\overline{1000}$ quando seu ponto periódico 4 passar pelo ponto crítico $x_{C_{1}}$ do mapa de retorno, conforme mostram as figuras $2.36(\mathrm{~A})$ e $(\mathrm{B})$, ou então muda para $\overline{2001}$ se o ponto periódico 1 passar pelo ponto crítico $x_{C_{2}}$, de acordo com as figuras 2.34(A) e (B). A seqüência $\overline{2000}$ muda para $\overline{2001}$ se o ponto periódico 4 passar pelo ponto crítico $x_{C_{1}}$ (não observado), ou então para $\overline{1000}$ se o ponto periódico 1 passar por $x_{C_{2}}$ (também não observado). Para a janela de período 3 a órbita $\overline{101}$ muda para $\overline{100}$ após a passagem do ponto periódico 3 pelo ponto crítico $x_{C_{1}}$, como mostram as figuras 2.37(A) e (B). Reunindo esses resultados, as dinâmicas das órbitas no interior das janelas podem ser representadas por duas seqüências: $\overline{10 \epsilon}$ para a janela de período três, onde $\epsilon$ pode ser 0 ou 1 , e $\overline{\epsilon_{1} 00 \epsilon_{2}}$ para a janela de período quatro, onde $\epsilon_{1} \in\{1,2\}$ e $\epsilon_{2} \in\{0,1\}$.

A figura 2.38 também mostra a órbita super-estável responsável pelas mudanças na descrição simbólica das órbitas no interior das janelas. As duas curvas que definem a órbita super-estável para a janela de período quatro, apresentam idênticas descrições simbólicas: $\overline{C_{2} 00 C_{1}}$. Entretanto, elas podem ser diferenciadas se introduzirmos os símbolos $\epsilon_{1}$ e $\epsilon_{2}$ em suas representações.

Assim a curva super-estável com $C_{1}$ constante é representada por $\overline{\epsilon_{1} 00 C_{1}}$, onde $\epsilon_{1}$ 


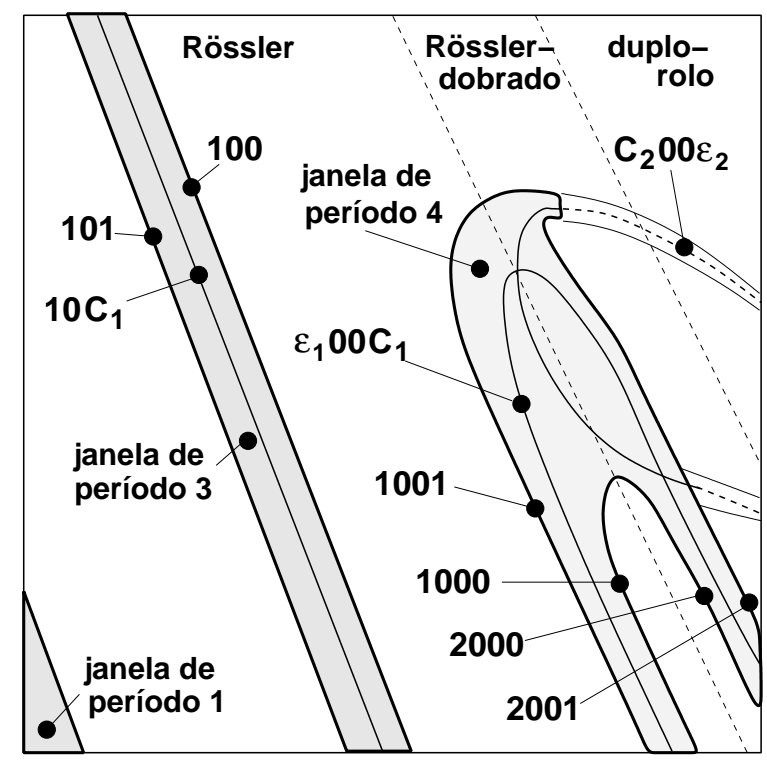

Figura 2.38: Seqüências simbólicas encontradas nas bordas das janelas de período três e quatro do espaço de parâmetros $\left(\Delta R_{1}, \Delta R_{2}\right)$ para o circuito de Chua. As bordas da janela de período quatro são formadas por órbitas representadas por quatro seqüências: $\overline{1001}, \overline{1000}, \overline{2000}$ e $\overline{2001}$. No interior dessa janela a órbita super-estável $\overline{C_{2} 00 C_{1}}$ é descrita por duas curvas: $\overline{\epsilon_{1} 00 C_{1}}, \epsilon_{1} \in\{1,2\}$ e $\overline{C_{2} 00 \epsilon_{2}}, \epsilon_{2} \in\{0,1\}$. As bordas da janela de período três são formadas por $\overline{101}$ e $\overline{100}$ com órbita super-estável $\overline{10 C_{1}}$. As linhas pontilhadas ao longo do espaço de parâmetros separam os três tipos de atratores: Rössler, Rössler-dobrado e duplo-rolo.

vale 1 ou 2, e é responsável pela mudança entre as seqüências $\overline{1001}$ e $\overline{1000}$ no caso de $\epsilon_{1}=1$, ou pela mudança entre $\overline{2000}$ e $\overline{2001}$ caso $\epsilon_{1}=2$, não observada na janela de período quatro. Já a curva super-estável com $C_{2}$ constante é representada por $\overline{C_{2} 00 \epsilon_{2}}$, onde $\epsilon_{2}=0$ ou 1 , e é responsável pela mudança entre $\overline{1001}$ e $\overline{2001}$ caso $\epsilon_{2}=1$, ou entre $\overline{2000}$ e $\overline{1000}$ caso $\epsilon_{2}=0$. Essa última mudança também não foi observada na janela de período quatro.

No interior da janela de período três existe uma única órbita super-estável, representada pela seqüência $\overline{10 C_{1}}$, que é responsável pela mudança entre as seqüências $\overline{101}$ e $\overline{100}$.

\subsubsection{Mapa bimodal e o espaço de parâmetros topológico}

$\mathrm{Na}$ vizinhança da janela de período quatro ocorre a transição do atrator do tipo Rössler para o atrator Rössler-dobrado. No espaço de parâmetros da figura 2.38 está assinalado em linha tracejada onde essa mudança ocorre. Durante a transição o mapa 
de retorno associado ao atrator do tipo Rössler desenvolve um terceiro ramo, a partir do ponto de mínimo $x_{C_{2}}$, originando um mapa bimodal. O estudo topológico das mudanças das órbitas periódicas em um mapa bimodal, como definido na seção 1.2.5, pode ser usado para caracterizar o espaço de parâmetros para o circuito de Chua e, em particular, caracterizar as janelas de período três e quatro.

Para um mapa bimodal $x_{t+1}=f\left(x_{t}\right), t=1,2, \ldots, n, \ldots$, com dois pontos críticos $x_{C_{1}}$ (máximo) e $x_{C_{2}}$ (mínimo), uma dada órbita descrita pela seqüência $X=x_{1} \rightarrow$ $x_{2} \rightarrow \ldots \rightarrow x_{n} \rightarrow \ldots$ existe se $f\left(x_{C_{2}}\right) \leq x_{t} \leq f\left(x_{C_{1}}\right)$. Fazendo uma analogia com a dinâmica simbólica, seja a seqüência $S(X)=s_{1} s_{2} \ldots s_{n} \ldots$ a representação simbólica da trajetória $X, \gamma(S)$ definido pelas relações (1.30), $K$ a seqüência simbólica extrema (seção 1.2.5) e $\sigma^{t}$ a $t$-ésima iteração do mapa de deslocamentos ("shift map"). Na linguagem da dinâmica simbólica, a órbita $S(X)$ é admissível (existe) se

$$
\kappa_{2} \leq \gamma\left[\sigma^{t-1} S(X)\right] \leq \kappa_{1}
$$

onde $\kappa_{i}=\gamma\left(K_{i}\right)=\gamma\left[S\left(x_{C_{i}}\right)\right], i=1,2$, são as coordenadas topológicas dos pontos críticos do mapa bimodal, definidas na seção 1.2.5. A condição de existência (2.65) para a órbita $S(X)$ define então uma área no plano $\left(\kappa_{1}, \kappa_{2}\right)$, área delimitada pelos valores de $\gamma^{\max }$ e $\gamma^{\text {min }}$ para essa órbita.

Para construirmos o espaço de parâmetros topológico determinamos na tabela 2.9 os valores máximos $\gamma_{1}=\gamma^{\max }(S)$ e mínimos $\gamma_{2}=\gamma^{\min }(S)$ para todos os ciclos de comprimento quatro encontrados nas bordas da janela de período quatro do espaço de parâmetros do circuito de Chua. Na tabela 2.9 determinamos também os valores $\gamma^{\max }(S)$ para os ciclos encontrados nas bordas da janela de período três. Observe que os ciclos usados para o cálculo de $\gamma^{\min }(S)$ foram obtidos através da permutação cíclica da seqüência $S$ com menor valor de $\gamma$. Os valores de $\gamma^{\max }(S)$ e $\gamma^{\min }(S)$ representam as linhas de bifurcações que dão origem às janelas, e estão representados no espaço de parâmetros topológico $\left(\kappa_{1}, \kappa_{2}\right)$ mostrado na figura 2.39. A região sombreada na figura 2.39 corresponde aos valores de $\left(\kappa_{1}, \kappa_{2}\right)$ para os quais os ciclos de período quatro $\overline{\epsilon_{1} 00 \epsilon_{2}}$, com $\epsilon_{1}=\{1,2\}$ e $\epsilon_{2}=\{0,1\}$, e de período três $\overline{10 \epsilon}$, com $\epsilon=\{0,1\}$, são estáveis no mapa bimodal.

Os ciclos representados no espaço topológico $\left(\kappa_{1}, \kappa_{2}\right)$ compõem a estrutura topológica das janelas de período três e quatro, descrevendo pictoricamente, através das mudanças em suas representações simbólicas, as órbitas super-estáveis existentes no interior das janelas. Assim a janela de período três, que surge estendida no espaço de parâmetros $\left(\Delta R_{1}, \Delta R_{2}\right)$, é descrita pela mudança entre os ciclos $\overline{101}$ e $\overline{100}$, ocasionada 
pelo cruzamento com a órbita super-estável $\overline{10 C}$ na direção de $\kappa_{1}$. Logo a janela de período três é uma estrutura de bifurcações de codimensão um.

Tabela 2.9: Valores máximos $\gamma_{1}=\gamma^{\max }(S)$ e míni$\operatorname{mos} \gamma_{2}=\gamma^{\min }(S)$ [definido pelas relações (1.30)] para as seqüências $S$ encontradas no mapa bimodal.

\begin{tabular}{ll|cl}
\hline$S$ & $\gamma_{1}$ & $S$ & $\gamma_{2}$ \\
\hline$\overline{1001}$ & $0, \overline{1221}=13 / 20$ & $\overline{0011}$ & $0, \overline{0011}=1 / 20$ \\
$\overline{1000}$ & $0, \overline{12221000}=27 / 41$ & $\overline{0001}$ & $0, \overline{00012221}=1 / 41$ \\
$\overline{2000}$ & $0, \overline{2000}=27 / 40$ & $\overline{0002}$ & $0, \overline{0002}=1 / 40$ \\
$\overline{2001}$ & $0, \overline{20010221}=28 / 41$ & $\overline{0012}$ & $0, \overline{00102212}=2 / 41$ \\
$\overline{101}$ & $0, \overline{121}=8 / 13$ & & \\
$\overline{100}$ & $0, \overline{122100}=9 / 14$ & & \\
\hline
\end{tabular}

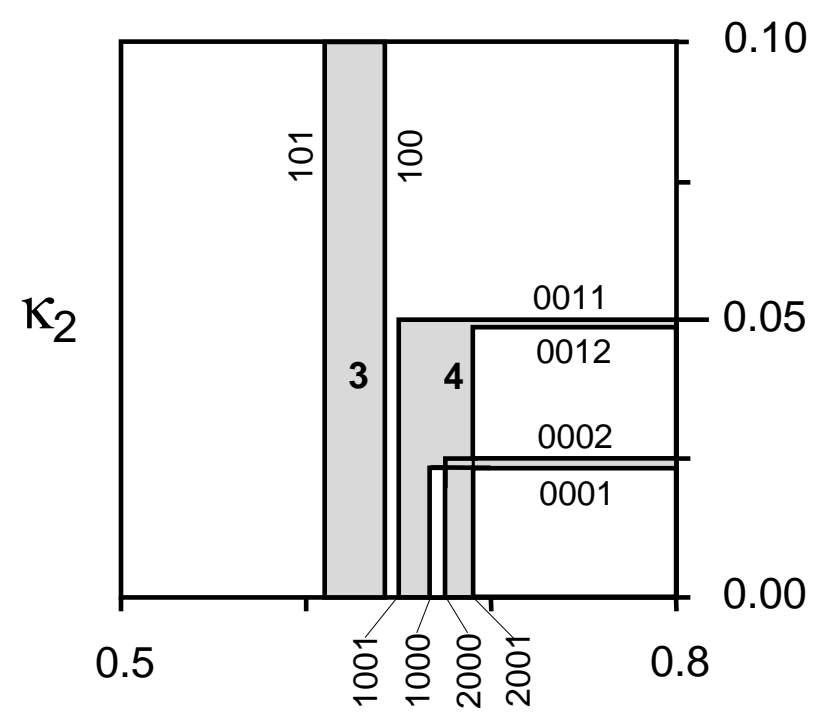

$\kappa_{1}$

Figura 2.39: Estrutura topológica das janelas de período três e quatro, formadas pelas órbitas de dinâmica simbólica $\overline{10 \epsilon}, \epsilon=\{0,1\}$ (período três), e de dinâmica $\overline{\epsilon_{1} 00 \epsilon_{2}}, \epsilon_{1}=\{1,2\}$ e $\epsilon_{2}=\{0,1\}$ (período quatro) no espaço de parâmetros topológico dado por $\left(\kappa_{1}, \kappa_{2}\right)$.

A janela de período quatro, mais complicada, é descrita pelas mudanças entre quatro ciclos, $\overline{1001}, \overline{1000}, \overline{2001}$ e $\overline{2000}$, os quais se associam em pares que trocam de parceiros 
entre si. As trocas entre os pares são dadas pelas duas curvas que definem a órbita super-estável. A curva super-estável $\overline{\epsilon_{1} 00 C_{1}}, \epsilon_{1}=\{1,2\}$, é responsável pelas mudanças entre $\overline{1001} / \overline{1000}$ e entre $\overline{2001} / \overline{2000}$, enquanto que a curva $\overline{C_{2} 00 \epsilon_{2}}, \epsilon_{2}=\{0,1\}$, provoca a troca dos parceiros com as mudanças entre $\overline{1001} / \overline{2001}$ e entre $\overline{1000} / \overline{2000}$. Como as mudanças ocorrem nas direções de $\kappa_{1}$ e $\kappa_{2}$, a janela de período quatro é uma estrutura de bifurcações de codimensão dois.

De acordo com a definição dada em [23], uma janela periódica em forma de camarão consiste de uma estrutura principal de período $n$ e uma infinita sucessão de domínios adjacentes de periodicidade $n \times 2^{m}, m=1,2, \ldots$, correspondendo à duplicação de período da estrutura principal. Os domínios de periodicidade $n \times 2^{m}$ não foram observados no espaço de parâmetros real do circuito, logo, não estão representados no espaço de parâmetros topológico na figura 2.39. 


\section{Conclusão}

Aplicamos técnicas topológicas, associadas à dinâmica simbólica, para caracterizar o comportamento dinâmico do circuito de Chua no espaço de parâmetros $\left(\Delta R_{1}, \Delta R_{2}\right)$.

$\mathrm{Na}$ primeira parte investigamos a dinâmica na vizinhança da janela de período três presente em $\left(\Delta R_{1}, \Delta R_{2}\right)$. Aplicamos a dinâmica simbólica aos atratores nessa região e estudamos a topologia para 6 diferentes seções de Poincaré de um dos atratores. A dinâmica simbólica, construída através da partição dos mapas pelo máximo da entropia, indica que uma interpretação simbólica binária, dada por um alfabeto com dois símbolos, é apropriada para descrever a dinâmica dos atratores. Além disso, a similaridade entre os planos simbólicos para cada seção, mostra que o mesmo processo dinâmico é observado em cada uma das seções analisadas.

As diferentes seções de um mesmo atrator geram mapas unidimensionais e também bidimensionais. Através da comparação com os mapas de Hénon e logístico, concluímos que as séries temporais para o circuito geram mapas essencialmente bidimensionais, mas com comportamento dinâmico no limite de alta dissipação ( $b \rightarrow 0$ no mapa de Hénon), aproximando as séries experimentais de um sistema dinâmico unidimensional.

Mostramos também a existência de fibras caóticas de codimensão um, que são linhas nas quais as propriedades métricas e topológicas, observadas no espaço de parâmetros $\left(\Delta R_{1}, \Delta R_{2}\right)$ do circuito, são preservadas. A existência das fibras foi mostrada por duas técnicas independentes. A primeira caracterizando os atratores sobre as fibras através da identificação de invariantes topológicos, tais como o conjunto de órbitas periódicas instáveis e o cálculo dos números de ligações associados a estas órbitas. Estes invariantes são constantes quando os parâmetros $\Delta R_{1}$ e $\Delta R_{2}$ são variados ao longo de uma fibra, mas mudam quando os mesmos parâmetros são variados em um caminho arbitrário. As variações dos parâmetros levando de uma fibra a outra, para deslocamentos em direção à janela de período três no espaço $\left(\Delta R_{1}, \Delta R_{2}\right)$, provocam a criação de novas órbitas e não alteram a topologia das órbitas antigas. Consequentemente, o número 
de ligações não muda para pares de órbitas existindo em mais de uma fibra. Outra caracteristica topológia que é preservada ao longo de uma fibra é o número de vezes que as diversas órbitas são detectadas no atrator, como verificado pelos histogramas de retorno aproximado, característica associada com a contribuição do conjunto de órbitas à medição do atrator como um todo.

A segunda técnica foi baseada na análise simbólica de grão grosso, aplicando uma dinâmica simbólica binária, construindo planos simbólicos e estimando a entropia topológica para os atratores sobre as fibras. Os planos simbólicos mostraram que, sobre uma fibra, a mesma distribuição de regiões permitidas e proibidas de visitação é observada, enquanto que a distribuição é diferente para planos simbólicos originados de fibras diferentes. Esse resultado é confirmado pelas estimativas da entropia topológica em função do comprimento das seqüências, que seguem a mesma curva para atratores situados ao longo de uma fibra, e são maiores à medida que aumentam as regiões permitidas nos planos simbólicos obtidos de fibras diferentes.

Mostramos ainda que o emprego dessas técnicas topológicas, ao contrário das técnicas de caracterização métrica (expoentes e dimensão de Lyapunov), permitiram identificar diferenças sutis entre fibras muito próximas uma das outras.

Na segunda parte investigamos a transição entre três atratores do circuito, Rössler, Rössler-dobrado e duplo-rolo, que foram caracterizados por três moldes topológicos: o molde da ferradura correspondendo aos atratores do tipo Rössler, o molde com três ramos correspondendo aos atratores Rössler-dobrados e o molde com quatro ramos associado ao atrator duplo-rolo. Esses moldes mostram que o fluxo mantêm, durante a transição para um novo atrator, a topologia do atrator anterior mas acrescentada de uma nova região topológica. Isso foi confirmado pelo surgimento de um novo ramo no mapa de retorno durante a transição entre os atratores. Destes resultados experimentais e de simulações numéricas com atratores com múltiplos ramos nos mapas de retorno, foi possível inferir um molde topológico genérico, uma matriz quadrada de ordem $n$, representando os atratores do circuito. Esse molde genérico é válido enquanto o fluxo que gera os atratores originar novas regiões topológicas e não ocorrer aniquilamento dessas regiões.

Finalmente, na terceira parte, estudando as mudanças das órbitas periódicas que originam as janelas de período três e de período quatro foi possível determinar suas estruturas topológicas e dinâmicas. Determinamos a topologia das órbitas periódicas estudando o comportamento dinâmico do circuito nas bordas das janelas, nas fronteiras 
entre os comportamentos periódico e caótico. Observamos que a janela de período três é descrita por dois ciclos, $\overline{101}$ e $\overline{100}$, cuja dinâmica simbólica é representada por $\overline{10 \epsilon}$, $\epsilon=\{0,1\}$, enquanto que a janela de período quatro é descrita por quatro ciclos, $\overline{1001}$, $\overline{1000}, \overline{2000}$ e $\overline{2001}$, com dinâmica representada por $\overline{\epsilon_{1} 00 \epsilon_{2}}, \epsilon_{1}=\{1,2\}$ e $\epsilon_{2}=\{0,1\}$.

Observamos ainda que as órbitas periódicas no interior das janelas mudam suas representações simbólicas ao passarem pelas regiões de super-estabilidade. Desse modo, no interior da janela de período três encontramos uma única mudança, assinalada pela transição entre o par de ciclos $\overline{101} / \overline{100}$, devido à passagem pela órbita super-estável $10 C$, enquanto que na janela de período quatro observamos duas transições (de quatro possíveis) entre os pares $\overline{1001} / \overline{2001}$ e $\overline{1001} / \overline{1000}$, devido à passagem pela órbita superestável $C_{2} 00 C_{1}$.

Estes resultados levaram à proposta de um modelo topológico para o espaço de parâmetros, baseado em um mapa bimodal, que corresponde ao espaço de parâmetros físico para o circuito de Chua onde, pela primeira vez, um espaço de parâmetros topológico foi obtido a partir de dados experimentais. 


\section{Bibliografia}

[1] E. N. Lorenz, Attractor sets and quasi-geostrophic equilibrium, J. Atmos. Sci. 37, $1685(1980)$.

[2] G. B. Mindlin and R. Gilmore, Topological analysis and synthesis of chaotic series, Physica D 58229 (1992).

[3] G. B. Mindlin, H. G. Solari, M. A. Natiello, R. Gilmore e X. -J. Hou, Topological analysis of chaotic time series data from Belousov-Zhabotinskii reaction, J. Nonlinear Sci. 1, 147, (1991).

[4] R. Shaw, The dripping faucet as a model chaotic system, Aerial Press, Santa Cruz, 1984.

[5] P. Martien, S. C. Pope, P. L. Scott e R. S. Shaw, The chaotic behavior of a leaky faucet, Phys. Lett. A 110, 399 (1985).

[6] J. C. Sartorelli, W. M. Golçalves e R. D. Pinto, Crisis and intermittence in a leakyfaucet experiment, Phys. Rev. E 49, 3963 (1994).

[7] R. M. May, Simple mathematical models with very complicated dynamics, Nature 261, 459 (1976).

[8] J.P. Crutchfield, J. D. Farmer, N. H. Packard e R. S. Shaw, Chaos, Sci. Am., 255 6, 38 (1986).

[9] H. Poincaré, Les Métthodes Nouveles de la Mécanique Céleste, vol.1-3 (GauthierVillars: Paris, 1899); reimppressão por Dover, 1957. Tradução em Inglês: New Mathods of Celestial Mechanics, (NASA Technical Translation, 1967).

[10] J. Hadamard, Les surfaces à courbures opposées et leurs lignes géodésiques, $J$. Math. Pures Appl. 4, 27 (1898). 
[11] M. Morse, Recurrent geodesics on a surface of negative curvature, Trans. AMS 22, 84 (1921); M. Morse, e G. A. Hedlund, Symbolic dynamics, Am. J. Math. 60, 815 (1938) , reimpresso em Collected of M. Morse, vol. 2 (World Scientific, Singapore, 1986).

[12] S. Smale, Differenciable dynamical systems, Bull. Am. Math. Soc. 73 747, (1967).

[13] J. Gleick, Caos - A criação de uma nova ciência, Rio de Janeiro, editora Campus, 1990.

[14] N. Metropolis, M. L. Stein e P. R. Stein, On the finite limit sets for transformations on the unit interval, J. Comb. Theor. A 1525 (1973).

[15] J. Birman and R. Williams, Knotted periodic orbits in dynamical systems I: Lorenzt's equation, Topology 22, 47 (1983).

[16] N. B. Tufillaro, H. G. Solari e R. Gilmore, Relative rotation rates: fingerprints for strange attractors, Phys. Rev. A 41, 5717 (1990).

[17] N. B. Tufillaro, R. Holzner, L. Flepp, E. Brun, M. Finard e R. Badii, Template analysis for chaotic NMR laser, Phys. Rev. A 44, 4786 (1991).

[18] N. B. Tufillaro, T. Abbott and J. Reilly, An Experimental Approach to Nonlinear Dynamics and Chaos, Addison-Wesley, New York, 1992.

[19] N. B. Tufillaro, P. Wyckkoff, R. Brown, T. Schreiber e T. Molteno, Topological time-series analysis of a string experiment and its synchronized model, Phys. Rev. E 51, 164 (1995).

[20] R. Gilmore e M. Lefranc, The Topology of Chaos, Wiley, New York, 2002.

[21] R. N. Madan, Chua's Circuit: A Paradigm for Chaos, World Scientific, Singapore, 1993.

[22] P. Gaspard, R. Kapral e G. Nicolis, Bifurcation phenomena near homoclinic systems: a two-parameter analysis, J. Stat. Phys. 35, 697 (1984).

[23] J. A. C. Gallas, Structure of the parameter space of the Hénon map, Phys. Rev. Lett. 70, 2714 (1993); J. A. C. Gallas, Dissecting shrimps: results for some onedimensional physical models, Physica A 202, 196 (1994). 
[24] M. S. Baptista, M. B. Reyes, J. C. Sartorelli, C. Grebogi e E. Rosa, Communication-based on topology preservation of chaotic dynamics, Int. J. Bifurcation and Chaos $\mathbf{1 3}$ 9, 2551 (2003).

[25] K. T. Hansen e P. Cvitanović, Bifurcation structures in maps of Hénon type, Nonlinearity 11, 1233 (1997).

[26] K. T. Hansen, "Symbolic Dynamics in Chaotic Systems", Oslo. Tese de Doutorado apresentada no Departamento de Física da Universidade de Oslo em 1993.

[27] R. Gilmore, Topological analysis of chaotic dynamical systems, Rev. Mod. Phys., 70, (4), 1455, (1998).

[28] F. Takens, Detecting strange attractors in turbulence. In: Dynamical Systems and Turbulence, D. A. Rand e L. S. Young (eds.) Springer Lectures Notes in Mathematics, vol. 898, Springer-Verlag, Berlim, 1980.

[29] T. Sauer, J. A. Yorke e M. Casdagli, Embedology, J. Stat. Phys. 63, 3, 579 (1991).

[30] M. B. Kennel, R. Brown e H. D. I. Abarbanel, Determining embedding dimension for phase-space reconstruction using a geometrical construction, Phys. Rev. A 45, 3403 (1992).

[31] J.-P. Eckmann, e D. Ruelle, Ergotic theory of chaos and strange attractors, Rev. Mod. Phys., 57 (3), 617 (1985).

[32] J. -P. Eckmann, S. O. Kamphorst, D. Ruelle e S. Ciliberto, Lyapunov exponents from time series, Phys. Rev. A 34, 4971 (1986).

[33] P. M. Morse e H. Feshbach, Methods of Theoretical Physics, parte I, McGraw-Hill, p. $928,1953$.

[34] M. Sano e Y. Sawada, Measurement of the Lyapunov spectrum from a chaotic time series, Phys. Rev. Lett. 55, 1082 (1985).

[35] J. L. Kaplan e J. A. Yorke, Functional differential equations and approximation of fixed points, H. O. Peitgen e H. O. Walther (eds.). Springer Lectures Notes in Math. 730, Springer-Verlag: New York, Heidelberg e Berlin, p. 228, 1979.

[36] Hao Bai-lin, Elementary Symbolic Dynamics and Chaos in Dissipative Systems, World Scientific, Singapore, 1984. 
[37] D. M. Maranhão, Caracterização Topológica de Atratores: o Circuito de Chua, São Paulo. Dissertação de Mestrado apresentada no Instituto de Física da Universidade de São Paulo em 2001.

[38] R. Devaney, An Introduction Chaotic Dynamical Systems second edition, AddisonWesley, Boston, 1988.

[39] J. Milnor e W. Thurston, On Iterated Maps of Interval (Lectures Notes in Mathematics, 1342) ed. A. Dold e B. Eckmann, Springer, Berlin, 1988.

[40] P. Collet e J.-P. Eckmann, Iterated Maps on the Interval as Dynamical Systems, Birkhäuser, Basel, 1980.

[41] D. P. Lathrop e E. J. Kostelich, Characterization of an experimental strange attractor by periodic orbits, Phys. Rev. A, 40 (7), 4028 (1989).

[42] O. E. Rössler, An equation for continuous chaos, Phys. Lett. A 57, 397 (1976).

[43] O. E. Rössler, Continuous chaos - four prototype equations, Ann. N. Y. Acad. Sci. 316, 376 (1979).

[44] P. Cvitanović, G. H. Gunaratne e I. Procaccia, Topological and metric properties of Hénon-type strange attractors, Phys. Rev. A 38 (3), 1503 (1988).

[45] C. Letellier, G. Gouesbet e N. F. Rulkov, Topological analysis of chaos in equivariante eletronic circuits, Int. J. Bifurc. Chaos 6 (12B), 2531 (1996).

[46] A. Tufaile e J. C. Sartorelli, Hénon-like attractor in air buble formation, Phys. Lett. $A, 275,211$ (2000).

[47] P. Holmes, Knots and orbit genealogies in nonlinear oscillators, em "New Directions in Dynamical Systems" ed. por T. Bedford e J. Swift, London Mathematical Socity Lecture Note Series 127 (Cambridge, 1988).

[48] G. Boulant, S. Bielawski, D. Derozier e M. Lefranc, Experimental observation of a chaotic attractor with a reverse horseshoe topological structure, Phys. Rev. E 55, R3801 (1997).

[49] G. Boulant, M. Lefranc, S. Bielawski e D. Derozier, Horseshoe template with global torsion in a driven laser, Phys. Rev. E 55, 5082 (1997). 
[50] H. D. I. Abarbanel, R. Brown, J. J. Sidorowich e L. Sh. Tsimring, The analysis of observed chaotic time data in physical systems, Rev. Mod. Phys. 65, (4) 1331 (1993).

[51] P. Grassberger e I. Procaccia, Measuring the strangeness of strange attractors, Physica D 9, 189 (1983).

[52] T. C. Halsey, M. H. Jensen, L. P. Kadanoff, I. Procaccia e B. I. Shraiman, Fractal measures and their singularities: the generalization of strange sets, Phys. Rev. A 33, 1141 (1986); J. D. Hanson, Phys. Rev. A 35, 1470 (1987).

[53] V. I. Oseledec, A multiplicative ergodic theorem: Lyapunov characteristic numbers for dynamical systems, Trans. Mosc. Math. Soc. 19, 197 (1968); A. Wolf, J. B. Swift, H. L. Swinney, e J. A. Vastano, Determining Lyapunov exponents from a time series, Physica D 16, 285 (1985).

[54] L. Le Sceller, C. Letellier e G. Gouesbet, Algebraic evaluation of linking numbers of unstable periodic orbits in chaotic attractors, Phys. Rev. E 494693 (1994).

[55] J. Neimark e L. Sil'nikov, Sov. Math. Dokl. 6, 305 (1965); L. Sil'nikov, Sov. Math. Dokl. 6, 163 (1965); Math. Sbornik. 10, 91 (1970); Sov. Math. Dokl. 8, 54 (1967).

[56] C. Grebogi, E. Ott, F. Romeiras e J. A. Yorke, Critical exponents for crisis-induced intermittency, Phys. Rev. A 36 (11), 5365 (1987).

[57] O teorema de Birman-Williams pode ser empregado a sistemas dinâmicos em $\mathbb{R}^{n}$, $n>3$, desde que o atrator estranho tenha uma única direção instável, ou seja, desde que seus expoentes de Lyapunov $\lambda_{i}, i=1,2 \ldots, n$ obedeçam

$$
\lambda_{1}>\lambda_{2}=0>\lambda_{3}>\lambda_{4}>\ldots>\lambda_{n}
$$

Para uma forte contração tal que $\left|\lambda_{3}\right|>\lambda_{1}$, a aplicação do teorema de BirmanWilliams leva a variedade estável de dimensão $(n-2)$ a um ponto na variedade bidimensional formada pela direções de $\lambda_{1}$ (expanção) e $\lambda_{2}$ (fluxo). Mas se a projeção for feita primeiro na direção de $\lambda_{4}, \ldots, \lambda_{n}$, o fluxo projetado estará em uma sub-variedade tridimensional de $\mathbb{R}^{n}$. Nessa sub-variedade os invariantes topológicos são bem definidos (a sub-variedade é tridimensional). Então, a última projeção, executada ao longo da direção menos contraente (direção de $\lambda_{3}$ ) preserva a organização das órbitas periódicas imersas no atrator estranho. 
[58] Kaj L. Nielsen, Methods in Numerical Analysis, The Macmillan Company, New York, segunda edição (quarta impressão), 1968.

[59] M. S. Baptista, "Perturbando sistemas não-lineares, uma abordagem ao controle do Caos", São Paulo. Tese de Doutorado apresentada no Instituto de Física da Universidade de São Paulo em 1996.

[60] M. Monti, W. B. Pardo, J. A. Walkenstein, E. Rosa e C. Grebogi, Color map of Lyapunov exponentes of invariant sets, Int. J. Bifurcation and Chaos 9, 1459 (1999).

[61] D. M. Maranhão, M. S. Baptista e J. C. Sartorelli, Experimental identification of chaotic fibers, manuscrito em preparação.

[62] E. Barreto, B. R. Hunt, C. Grebogi e J. A. Yorke, From high dimensional chaos to stable orbits: the structure of parameter space, Phys. Rev. Lett. 78,4561 (1997).

[63] M. S. Baptista, C. Grebogi e E. Barreto, Topology of windows in the highdimensional parameter space of chaotic maps, Int. J. Bifurcation and Chaos 13 9,2681 (2003).

[64] R. Gilmore e K. W. MacCallum, Structure in bifurcation diagram of the Duffing oscillator, Phys. Rev. E 51 2, 935 (1995).

[65] O. Biham e W. Wenzel, Characterization of unstable periodic orbits in chaotic attractors and repellers, Phys. Rev. Lett. 63, 819 (1989).

[66] P. Grassberger, H. Kantz e U. Moening, On the symbolic dynamics of Hénon map, J. Phys. A: Math. Gen. 22, 5217 (1989).

[67] L. Jaeger e H. Kantz, Structure of generating partitions for two-dimensional maps, J. Phys. A: Math. Gen. 30, L567 (1997).

[68] H. P. Fang, Dynamics of strongly dissipative systems, Phys. Rev. E 49, 5025 (1994).

[69] H. P. Fang, Universal bifurcation property of two or higher-dimensional dissipative systems in parameter space: Why does 1D symbolic dynamics work so well?, J. Phys. A: Math. Gen. 28, 3901 (1995).

[70] W. M. Golçalves, R. D. Pinto e J. C. Sartorelli, Infering statistical complexity in the dripping faucet experiment, Physica D 257385 (1998). 
[71] W. M. Golçalves, A Experiência da Torneira Gotejante. São Paulo. Tese de Doutorado apresentada no Instituto de Física da Universidade de São Paulo em 1996.

[72] D. M. Maranhão e C. P. C. do Prado, Evolution of chaos in the Matsumoto-Chua circuit: a simbolic dynamics approach, Braz. J. Phys. 35 1, (2005).

[73] R. Hegger, H. Kantz, e T. Schreiber, Practical implementation of nonlinear time series methods: The TISEAN package, Chaos 9, 413 (1999).

[74] C. Grebogi e E. Ott, Crises, sudden changes in chaotic attractors, and transient chaos, Physica 7D, 181 (1983). 


\section{Apêndice $A$}

Evolution of chaos in the Matsumoto-Chua circuit

Dariel. M. Maranhão e Carmen P. C. Prado

Brazilian Journal of Physics 35 (1) (2005) 162-169 


\section{Apêndice $B$}

Experimental identification of chaotic fibers

D. M. Maranhão, M. S. Baptista e J. C. Sartorelli

manuscrito em preparação 


\section{Apêndice C}

Topological characterization of experimental periodic windows

D. M. Maranhão, M. S. Baptista e J. C. Sartorelli

manuscrito em preparação 